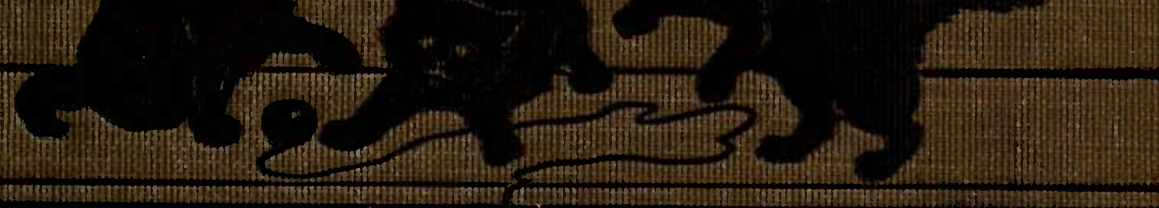

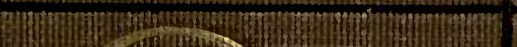
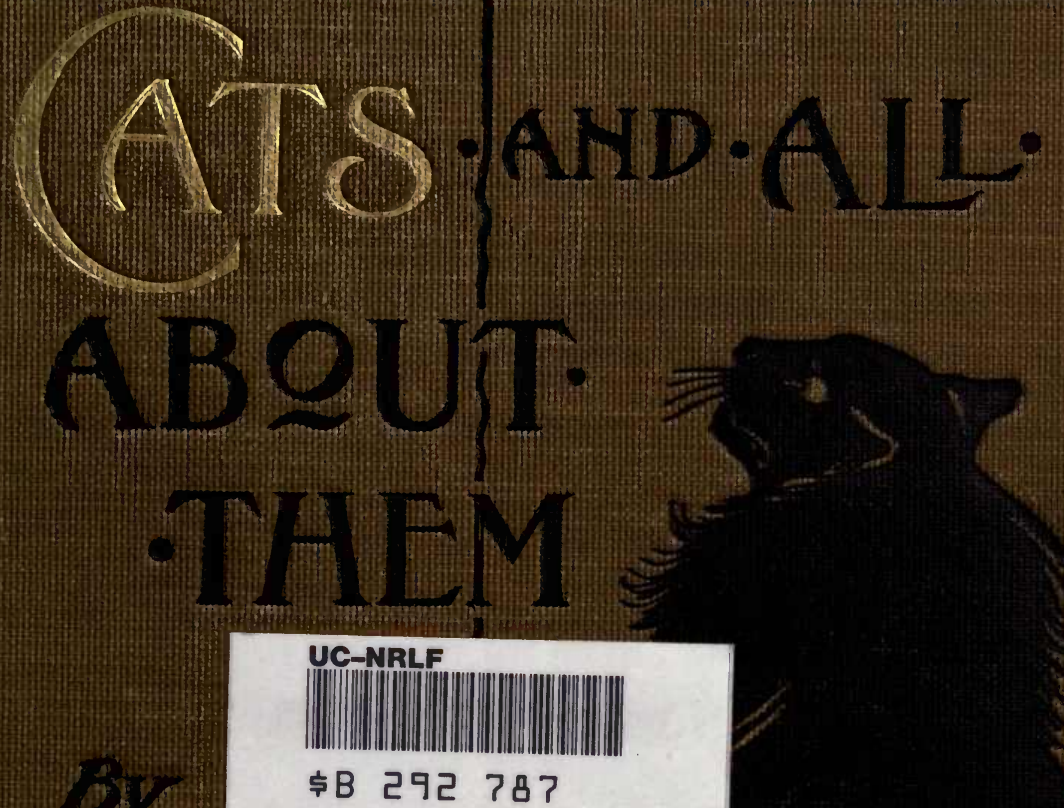

Arapees

Simposer

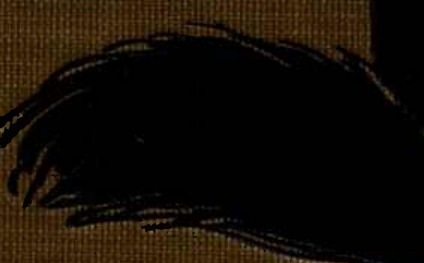




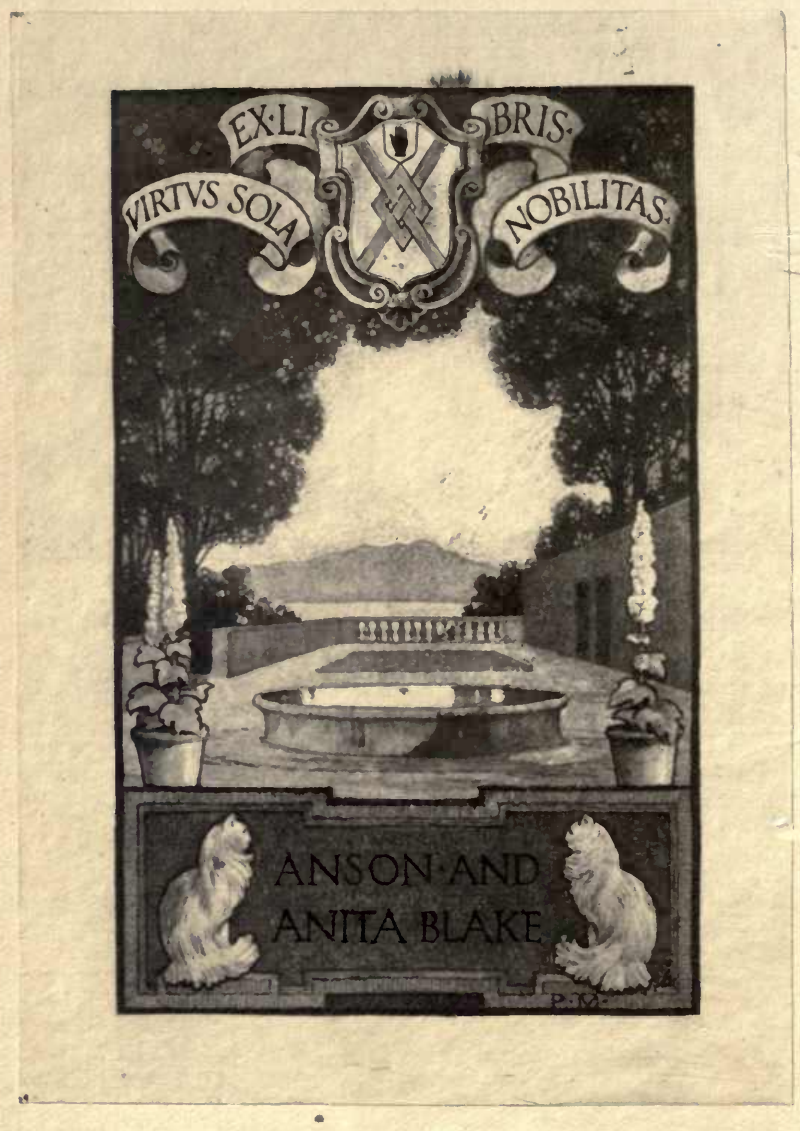


Airing D.S. Bake

223 , Piedunut hay
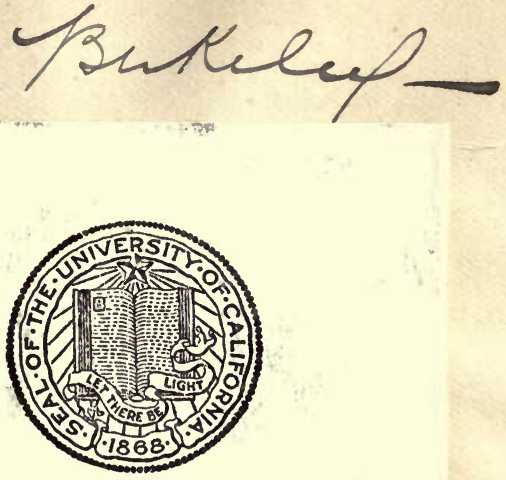

THE LIBRARY

$\mathrm{OF}$

THE UNIVERSITY

OF CALIFORNIA

BEQUEST

OF

ANITA D. S. BLAKE 

CATS AND ALL ABOUT THEM 




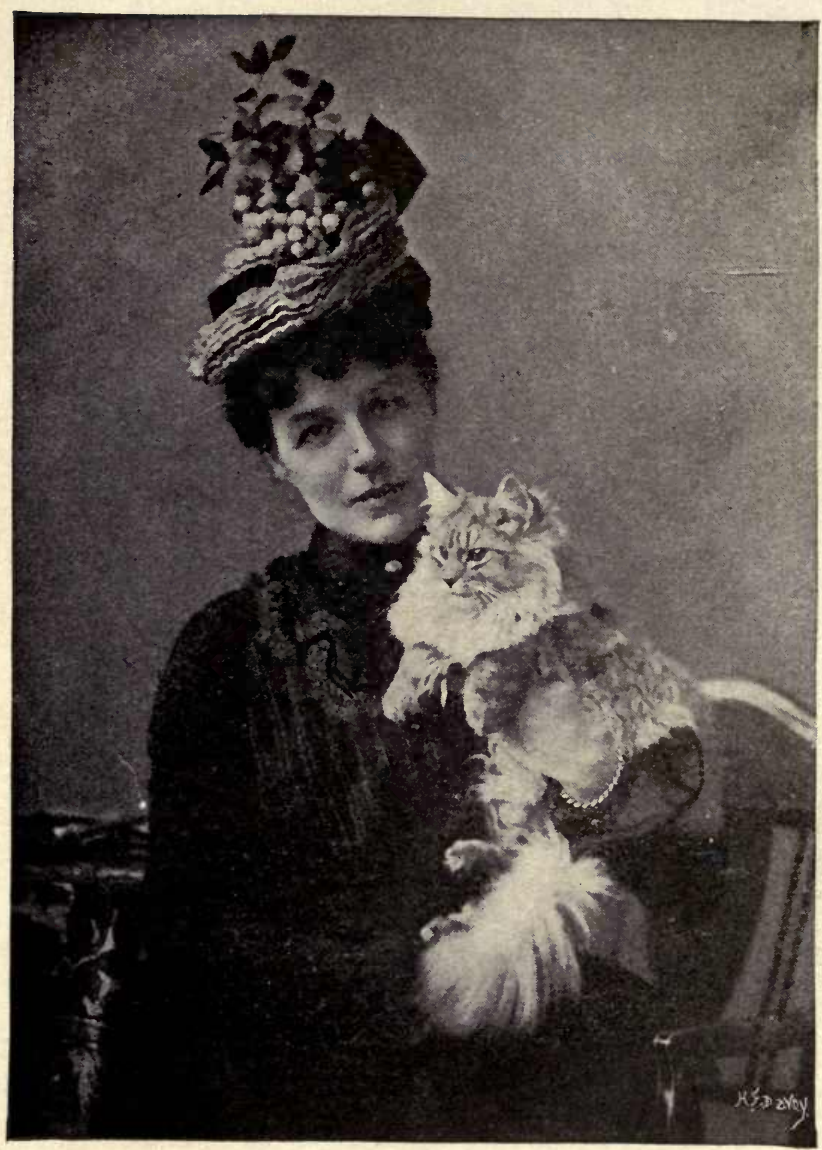

Miss Frances Simpson and her Silver Male "Cambyses" Gunn \& Stuart, photo, Richmond 


\section{A T S}

\section{AND ALL ABOUT THEM}

BY

FRANCES SIMPSON

WITH TWENTY-FOUR ILLUSTRATIONS

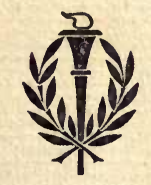

NEW YORK

FREDERICK A. STOKES COMPANY

PUBLISHERS 
Publisheid IN SEPTEMBER, I9O2

\section{GIFT}




\section{THE MANY KIND FRIENDS}

KNOWN AND UNKNOWN

THAT I HAVE

MADE IN PUSSYDOM

I DEDICATE

THIS LITTLE BOOK

Durdans House,

ST. Margaret'S-ON-Thames 



\section{PREFACE}

IT has been suggested to me by many of my "catty" friends that I should write a small handbook for cat fanciers. By arrangement with the Kennel Publishing Company I have been enabled to utilise the paragraphs of Practical Pussyology which have appeared during the last fifteen months in Our Cats. I have had many years' experience with cats and kittens, and have also a real love for them, without which I do not believe any one can be a successful breeder and exhibitor of cats. What is worth doing at all is worth doing well, and to combine profit with pleasure is a most desirable end to have in view. The object, therefore, of this little book is to assist cat lovers to become cat fanciers. I trust that it may be found helpful and instructive. 



\section{CONTENTS}

I. BREEDS AND VARIETIES • • • • , $\quad$ I7

II. Care and Management - • • • 24

Practical Hints • • • • • - 3 I

III. BReEding and Exhibiting • • • • 53

Practical Hints . . . . 60

IV. Diseases and Remedies • • • • • 77

V. Cat Clubs and Cat Homes • • • 95

VI. Miscellaneous . * * • 107 



\section{ILLUSTRATIONS}

r. Cover. Design by Mrs. Paul Hardy

2. Frontispiece. Miss Frances Simpson and her Silver male Cambyses

3. Grntian. A lovely Blue female, owned by Lady Marcus Beresford, and bred by Mrs. O'Brien Clarke. Her sire was Goliath, a superb cat for size and colour. Gentian was a prize-winner at Westminster in 1899 , when her marvellous coat excited general admiration . . .

4. Imperial Blok was bred by Rev. P. L. Cosway, his present owner, from Angela and Blue Noble. This youngster has already made a name for himself in the show pen. $\mathrm{He}$ was born August 30 th, Igoo, and took prizes at Castleford and Wakefield. At Slough, I90r, he carried off the special for the soundest coloured Blue, and has since gained high distinction at Manchester. Imperial Blue is now placed at stud in our advertisements for the first time

5. Royal Bobs. This fine Blue male was bred by H.H. Princess Victoria of Schleswig-Holstein from Lady Marcus Beresford's Blue Boy II. and Duschar. He was purchased when a kitten by Mrs. Collingwood, and at his first appearance at the Botanical Gardens, in rgor, he took Ist in the Cat and Ist in the Kittten Class. Since then he has taken four other Ist prizes and two championships, besides many specials. Royal Bobs is a dark Slate Blue, but very sound in colour, with a beautifully shaped head and fine eyes. . .

6. Othello, as his name denotes, is a Black Persian, and claims such noted cats as Beauty Boy, Lord Albemarle 
and Peter Fawe among his ancestors. Mr. Robert Little, who is famed for his breed of beautiful Blacks, is the possessor of Othello, who is not yet a year old. He has done a lot of winning already, both in kitten and adult classes, and bids fair to lead the way in the Black classes at our best shows

7. Piguante Pearl was bred by Mrs. Pettit from her wellknown White stud cat King of the Pearls and Beautiful Pearl. This lovely female is quite the most beautiful specimen of a long-haired White Persian, having glorious blue eyes with a full coat of finest texture. Piquante Pearl is a winner of numerous Ist prizes, championships, medals, and specials at the Crystal Palace and Westminster Shows. Some of her lovely kittens have been exported to America . . . . . . . .

8. Champion Backwell Jogram is the only Smoke champion and the winner of many Ist prizes, medals, and specials. At the Crystal Palace Show, rgor, this fine Persian cat won the special offered by the Duchess of Bedford for the best Smoke male in the show. Jogram is owned and was bred by Mrs. H. V. James, who is one of the most enthusiastic breeders of this handsome variety. He has sired many noted winners, and is much in request as a stud cat . . . . . . .

9. Teufer. Mrs. Sinkins is the breeder and owner of this most beautiful Smoke male, who, although only 18 months, has won many prizes. Good Smokes of his type are few and far between. His colouring is perfect, and his face and head quite free from the tabby markings that so often mar the beauty of this breed. Teufel greatly distinguished himself at the Westminster Show, 1902, where he won the Challenge Cup, Breeders' Cup, Ist prize, and numerous specials .

IO. Champion Fulmer Zaida is the renowned Silver female owned by Lady Decies. This cat has won more prizes than any other in the Fancy, numbering over 150. Zaida is almost an unmarked specimen, and her colour is wonderfully pure. She has carried off the highest honours at all the leading shows, and will probably continue to win whenever exhibited . . . . 
II. The Absent-Minded Beggar is a fine Silver by Lord Southampton and Dimity, both well-known cats. He is unusually pale in colour, with beautiful green eyes. Mrs. Nield, of Bowden, now owns the Beggar, who is greatly in request as a sire. His kittens inherit his beautiful qualities of coat and colour . . . .

22. LORD HAMPTON, another Silver, is also an inmate of the Hart Hill Cattery, and was purchased by Mrs. Nield from Mrs. Davies, of Caterham. As a kitten this lovely Silver greatly distinguished himself, taking many prizes. $\mathrm{He}$ has a grand-shaped head, but was out of coat when the photo, which we reproduce, was taken. Lord Hampton has sired some splendid kittens . . . . .

13. Silver Starlight is the property of Miss Snell, of Wimbledon. This Silver male cat is beautifully pure in colour. He distinguished himself at the Crystal Palace, I900; Brighton, Ig0o; and at Westminster, Igor, he made a great name for himself by winning the Challenge Cup and numerous special prizes. Amongst his progeny may be mentioned Puck III., a winning kitten, now in the possession of H.H. Princess Victoria of Schleswig-Holstein . . . .

14. LORD NOGENT is a well-known shaded Silver male belonging to Mrs. Ormerod, who is a most successful breeder of Silvers and Smokes. He is the son of Lord Argent. The Silver Lambkin and Lord Southampton are his grandparents. He has taken several ist and and prizes, and sired many noted winners; amongst others may be mentioned Maritana, the perfect Smoke, purchased by Mr. Cosway. Lord Nugent has a fine head, and is unusually massive in build for a Silver . . . . 60

I5. TORRIngton SUnnysides. This rich-coloured Orange male is the property of Mrs. Vidal, of Sydenham, and was bred by her. $\mathrm{He}$ is by Champion Bundle and Torrington Owlet, and was born in 1899 . He has gained many prizes, and at Westminster. Show, I902, he won the Challenge and Breeders' Cup, Silver Medal, and several specials 
16. Champion Romaldirirk Admiral, one of Miss Winifred Beal's celebrated Heavenly Twins. This grand Cream stud cat has never been beaten in his class, except by his brother. His prize-winning record is too long for insertion. This cat is in the proud position of being a Champion in the N.C.C. and the C.C., having carried off no less than 14 Championships. Matthew, of The Durhams, a well-known winning Cream, is sired by the twin-brother Midshipmite . . . . .

17. Champion Royal Yom Yom is one of the best Tortoiseshell queens in the Fancy. Her colouring is well broken, and she is a beautifully formed cat. Miss Kate Sangster, her owner, has won many prizes with her at all the leading shows. Very poor justice can be given to this special breed in a photograph, as the beauty of a Tortoiseshell chiefly consists in the equal distribution of the three colours . . . . . . .

18. Champion Persimmon is the celebrated Brown Tabby Persian, owned by Miss Frances Simpson. He is perfect in shape, with an immense head, short snub nose, and tiny well-placed ears. He was purchased by his present owner at Brighton Show, I898. Since then he has won whenever shown, and is now a Champion in both the N.C.C. and C.C. Clubs. $\mathrm{He}$ has sired a long list of beautiful brown Tabby prize-winning kittens

19. Champion Ballochmyle Brother Bump. This grand Short-haired Blue (commonly called Russian) is the property of Lady Alexander, and has won a first prize whenever he has appeared in a show pen, and, curiously enough, each time under a different judge. He won the Challenge Cup at Westminster in I900, and since then three championships at N.C.C. Shows. He is beautiful in colour, has a well-shaped head, and grand orange eyes

20. Champion Wankee, the noted Siamese, is owned by Mrs. Robinson, of West Kensington, who has always been an enthusiastic and successful breeder of Siamese. He has won over 30 prizes, and sired, among other notable kittens, Beba, Menelik, Sam Sly, and Chaseley Robin, all winners of championships. 
21. Tiam-o'-Shian IV. is another Siamese of high repute, the property of Mrs. Vyvyan, who bred him; but Tiam resides with Mrs. Parker Brough whilst his owner is abroad. He is a magnificent type of Siamese, even in colour, with deep seal] points. He comes from Miss Forestier-Walker's celebrated strain; and amongst his progeny may be mentioned Champion Eve, Suzanne, and Kitya Hara . • . • . • .

22. Brandon Queen Cheztah is a lovely Brown Tabby shorthaired cat, belonging to Mrs. Bernard Wentworth. This puss is well and distinctly marked, and rich in colour. One of her kittens, Brandon Tommykins, took high honours at Westminster Show in Igor . . . .

23. Manx Silverwing, a quaintly marked little Silver Tabby, formerly owned by Mr. Foalstone. At the Manchester N.C.C.C. Show she was purchased by Mr. Ward, of Longsight. Silverwing has won many prizes, and calls forth great admiration whenever exhibited . . .

24. Persimmon Laddie, a sable Neuter by Persimmon and Birkdale Fina, is the great pet of Miss Rosamound Whitney, an Irish fancier, who is an enthusiastic admirer of Brown Tabbies. Laddie took highest honours at the Northern Cat Club's Show at Manchester, Igor, and was justly admired for his gorgeous colouring and marvellous coat. Laddie took special for the best Tabby Neuter at Westminster, 1902, and first at Liverpool, 1902

25. Bonnie Boy. This promising young Blue is owned by Miss Frances Simpson, and was exhibited by her at the Crystal Palace, rgor, when at four months old he took 2nd prize in a class of 39 kittens, the limit age being eight months. Bonnie Boy was also awarded a special prize for the best orange eyes in the kitten classes. He is from Miss Patterson's celebrated strain of Blue Persians, and his mother is a Black, owned by Mrs. H. B. Thompson. The photo was taken when he was three months old 



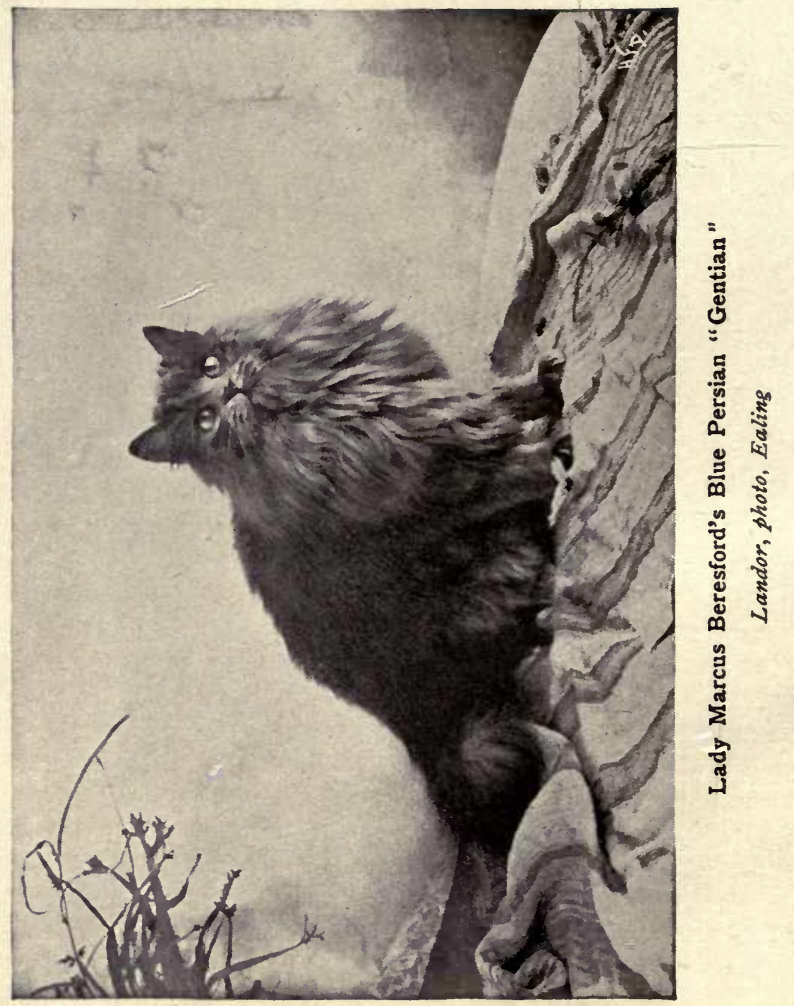




\section{I \\ BREEDS AND VARIETIES}

I Do not intend to discuss the ancient history of cats, or to raise the question as to whether they were amongst the animals who entered the Ark; nor is it necessary to allude to the Wise Men of the East who worshipped the cat as a deity : I wish rather to confine my remarks to cats as they are known to-day. Of these, then, there are two distinctive breeds, viz., the Long-haired or Persian Cats, and Shorthaired or English and Foreign Cats.

In both long- and short-haired breeds there are "selfcoloured," "broken-coloured" and "any other coloured" varieties. Apart from the length and texture of fur, the points of the animals are practically the same, whether longor short-haired. They should be cobby in build and short on the legs, the head should be round and broad, eyes large and full, nose short, ears small and wide apart. So much for the general contour of the cat.

With the majority of fanciers the long-haired cats are the most popular. I will start with the self-coloured longhaired cats, viz., Black, White, and Blue.

I do not think sufficient attention or admiration is given to Black Persians, and very few fanciers have taken up this handsome breed. The Black Class is generally the worst filled at our Shows, and yet a black cat is said to bring luck, and a black cat does not show the dirt! In the early days of the Fancy, the question of eyes was one left in abeyance, but now we have a special standard for each breed, and blacks must have orange or even amber eyes to find favour 
with the cat critique and judge. Then, again, a white spot at the thrcat was not formerly considered a very damaging blemish, but nowadays even a few stray white hairs may be a cause of disqualification. At certain times of the year this breed shows signs of rustiness and a brown tinge mars its beauty, but when in full coat the colour should be black as coal with a shining glossiness on the silky fur.

A White Persian Cat, with correct blue eyes, in full coat and spotlessly clean, is indeed a "thing of beauty," but let no one try to keep one of this breed unless they live in the country. A white cat soiled is a white cat spoiled, and I have known a famous prize-winner put down by the judge on account of its dirty condition. A peculiarity of this breed is that the cats are frequently deaf. It is also the only breed which sports odd eyes, and in almost every litter of whites one or more of these curious freaks will appear.

And now to turn our attention to Blues, that lovely breed which has become so deservedly popular. I exhibited the first pair of Blues at the Crystal Palace many years ago, and ever since we have lived and loved together! I am now the Hon. Sec. of the Blue Persian Cat Society, with nearly two hundred members. At all the Shows the entries of Blues outnumber all other classes, and there is a greater demand for Blue kittens than for any other colour.

When Blues were first started the colour was decidedly darker than at present; it was a slate blue, but of late years fanciers have been striving to obtain a paler tone. I think, however, that the "happy medium" is the best. In the standard for Blues the largest number of points is given for soundness of colour, and it is most essential that no shadings or markings should appear in these cats, which should be absolutely level in colour throughout. It is only in recent years that fashion and custom have decreed that Blue Persians must have orange eyes. Certainly they tone best with the colour of their coat, and greatly enhance the beauty of heir appearance. It is a pity, however, to sacrifice other essential points to this one feature. Judges are sometimes inclined to put down a fine specimen which has every point in its favour except the orange eyes. I advise that, if you possess a grand-shaped, fine-coated Blue with green eyes, 
find a mate with deep amber eyes, and keep your greeneyed puss away from Shows! Blues may be considered a fairly hardy breed of Persian, and they make lovely pets.

Smokes are rather a neglected variety, and may be said to be a mixture of the three self-coloured breeds-black, white and blue. A perfect Smoke is most difficult to breed, and unfortunately for only a short time during the year do they keep their good looks. When they shed their coats Smokes are often transformed into bad Blacks, and this is disappointing, and specially vexatious to the fanciers who desire to exhibit their cats frequently. The points of the Smokes have been keenly discussed in catty circles and Specialist Clubs. Their coats should be dark cinder-colour, shading to white with a light ruff and ear-tufts; eyes amber. Of late years attempts have been made to cross Smokes with Silvers and Blues, but I consider that Smokes should only be mated with Smokes to keep the correct colour and points.

And now for the consideration of Silvers, commonly called Chinchillas, otherwise named Shaded-silvers, and very often labelled "Wrong Class"! To novices in the Fancy this may sound a little mixed, so let me explain. These beautiful cats have been through stormy waters, so to speak. A Specialist Society was started last year for this breed which also included Silver Tabbies and Smokes. The Silvers were subdivided into Self-silvers and Shaded-silvers. As, however, no Self-silver has yet been born or bred, there was naturally a difficulty in filling any class set apart for these particular specimens at the Shows. So the lightest Silvers were considered eligible, and then came the difficulty for exhibitor and judge to draw the line between the two varieties, and to decide what degree of paleness constituted a Selfsilver (so-called) and what amount of dark markings would relegate the specimen into the Shaded-silver class. Naturally it became a Silver puzzle and a Silver muddle. Exhibitors waxed wroth and judges became exasperated. Then the term "Self-silver" was abandoned, but the endeavour to breed a Silver without any shadings or marking is still the height and ambition of many a fancier of this beautiful breed. There is a great fascination about these Silver Persians, but they have been so inbred of late years that great delicacy has 
resulted, and many a tale of woe has reached me concerning the difficulty of rearing Silver kittens. But I feel sure better times are in store for this breed, and certainly Silvers vie with Blues in popularity. The points of a Silver cat may be summed up thus: A pale shade of silver as free from shadings and tabby markings as possible; eyes green. For some time it was considered that Silvers might have either orange, yellow, or green eyes, but now the highest authorities in the Silver Society incline towards green eyes. I think judges in general give their verdict in favour of this colour, and I am sure they all desire only one class for Silvers and to keep them as distinct as possible from Silver Tabbies; the one class, namely, Silvers, to be as free from markings as possible, and the Silver Tabbies to have clearly defined black markings on a pure silver ground work. It is these markings that give the distinguishing feature to the beautiful breed of Silver Tabbies. I admire the splashed-type more than the delicately pencilled variety. There are very few really good specimens in the Fancy, and it is a great pity some of our clever breeders do not take up Silver Tabbies and try to prevent them from being crossed with nondescript Silvers, thus weakening the markings and damaging the breed.

I think it is generally known in the Fancy that I am partial to Brown Tabbies, and truly I believe they occupy the warmest corner of my cat-loving heart ; perhaps, because I first started with a Brownie, or possibly because they have been a very looked-down-upon breed. However, as every dog has his day, so I hope a good time is coming for this truly handsome type of cat, so suggestive of a tiger. In build Brown Tabbies ought to be decidedly large and massive. The groundwork should be a rich tawny colour, with dark black markings very clearly defined; the legs evenly barred, and distinct rings round the neck, like so many chains. What are generally exhibited as Brown Tabbies lack the orange or golden tone, and have too much drab or grey in their colouring. The eyes should be yellow or orange. Any white in Tabby cats is a decided blemish.

There is a tendency now to breed Orange cats with tabby heads and legs and self-coloured bodies. This seems a mistake. No doubt an entire Orange cat without any markings would be very handsome, and perhaps some of our 


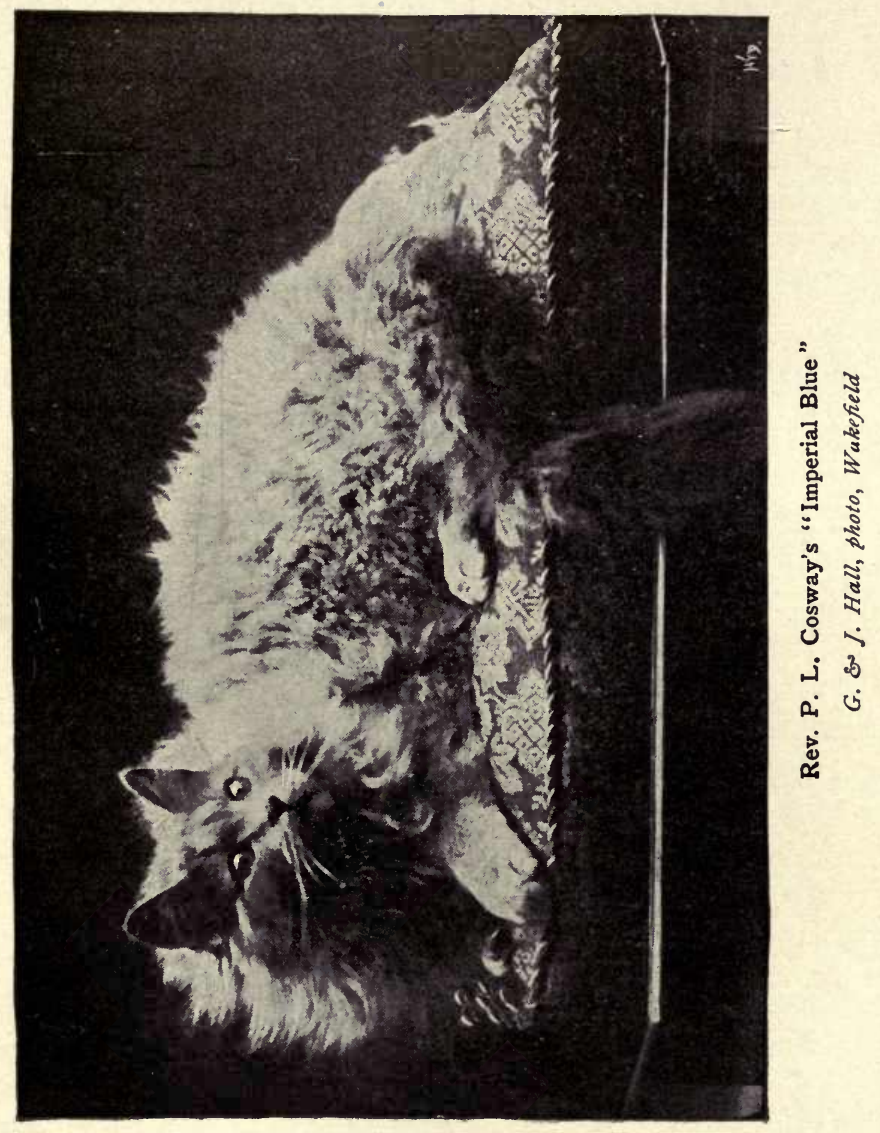



enthusiastic Orange fanciers may succeed in breeding such a cat, and also produce blue eyes! At present the classification generally stands for Orange cats, marked or unmarked. The colour of the eyes should be a bronze gold, or hazel brown. Orange females are much rarer than Orange males.

Cream Persians are very much to the fore now, but the name is suggestive of a cat much paler in colour than those seen in the Show pens. These cats should be as selfcoloured as possible, without tabby markings or shadings. They are often rather patchy in colour, and lean towards fawn rather than cream. Their eyes should be the same golden or hazel colour as in the Orange breed.

It is seldom a really good specimen of a Tortoiseshell is seen. These tricolour cats of black, orange and yellow should be patched, just like the marks in a piece of tortoiseshell. There should be no streaks, stripes or tabby markings in a good Tortoiseshell cat, and the colours should be well broken and evenly distributed over the body, head and legs. The brighter colours should predominate, and no white is permissible.

To novices only in the Fancy need I remark, that Tortoiseshell Tom cats are extremely rare. Tortoiseshell and white long-haired cats are by no means common. Most of those exhibited have too much white about them, and might justly be called White and Tortoiseshell. To be correct, the black, orange and white should be evenly balanced, and the chest and nose should always be white, with patches of colour on either side of the face.

And now to consider the Short-haired breeds. My remarks as to the Black, White and Tabby long-haired cats equally apply to the short-haired varieties. The Blacks must have no white, and the Whites be pure in colouring. The eyes of the former should be orange, and of the latter blue. It will be easily understood that the markings in the Tabby short-haired cats are much more vivid and distinct than in the long-haired breeds. There are also* Spotted Tabbies, but they are rare. In these there should be no lines whatever-not even rings. The more the spots appear

* Strictly, of course, this is a contradiction in terms, for "Tabby" means " Striped." Still the name "Spotted Tabby" has become established and is intelligible. 
to the exclusion of any other markings the better the specimen. I have never seen or heard of an Orange-spotted Tabby.

The commonest of all cats are Short-haired Tabbies and Whites, and Blacks and Whites. We see these specimens on many doorsteps. The markings are sometimes quite grotesque in their distribution. It seems almost a pity to so far encourage these cats as to give classes for them at our Shows. The "Any other colour" class is set apart in both the long- and short-haired sections for this description of cat, and for those that cannot really be properly classed, such as very light Smokes, Tortoiseshell Tabbies, and Blue Tabbies. Formerly Self-coloured cats with white spots were entered also in this class, but it has wisely been decided that these must take their chance in their own classes. The Blue Short-haired cat, commonly called Russian, has a coat resembling plush in texture. These cats are supposed to have first come from Archangel, but the best authorities seem to agree in believing they are not a distinct breed, and therefore they are now classed at our Shows amongst the short-haired English varieties. Blues should have deep orange eyes, and the colour of coat may be light or dark, but must be even throughout, without any appearance of stripes or markings. A w hite spot, as in other self-coloured cats, is a blemish.

The interest in Manx cats is rapidly and surely increasing. These quaint pussies are very intelligent, faithful and affectionate, bu $t$ I must confess the love of this particular breed appears to me to be an acquired taste. The first, and allessential point, is that a Manx cat should have absolutely no tail: one should be able to feel where the backbone ends. Some Manx cats have a tuft of skin or hair, or a stump, but such appendages count against these specimens in the Show pen. The fur of the Manx cat is longer and softer than is found in the ordinary short-haired cat; its hind legs resemble those of a rabbit; and the absence of tail gives an appearance of still greater length of limb. Self-coloured Manx cats are much rarer than Tabbies, and I know of a Tortoiseshell Manx-needless to say, a female.

Perhaps the most difficult cat to breed and rear in this country is the Siansese. Some fanciers declare these cats 
cannot stand our climate, and others attribute their great delicacy to those terrible pests-worms-to which this breed is very subject. Certain it is that breeders of Siamese have much to contend with and many disappointments to suffer. The Royal Cat of Siam, so called from the original breed being kept in the Palace of the King of Siam, is one of the most fascinating cats to keep as a pet. They have wonderful intelligence, and seem to have great powers of attaching themselves to human beings. In colouring they resemble pug-dogs. When born they are nearly white, and gradually turn a pale fawn. Their ears, muzzle, tail and legs should deepen to a dense brown chocolate colour. The markings of the ears should be sharp and distinct. The eyes should be a lovely bright blue, large and round. On the question as to whether the tail of a Siamese cat should be kinked or not kinked, no two opinions appear to agree, though H.M. the King of Siam is quoted as saying they ought not to be. A rather strange characteristic of this breed is the tendency to darken in coat as they grow in age. For this reason it is well to have the classes at Shows divided according to age. Siamese cats may be said to be in their prime at a year old; after this their colouring becomes blurred.

The only other foreign cat that calls for attention is the Abyssinian or Bunny cat, and it is not often that specimens are exhibited at our Shows. We have no special fanciers of this breed. The fur has a groundwork of reddish-brown ticked with darker brown markings. The coat should be close and soft.

The "Maltese" (Short-haired Blue) cat of the United States is not known by that name in England, nor has the American "coon cat" or the Mexican hairless cat yet been seen on our Show benches. References to the two former of these will be found on a later page. 


\section{II}

\section{CARE AND MANAGEMENT}

THOSE who have had a long experience with cats or kittens know how impossible it is to lay down a hard-and-fast rule regarding their feeding and management. As with human beings so it is with cats. They have their likes and dislikes, their dispositions vary, and their constitutions are totally different. If we wish our pets to thrive we must study them individually, not collectively. There is a saying that "what is one man's meat is another man's poison," and I have known some kittens to grow fat and look well on food on which others have dwindled away.

It is a mistake for a novice to start with a large number of cats, for failure is sure to follow. Two good females is enough to begin with, and these would probably be indoor pets.

Kittens are no trouble to "settle down," but with grown cats it is very different, and it is well to find out from pussy's late owner whether she has been a house pet or cattery cat, as well as her favourite diet, and whether she had been used to sawdust or earth in her sanitary-pan. Her happiness on entering a new home depends greatly on her own disposition. Some cats do not seem to mind a change of abode and ownership in the least, and are most affectionate and demonstrative on being liberated from the basket. They will eat anything that is placed before them. Unhappily there are others that, as soon as they find themselves in a strange place, are frightened and miserable, and will rush into the farthest and darkest corner of the room under a 


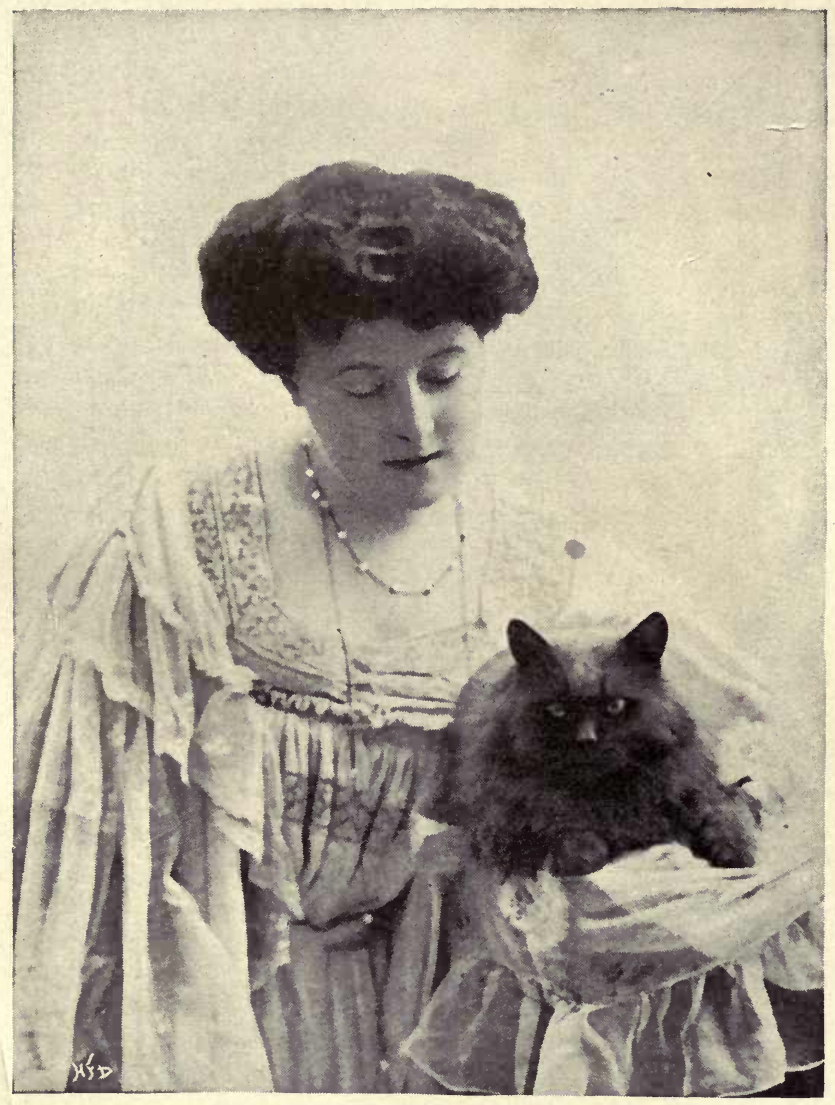

Mrs. Collingwood's "Royal Bobs"

Charles, photo, London 

chair or sofa. It is kindest in these cases to leave puss alone for some time; then try by gentle persuasion to coax her out of her hiding-place with a saucer of milk or some "tit-bit." She may refuse all food for two or three days, but before long she will get accustomed to her new surroundings, and at the end of a week or ten days will probably be perfectly happy and contented.

Of course, for the first few days it will be necessary to keep windows and doors shut, and to show her constantly the pan she is to use-or to take her into the garden, so as to teach clean habits. If, when she is in the garden, you find she has made a sudden dart, do not attempt to chase her; it is the worst thing you can do. Wait until she is inclined to stop and look about; then call her gently. You will probably find she does not want to run away. But be careful how you take her up. Some cats will not be handled, and will struggle and fight and scratch and bite, but a cat cannot escape if you catch her by the skin at the back of the neck. I do not mean that you should keep her in a hanging position, but your right hand would be holding her neck as you nurse her in your left arm. Cats are naturally timid, and it is curious to note what antipathy they have as a rule to men, though they will grow as devoted to a master as to a mistress. But a strange man's step fills them with alarm.

The golden rules to observe in the feeding of cats are Regularity and Moderation. An authority on cats recently told me that the primary cause of the majority of the ills that the cat is subject to is over-feeding, and the consequent over-taxation of the digestive organs. Two solid meals a day besides milk twice, are quite sufficient for any ordinary cat (nursing mothers and young kittens excepted-of which I will speak later). For breakfast a solid meal of some "food" such as The Phœnix Food, Melox, and those prepared by "Salvo," Freeman, and Mellin; any of these given hot make a delightful breakfast. Porridge and fish or fish and rice are very much appreciated-and if you wish to flavour equally any of the "food," it is a good plan to get the fish and put it on a dish and pour some boiling milk or water on it; then mash up the fish with a fork and pour the fish and milk (or fish and water, as the case may be) over the "food," biscuit, rice or oatmeal porridge; then mix well together to 
give the whole food a fishy flavour. For supper give a meat meal-raw meat, horseflesh, liver, tripe, rabbit, or lights-but do not give lights constantly if any lung trouble is suspected among your pets. Where several cats are kept it is advisable to get a mincing-machine, as not only does it save considerable time, but the food finely minced is much more digestible than cut up meat, however small. Green vegetables should be given in moderation, as they act as a blood purifier. Every care should be taken not to give fond that is the least tainted. For growing cats or kittens that may be at all weak in their limbs, lime-water is indispensable, as it gives strength and forms bone. A dessert-spoonful of lime-water in milk should be given to cats, and a little less to kittens. In the spring of the year a pinch of sulphur powder (the black for preference) should be mixed with the first meal of the day twice a week, as a preventive of skin troubles.

On no account should you allow your queen to mate more than twice in the year, nor should these litters follow too closely-as it is a strain on the mother, besides making her dreadfully thin; and it must be remembered that this will affect the kittens, making them weakly and delicate. Gestation lasts nine weeks (sixty-three days), but cats often go three days and even longer beyond that time. As the day for the "accouchement" approaches, it is as well to give a small dose of oil or to feed on sardines as the bowels should be kept well opened. The bed should be made a week or more beforehand and be shown to "Madame" for her approval. It is best to have a box-fairly high so as to keep out all draughts, yet not high enough to prove an inconvenience to puss each time she jumps in and out. Hay is nicest to put in the box-and a little insect powder should be sprinkled underneath. After the kittens have arrived a piece of blanket on the hay is much appreciated by the mother, but neither she nor her kittens should be handled for at least twenty-four hours.

If it is a first litter or if the mother is not reliable, a foster-mother should be in readiness. For preference in such cases get a strong English cat, as they are more robust than Persians, and often far more loving mothers. Four kittens are enough for any average cat to bring up. In the 
selection of a foster-mother the age of both litters should be about the same (at any rate within a week) as the mother's milk varies according to the age of her offspring, and not only this, but new-born kittens require more maternal watching and warmth than kittens of three or four weeks old.

If it should happen that the mother dies or deserts her babies or has no milk, and a foster cannot be found, you must do your best to bring them up by hand. This involves much care and patience. A hot-water bottle covered with flannel comforts the tiny mites. They should be fed every two hours during the day (and at least twice during the night) for the first fortnight with milk and water and a tiny pinch of sugar. Up to the end of the first week the proportion of milk and water should be one part milk and two parts water, including a little lime water. At the end of the first week it should be half and half till three weeks is reached, when it should be three parts milk and one water. At three weeks old, if milk is not given, Mellin's Food is to be highly recommended, and the proportions of "Mellin's," milk, and water are given with the directions for "infants and invalids," and common sense tells one which of the directions to adopt. At five or six weeks old, solid food ought to be given in very small quantitiesthree quarters of a teaspoonful of the finest and most tender minced raw meat twice a day (but not given consecutively), Mellin's food two or three times; and a little thin arrowroot may be given for a change, beef-tea or a tiny helping of fish mixed with warm milk. This same diet only in rather larger quantities may be given till eight weeks old; from that age to three months a little rice and gravy, Spratt's puppy biscuit (very finely mashed), Salvo's or Freeman's food or Phœnix with gravy. Rabbit-broth or fishy flavour can be introduced, and is very much enjoyed. Milk puddings too are good for kittens. Be sure to offer your cats grass, as it is nature's own mediçine, and animals will not take it unless they need it. A nursing mother should have three solid meals a day, and milk twice if she will take it, but do not give her too heating and stimulating a diet, as it is apt to produce scurf in the kittens. When this is noticed give the mother a pinch of sulphur powder on her first meal two or three times a week. 
What fanciers dread most in their litters are bad eyes; if they are the result of cold they are not so hard to cure but the usual cause is debility and worms in the mother or other constitutional weakness. If the kittens are only a few weeks old the mother should have a worm dose as this affects the milk and acts on the kittens beneficially. The kittens themselves should not be dosed under three months old. It is cruel to take a kitten from the mother until eight weeks old. Never dose a cat for worms when in kitten after the first fourteen days as it would be more than likely to cause a miscarriage. These hapless events usually occur at the end of five weeks, and are generally caused by fright, chill, or weakness, or are the result of old age of either of the parents (generally the mother). If once a mishap has occurred history may repeat itself and especial care should be taken at the time which has proved the most critical to the mother in previous matings.

I should mention that diarrhœa is another ailment very common in kittens and there are various causes-chill, indigestion and worms. This troublesome complaint should at once be stopped or the kitten loses strength and succumbs. Fleas and those horrid little lice also work great havoc. And I have seen more than one victim to these pests, with deadly white lips, nose and mouth, the coat all rough and wiry, the kitten itself a bag of bones with no real disease except what the insects have caused, for they suck the blood, thus causing anæmia, and irritate the sufferer almost to madness. A tooth comb will get rid of all the dirt and nearly all the fleas ; then rub a little insect powder into the fur, but never use insect powder on very young kits as the mother has a horror of it and might desert her kittens in consequence. It is often necessary to toothcomb young kittens. $\mathrm{Mr}$. Ward, of Manchester, makes a very good powder which kills lice, but it does not destroy the vitality in the eggs at once, so the powdering will have to be repeated at intervals. This powder has a very inoffensive smell, but I would not recommend using it on kittens until six weeks old.

I have not yet mentioned out-of-door catteries. These are best made of wood-raised up from the ground-and should be covered with felt or corrugated iron. There should be plenty of ventilation, avoiding draughts. A wired-in run is 


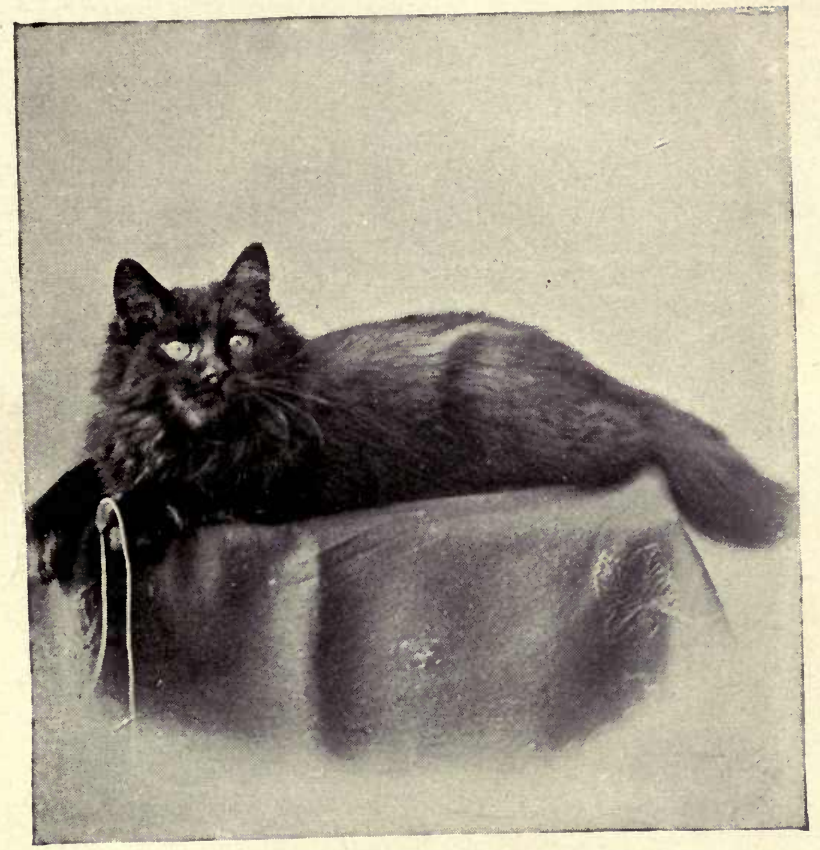

Mrs Robert Little's "Othello"

Nottle, photo, Beckenham 

most desirable and ought to be covered over so that in wet weather the cats should not have to be shut in their rooms all day. There is no doubt that cats thrive best out of doors and can stand any amount of dry cold. Artificial heat ought not to be encouraged; it makes cats delicate and very susceptible to cold and other catty complaints; while invariably giving kittens weak eyes. The cattery cat is far better off with the temperature even, and with a nice comfortable bed in a cosy corner of her "room" - a box with plenty of warm hay for the winter months and paper for the summer months.

Great attention should be paid to keeping the sanitary pans clean and well supplied with earth or saw-dust, otherwise pussy is encouraged to be dirty, for she will not go to a pan which has nothing but wet mould, and she much resents a pan that one of her neighbours has used. If two or three cats have to share accommodations it is best to have two or three pans about. Londoners especially should lay in a stock of Japanese mould, as supplied by Carter's of High Holborn. All feeding vessels should be kept scrupulously clean and never left standing about.

In advocating out-of-door catteries it must be understood that it would be madness to put a cat out in mid-winter which had hitherto been a house-cat. She would probably be dead from pneumonia within a week. But cats put out for the first time in the early summer thrive all the year round better than those who lead an indoor life. They have healthier appetites and grow better coats.

Speaking of coats reminds me that a cat comb and brush should be kept and each cat combed down once a day. It prevents their hair from matting, brings out the old coat, and causes the new coat to come on more quickly, and last, but certainly not least, it keeps the coat clean and free from insects.

I have spoken of nursing mothers and kittens, but not of stud cats, Stud cats require more meat and stimulating food than others; and a day should not pass without their having a plateful of meat. Raw meat occasionally is absolutely essential.

Never forget to keep your Tom cats well supplied with grass, for having no amount of exercise they require it 
Above all things don't overwork your stud cat, and try to avoid inbreeding. I can highly recommend Boulton \& Paul's capital houses for stud cats. I have had one for four years, and it has answered splendidly; and my cat Persimmon, who inhabits it, has never ailed anything. Mine is a double house, but I had the partition taken down, so that there is quite a fair-sized exercise ground.

A few words about gelded cats will not be out of place in this chapter, my remarks being applicable to both long and short haired neuters.

For reasons that are easily understood it is necessary, if you wish to have a house pet of unimpeachable manners, to have your male cat doctored when he arrives at years of discretion, or in this case I might say, indiscretion! I consider between five and six months the best time for a cat to be gelded. These cats grow to an enormous size, and their coats are generally very long and thick. They do not shed their fur to the same extent as ordinary cats. Certainly they should always be judged in a separate class at all shows. The neuter class at good shows is often most attractive and weil filled. As a rule these cats are more docile and better-tempered than others, and though they are considered a lazy set, yet rats and mice will be generally kept under by the household pet. When fanciers are overwrought by disappointing litters, troublesome Toms and prolific females, I have more than once heard them exclaim: "I shall get rid of all my cats, and only keep neuters !" 


\section{II (continued)}

\section{PRACTICAL HINTS ON CARE AND MANAGEMENT}

\section{Kittens.}

IT is always advisable when buying a kitten to make inquiries as to the way in which it has been fed, so as to continue the same régime for at least a few days. Any sudden change of diet for young kittens is to be avoided.

For delicate kittens raw meat should be passed through a mincing machine, or if the animal is really extremely weak and ill, then let it be rubbed through a sieve, so that the digestive organs will have little or no work.

Teach your kittens when young to lap water. It is a capital thing for all animals, especially with a small bit of sulphur in it.

There is a great knack in teaching young kittens to feed themselves. When they are about three weeks is the time to try and get them to take a little milk and warm water: say about twice a day. I find a shallow plate is better than a saucer, for when the mites dip their mouths into the milk they do not get out of the depth! It is curious how stupid some kittens are in making the start towards independence iu feeding, whilst others in the same litter quickly master the difficulty of lapping on the surface of the milk. Some are taught better if the milk is held to their mouths in a 
spoon. Add a pinch of sugar to the milk and warm water.

In bringing up young kittens by hand, the mistake is often made of giving too much food and over-loading the little creatures, who in consequence suffer from acute indigestion. A teaspoonful of milk or Mellin's food at a time is sufficient, and this may be given every two or three hours. It is best to try and not awaken kittens in order to feed.

Of course one is sometimes obliged to feed by force, but this should be resorted to only as a last extremity. I have often spent an hour or more in trying, by all sorts of persuasive means, to get a kit to feed of her own sweet will, and have felt a throb of pride when my efforts have been crowned with success.

Some kittens will begin to feed themselves at three weeks, and be quite able to leave their mothers when they are five or six weeks old. I do not think, however, that kittens should be sent adrift till they are at least two months old, by which time they will have some idea of the methor by which their careful and attentive mother has kept them clean and tidy.

I do not approve of raw fish, especially for young kittens, it is not easily digested and often causes diarrhœa.

There is a knack about teaching young kittens to be clean. As soon as they are able to scramble out of their basket care should be taken not to allow them to run into corners. When this occurs pick them up and put them in the pan of earth or mould provided for them. With patience and perseverance you will find the little creatures will accommodate themselves to circumstances and the pan!

The weakest part in a young kitten is, undoubtedly, the eye, and I think breeders will bear me out in my statement that they have a great deal of trouble with bad eyes in kittens. Several lotions and ointments are supplied, but sometimes I have found these irritating. Use sweet oil to keep the lids 


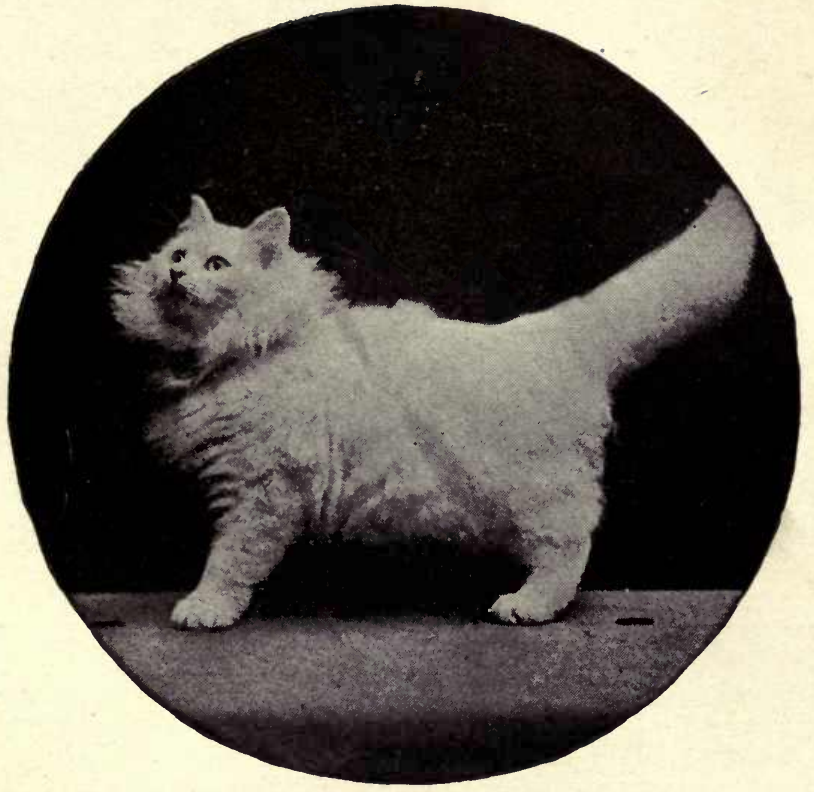

Mrs. Pettit's White Persian "Piquante Pearl"

Russell \& Sons, photo, London 

from sticking together, give plenty of fresh air and sunshine when possible, and leave the rest to the mother.

A good guide as to the health of kittens is their weight ; and a kitten to be in really prime condition should weigh one pound to every month, say up to six months old. So if you find a three-months-old kit much below three pounds you should feed him up.

It is a capital plan to teach your young kittens to sometimes take their food from a teaspoon, so that when it is necessary to administer a dose of medicine it comes more natural to them.

I have often noticed that very long-coated kittens are the most delicate, their strength having gone into their fur. I recently came across a litter of Blues that at three weeks old were enormous to look at on account of their extraordinary coats. They were really tiny limbed creatures, and they dropped off one by one without any apparent cause. I do not know if there is anything in the notion that if the male cat is very strong and healthy the offsprings will consist of more males than females, but from experience I have found that an old queen will almost invariably breed females largely in excess of males.

I believe that all kittens are born healthy, and, therefore, supposing the mother is weak and delicate, it is best to have a foster ready, and take each kit away as it is born, not allowing it to suck from the mother at all. I have recently heard of great success following this course. The mother was consumptive, but the four kittens given at once to a healthy foster are splendidly strong.

Kittens generally shed their first teeth when between five and seven months old. This is often a very critical time, and I have known several cases of convulsions occurring. Owners of cats should frequently examine the mouths of their pets, if they suspect any teething trouble. It is sometimes necessary to draw some of the old teeth to make way for the new comers. I can tell of one poor cat who refused 
all solid food, and for no apparent reason. I opened his mouth, and discovered a double row of teeth, and at once extracted several loose ones, which must have been the cause of great pain and discomfort.

I object to sawdust for young kittens. I have just heard of a case in point, where sume of the small particles got into the kitten's ear, and the little creature, in its endeavour to get rid of the tickling, caused a bad sore by scratching.

There is no doubt that as a pick-me-up for delicate kittens the sea air is much to be recommended. It is quite wonderful to see the transformation in these little mites after a few days of sunshine by the sea. Their eyes become clear and bright and their appetites require something more than air and light to satisfy them.

You may, perhaps, observe a sort of roughness under the fur of your kitten, and fancy it is some skin trouble, whereas in reality it is quantities of flea dirt. This is very injurious. Use a small tooth comb, and then part the fur, and brush with rather a hard brush.

When kittens reach the age of four weeks they should begin to learn to lap. A shallow plate filled with milk and warm water is better than a saucer. Begin by just dipping the kits' mouths into the milk. They will rather resent this treatment at first, and make a spluttering, but the cunning ones will grasp the situation and make another attempt on their own account. They will quickly learn not to dip their heads too deep, and their joy is great when they find they can lap up the milk without nearly choking themselves.

\section{Mother and Young}

The best months for our pussies to have their families are April and May, then the young kittens have the summer before them, when they can enjoy plenty of out-door air and exercise. 
Perhaps you may have noticed a decided partiality for bottom drawers that your puss will display as the date of the expected arrival draws near. I think in this respect a mother cat shows her good sense, for certainly if a bottom drawer can be spared, it is a very safe and convenient home for a litter of kits. They are out of draughts and danger, and if the drawer is left an inch or two open, they can get plenty of air. Of course, whilst the mother is nursing them a larger opening is necessary, so that she may jump in and out.

Do not allow your cats to have their kittens in outside catteries during cold weather. The mother is not able to attend to them properly till all are born into the world, and, therefore, the neglected ones are sometinies perished to death before they can cuddle up to get the natural warmth they so much require.

When cats are in kitten great care should be taken in handling them, and if it is really necessary to lift your puss, do so with both hands, placing one under her hind quarters. It is very injurious to attempt to pick up a cat in this interesting condition under the front paws, thus leaving the heaviest part of the body suspended.

It is most important that all female cats should be freed from worms before being allowed to breed, or even to mate. So orten young kittens fall victims to these pests, having sucked in the disease with their mother's milk. I highly recommend Ward's worm powders, but as all vermifuges are weakening, a specially nourishing diet should be given at the same time.

After our puss has given birth to two, three, or four kittens, we are often led $v y$ her size to suppose there are more to follow. Sometimes we may be right, but more probably it is only a temporary enlargement, and in a day or two we become, perhaps, concerned to find the mother's sides very visibly decrease. Give hot milk and farinaceous food to your puss just at first after the birth of kittens.

Some pussies greatly resent being looked at during the 
first days of their motherhood. They will show their displeasure by carrying off their kittens and hiding them. I have just heard of a case where the kits mysteriousiy disappeared from their basket, and after diligent search the litter of four was found carefully packed away in one of the boots beionging to the gentlemen of the house! It is best to place the bed in some secluded and dark corner, and not to trouble the family with frequent visits.

It is a bad habit to feed your puss in her hamper when she is nursing her kittens. She may be averse to coming out and leaving the precious family, but it is best for her to stretch her legs, and cleaner and nicer in every way.

It is after the first week or ten days that a nursing mother begins to feel a large family trying. There is really no immediate necessity for a foster when the mites are only a day or two old.

Don't distress yourself if your mother pussy refuses her usual saucer of milk when she is nursing a family. The instinct in animals, even in mere cats, is wonderful, and if puss prefers water to milk, be sure she has her reasons, which are unknown to the human mind.

When a cat is nursing let her have plenty of hot milk. This will be a great assistance to her in providing sufficient nourishment for her family. Warm Bovril or Kreochyle is also very sustaining, to which I find cats are very partial.

Sleep is almost as essential as food to young kittens, so when you see them cuddled up comfortably, do not disturb them and always avoid handling them. Perhaps through some disaster or because your puss deserts her kits, she is left with a lot of milk, It is best to give her a dose of castor oil and rub her breasts gently and frequently with camphorated spirit or eau de Cologne, diluted with a little warm water. In about three or four days the milk will dry up. It is very seldom that cats suffer from milk fever.

Don't let your Persian queens bring up more than four 


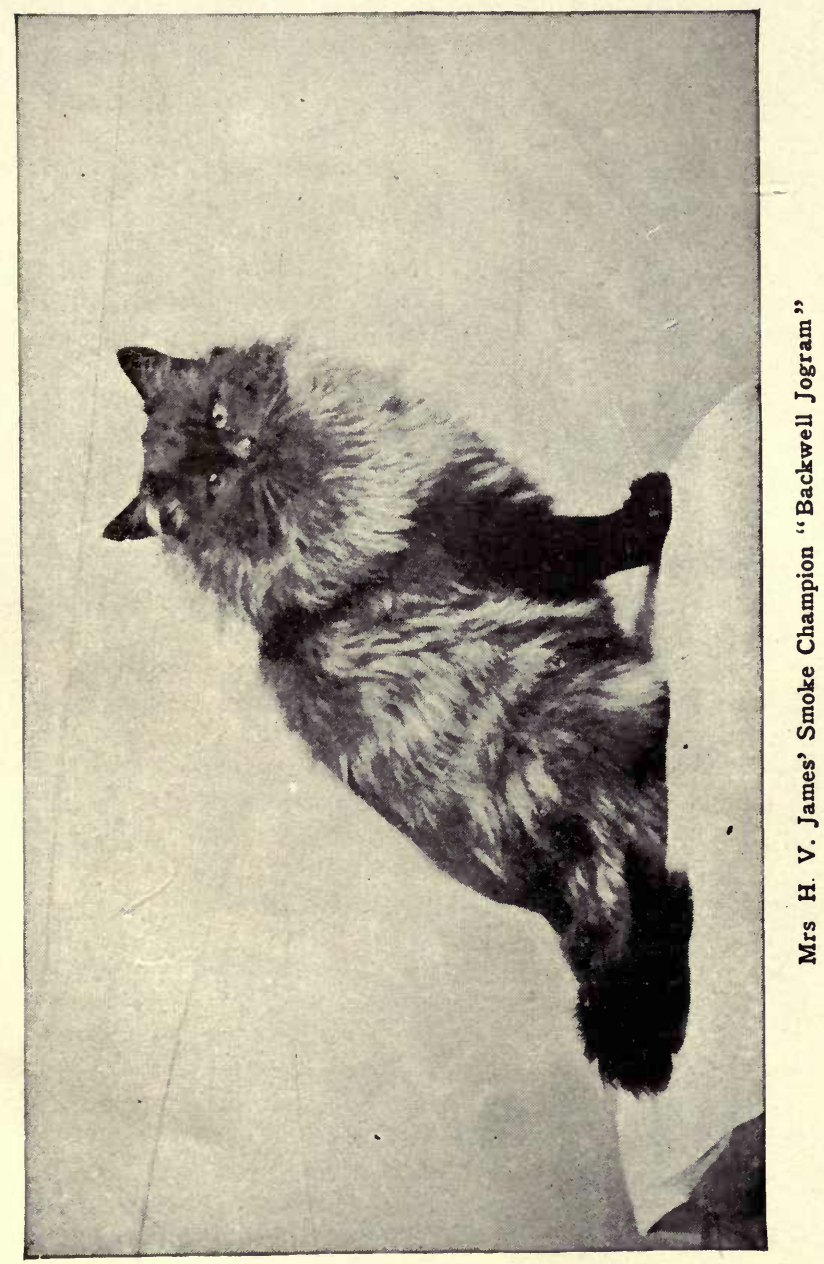




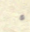

5 
kittens. Try and secure a foster to assist if the litter is a larger one. It is when kittens are about a week old that the mother begins to feel the strain upon her. A nursing mother should have four good meals a day.

It is well to bonk a foster cat if our queens are not good mothers. The difficulty is generally to fix the date of the arrival of the foster mother's kittens. It is best to have the foster in the house a few days before the litter is expected. A cat should not be allowed to take a railway journey having just had a family, as the shaking is likely to upset the puss.

There is really no difficulty in transferring kittens to foster mothers, and it is well to keep common cats in view at about the period when our valuable queens are due to kitten. I have found the following plan answer splendidly. Take it for granted your Persian queen and the common or garden cat have litters about the same time. You proceed to painlessly destroy all but one of the foster's family. Then place two or three, or all of the valuable kittens in the nurse cat's bed, mixing them up with the one kitten, baving in the meantime removed the mother. In this way the new kittens will become scented as it were with the surroundings, and on her return the mother will give a few sniffs, and probably cuddle down quite contentedly, with only a vague suspicion that something has happened.

Some cats will be excellent mothers to a large family, but if anything should happen to any of the litter and she is left with only one or two she will desert them. It is better to try and procure other kittens to put with her, and let her foster these with her own.

Kittens should not be taken from their mother before two months, and those that are left another month are generally the better for it. Not only is it well for the cat to suckle her young as long as possible, but the natural warmth is very essential for kittens of tender age. Avoid handling your cat when she is in kitten, and when the family arrives resist the temptation of picking up the tiny mites. Some mothers resent this, and will of en hide away their offspring, 
and they have been known to eat them in consequence of undue interference.

I was once possessed of a lovely blue female, whose only fault was neglecting her offspring when about a fortnight old. I hit upon the plan of using the filler of a fountain pen. I charged this with warm milk and water, and placing the end in the kitten's mouth, I gently pressed the rubber. The kits sucked away with great glee. This is a much better mode of getting food down young kits' throats than by using a spoon. I believe Mr. Ward, of Manchester, has improved upon my patent, and a glorified fountain-pen filler is now provided by him. This has a piece of india-rubber fixed on the part of glass tube which is put in the kitten's mouth, and thus all risk of their biting the glass and breaking it is done away with. Let me recommend all breeders of kittens to have one of these useful articles amongst their catty requisites.

It is not very safe to put Keating's Powder on your baby kits, but, if troubled with fleas, sprinkle some amongst the hay at the bottom of their basket, under which place a newspaper. You will be astonished what a number of fleas, dead and dying, will be found on removing the basket. Change the hay frequently, and sprinkle fresh powder. In this way, both mother and kits will be kept free from these pests.

Don't have anything to do with red baize or flannel in making a bed for young kittens. If these materials get wet the dye comes out and stains the coats horribly. The other day I came across a little family of Blues with red tails !

In wintry weather it is risky sending our precious queens on long journeys. Make use of large sheets of brown paper as coverings to the hampers. This defies the wind much better than woollen wrappers or linings.

I am often asked how it is best to set about breeding Persian cats so as to make it pay, and I invariably answer by telling my inquirers to procure two thoroughly good, healthy pedigree queens. At the present time, I should 
suggest a Blue and a Silver. Send these to mate with wellknown sires, and advertise the kittens just before they are ready to leave their mother, say at about eight weeks old.

Avoid the use of drugs of any kind for your cats when in kitten. Give extra food, and when the interesting event draws near, prepare a nice box or bed in a secluded corner. Some cats much prefer paper to hay or straw; others like a folded blanket.

\section{Male and Stud Cats}

I am sure it is a mistake if you have a stud cat to allow him his liberty one day and then shut him up again. $\mathrm{He}$ will pine and fret much more than if kept in contınual confinement. It is important, however, that our male cats should have plenty of fresh air and a long enough run to täke some exercise.

One of the advantages of cat shows is that we are enabled to take stock of the various males, as in some cases advertisements of stud cats are a little misleading. I attach great importance to size of head and form of body. Sufficient attention is not paid to mating cats when they are not showing any irdication of moulting. Choose a stud cat in good coat if possible. The outward characteristics are in a great measure transmitted by the male, so look well to markings, colour, and shape of the stud cat selected.

The usual fee for the services of a good stud in the cat fancy is $\mathcal{E}_{\mathrm{I}} \mathrm{Is}$., and the expense of carriage is defrayed by the sender of the queen. In the United States the charge is from five to ten dollars.

A word to novices. Beware of keeping your male cats together after they have passed ten months, as I have recently heard of a tom who attacked his brother very suddenly and nearly killed him.

It is a good plan to try and accustom your cats to be tethered up. My stud cat is quite happy on a long cord. 
He gets to know about the distance he can walk round. In this way he has a fair amount of exercise and plenty of fresh air.

\section{Catteries and Appliances}

If you decide to keep your cats and pets in a cattery, bring them indoors now and again and thus accustom them to home life and human beings. It is much pleasanter to have a really domestic cat, rather than one that darts away when approached and is frightened at every sound.

All wooden catteries should be well raised from the ground. It is important to have good ventilation. It is a capital plan to have movable wooden shutters, so that in extra windy or damp weather these can be easily put up to form a shelter.

In constructing a cattery, be sure and have plenty of shelves fixed up. All cats have a weakness for sitting on a shelf, however hard or narrow.

During the winter we are sometimes wishful to heat our catteries, although I am not in favour of artificial heat. After a heavy rain or dense fog we have recourse to a little oil stove. Be careful to protect this in some way by wire netting or a fire guard. I have known a cat to waft its tail over the top of one of these stoves, and it was more than singed!

Cats are essentially and naturally clean animals, and it is often the fault of their mistresses and caretakers that they become dirty in their habits. Keep their earth tins clean and sweet, and you will seldom find that pussy offends. Cats so much prefer to have something to scratch in and scratch over.

Japanese mould is splendid for use in cats' tins. This can be purchased at Carter's well-known firm in High Holborn. It has the advantage of being a great absorbent, consequently 


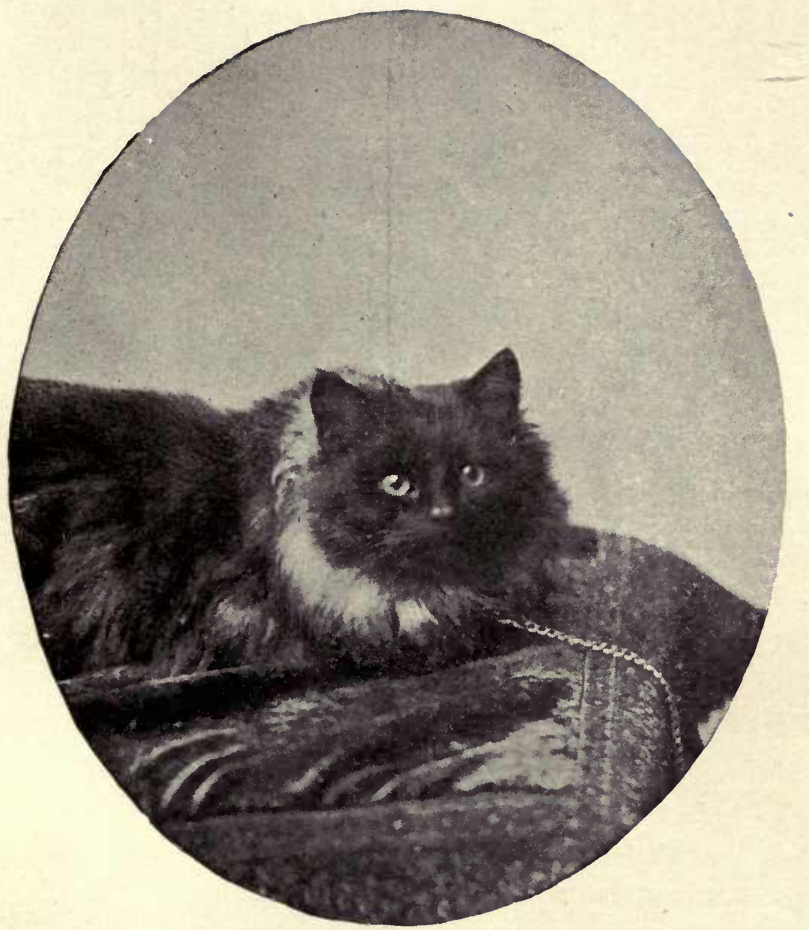

Mrs. Sinkin's Smoke "Teufel"

Debenham \& Smith, photo, Southampton 

no disagreeable odour is noticed, and the mould need not be changed so frequently as ordinary earth.

A house pet whose behaviour cannot be relied upon is not a desirable inmate. It is always best to have an arrangement of an earth tin in some quiet corner, and to accustom the cat to make use of this in an emergency.

I never advocate any artificial heat for cats or kittens, but if you have a delicate specimen, or one suffering fron a cold, and the weather is severe, then I have found that a hot bottle at night is a great comfort. The india-rubber ones are the most handy, but failing these, a stone gingerbeer bottle filled with boiling water, and tightly corked, answers the purpose. Wrap it in flannel and place in the bed last thing at night.

It is a good plan during the winter months to keep a store of dry earth in some covered place, so that you can have a constant supply with which to replenish your tins. There is nothing a cat resents more than being asked to use a tin containing damp earth.

All sleeping boxes or hampers for cats should be raised, and, even for a cat sleeping in the house, a bed, on a chair or box, is much to be preferred to letting her lie on the ground where there is certain to be a draught.

Be sure and let your pussies have an abundance of hay in their beds during the winter months. Boxes are warmer than hampers, and the top should be covered over so that the cat may crawl in from the front over a ledge of a few inches of wood. Then when inside the bed she is protected from any ground draught.

The straw or hay provided for our cats should be changed at least once a week, and oftener in summer. A little Mothalene sprinkled at the bottom of the box or hamper keeps down troublesome insects.

During the summer do not put too much hay in your 
cats' beds; in fact, I prefer a sheet of newspaper laid at the bottom of the box or hamper. Hay is heating, and encourages fleas.

Some cats have a most troublesome and irritating habit of rubbing their heads against the walls or wire neiting of their houses. A sheet of glass about the height of the animal will prevent the destruction of their coat and ruft from the continued friction.

If you use wire netting in your catteries be very careful that the ends are neatly finished off and that no sharp bit of wire is left sticking out. I have known cats receive severe injuries to their eyes from scratches, and often their coats suffer from being caught on the rough ends of the netting.

It is always best to keep separate and distinct saucers and plates for our pussies' use. I would recommend the blue and white enamelled ware, which is unbreakable. I find, also, that it is often very convenient to heat the milk in one of these plates instead of troubling to boil it in a pan. If a saucer of milk is placed on a closed stove for a few minutes it soon becomes hot, and no injury is done to this enamelled ware. The basins are also very handy, but for Long-haired cats the plates are better, as pussy's ruff is less likely to become solled with the food.

I find that my cats prefer a circular basket as a bed to a square one; they seem able to curl round more comfortably. This is specially the case with a mother puss and her litter of kits.

Have you remarked how fond cats are of each having their own plates and saucers from which to feed? I have lately invested in some nice deep white saucers. They were a "job line" at twopence-halfpenny the dozen!

If you are building cat-houses, remember that a concrete floor is much better than a wooden one. It may seem cold in winter, but a piece of movable linoleum or cork "lino" will add to the appearance and comtort of the cattery. 
During very hot weather our stud cats who inhabit houses suffer a good deal when the sun strikes down upon them. I cover the front of my cattery with an old rug and then make free use of the garden hose, letting it play upon the top and saturating the thick cover. This has a wonderfully cooling effect, which lasts some time. During the process my cat retires into his sleeping apartment.

It is difficult to procure suitable earth tins for our cats. I tried several, but they were either too shallow or too deep, so decided on ordering some of the required size made in galvanised iron, at Whiteley's. Large earthenware flowerpot saucers, well glazed, are also very suitable.

\section{Hints on Food}

If you can persuade your pussies to eat Spratt's Cod Liver Oil Puppy Biscuits you do them a good turn and yourself also, for they are very nourishing and inexpensive. We all acknowledge that raw meat is an excellent diet, but if we are possessed of a number of queens, two or three stud cats, and several litters of growing kittens, then the butcher's bill becomes a serious consideration. The biscuits should be soaked for some hours till soft enough to be mashed through a fork; a tablespoonful of the red gravy from a roast joint added, diluted with a dash of hot water and a sprinkle of salt. The kits will not leave much beside the pattern on the plate.

A cat will often refuse her food simply because she cannot smell it. It is therefore important to clear the passage of the nose. Sometimes if you can put one piece of food into your pussy's mouth, she will then taste it, and continue to eat of her own accord.

A cat or kitten must be very far gone to refuse Brand's essence. So, if all food fails, try this. I find they generally prefer it in the jelly, and to lick it out of a spoon.

Oatmeal is such a splendid food for our pussies during winter, but I do not find they are very partial to it. I would 
suggest mixing the meal in water in which liver has been boiled, and adding a few bits of the meat with it to make the dish more tasty.

Another nice winter meal is Hovis bread (brown), with boiling milk poured over it. A change may be made by scalding the bread till soft, then pour off the water, and stir in a tablespoonful of condensed milk.

Not only do bones amuse a cat, but they benefit the teeth considerably, and help to strengthen the jaws. Large bones are preferable, with, of course, a little flesh on them. Avoid small ones, as they are apt to be swallowed and stick in the throat.

During the very hot weather butchers very wisely put their meat in ice, or in cold rooms, especially arranged for keeping it. It is not advisable to give raw meat in its frozen state to cats, and so I should recommend just scalding it, or pouring boiling water over it. Some people prefer to slightly cook the meat, leaving all the red juice in it.

Two meals a day are as a rule sufficient for healthy cats, but some who are "bad doers" require special treatment and should be offered food in small quantities three or even four times a day. If a large dish ot food is placed before a cat who feeds badly, it is very apt to sicken her and make her refuse to eat at all.

I have found macaroni, well boiled and mixed with gravy, a capital food for cats and kittens. It makes a change, and is generally highly approved of.

We see a number of pictures in the daily papers of plump, pretty babies who have been brought up on Mellin's Food. Now, it stands to reason that what is nourishing for infants must also be good for young kittens. I know of several cat fanciers who swear by Mellin's Food.

I advocate a mixed diet for cats, and therefore recommend ringing the changes on raw meat, cooked meat, with vegetables and gravy; fish, mixed with rice and boiled milk. I 


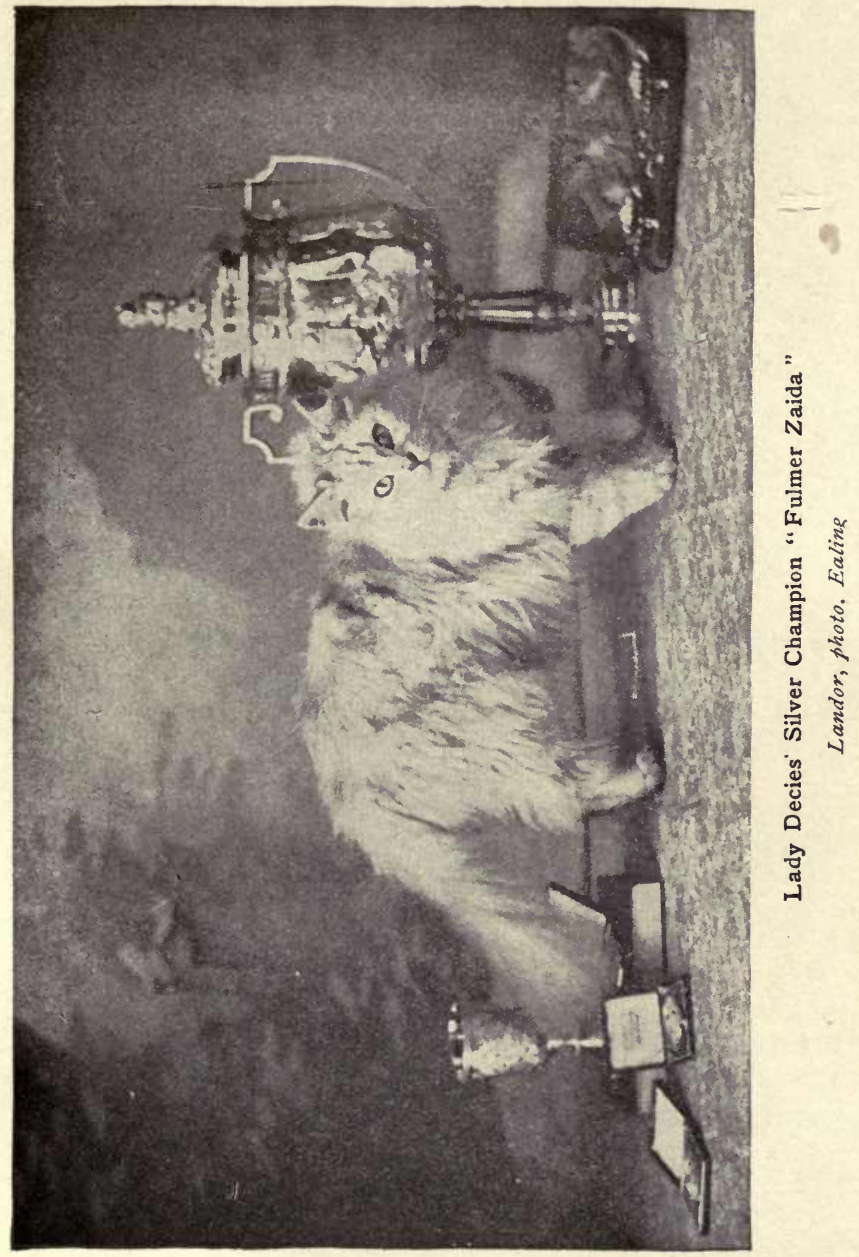


consider two meals a day sufficient for cats, and three meals for kittens, under ordinary circumstances. Tom cats, when at stud, should have an extra meal given to them, and a nursing mother just as much as she will eat. I do not approve of tit-bits given between meals, which is harmful to the digestion.

I have been told by an experienced fancier that tripe is an excellent food for cats, and that they are extremely fond of it. I intend to give it a trial, as one is always glad to know of something in the way of a change in pussy's menu.

An inexpensive meal for a cat is jelly made from bones, which can be procured from your butcher for a few pence.

I am sure that most cat fanciers on a large scale will bear me out in my statement that hardly two cats feed alike, therefore I consider that no strict bill of daily fare can be laid down. With some cats breakfast seems the all important meal, and others will rejoice when supper time arrives. Two good rules to follow are these: Food should never be left, and water must be continually supplied.

Sardines are rather an expensive luxury, but during cold weather I treat my cats to some twice or three times a week. I find that breadcrumbs mixed in the oil makes more of a meal and takes away from the richness of the fish.

A fowl's hear, with the feathers on it, is said to be an excellent thing for cats. Sometimes when the appetite has quite failed, the sight of this delicacy will tempt pussy to start eating again. The same, if a sparrow can be trapped or shot, and given freshly killed.

I am not an advocate for bread and milk for kittens, yet I must confess I bave seen some wonderfully healthy specimens brought up on this diet. I should anyhow advise brown bread, and the boiled milk should be poured over the pieces of about half an inch in size. 
The last meal for cats should be the most substantial one, as it has to last until the morning. During cold weather a cat will sleep better and feel warmer if it has enjoyed a good supper.

Do not give liver frequently to your cats. This food is very laxative and will cause diarrhœa. If, however, you allow your pussies to have it now and then, be sure and boil the meat very slowly.

I consider that cats require more feeding in cold weather than in hot, and I generally treat my pussies to an extra meal in the middle of the day during the winter months.

$\mathrm{Raw}$ beef is generally considered the best meat for animals, and next to this mutton. Veal and pork should not be given.

I consider Freeman's Scientific Food capital for cats. I have used it for two years, and my pussies never tire of it. I mix it with fish or meat stock. I am sure that once tried it will be always used.

I do not think fanciers estimate at its proper value pure cold water as a drink for cats. No doubt good fre:h country milk is nourishing, but at the same time it is rich for young kittens, and I have known a promising family laid low with liver complaint simply by allowing the kits to lavish an allowance of milk. I recommended water instead, and I hear that they are on the frolic again.

Loss of appetite is often the result of a bad cold. Pussy loses the sense of smell, and refuses her food, even thongu the greatest delicacy is offered to her. Just pop a piece of the meat or fish into her mouth; she will then realise how good it is, and will turn to the plate and make quite a hearty meal.

Cat fanciers often fail to realise that their pets are thirsty in winter as well as summer. During cold frosty we:ther warm water should be added to pussy's drinking bowl. 
Animals will appreciate this attention, for freezing water is not pleasant to the tongue.

Just as with human beings so with cats ; in cases of continuous sickness soda and milk is sometimes the only food that can be kept down.

Do not let your pussies drink icy cold milk or water, it is most trying to their digestion and not comforting to their interiors. I find my cats like their milk in winter steaming hot and it is wonderful how hot they can lap it.

It is very important that cats should be given a good proportion of vegetable diet. This is more especially necessary if grass is not easily obtainable. Some fanciers are in favour of lentils, and no doubt they are very nourishing, but as a rule pussy does not take kindly to this food, and an early training is necessary. Lentils should soak for some hours and then be slowly boiled. They are best mixed with scraps of meat and gravy.

If your cats cannot have access to grass, then sow seeds in pots and leave in the cattery. Cats always prefer the coarser kind of grass.

I find that of all sorts of grass and green food, cats are fondest of ribbon grass. I have some specially sown in the garden, and every morning I twist it in and out of the wire of my cattery, and the pussies bite away at it with great delight.

Don't forget when you wish to administer any kind of oil to cats or kits to have the spoon quite hot. It is best to stand it in the boiling water, then pour in the oil, which you will find will slip down the cat's throat very easily, and not remain sticking to the spoon or the patient's mouth.

Some cats will thoroughly enjoy to nibble at a piece of bread and butter. One of my cats always makes her appearance at afternoon tea, and expects to be offered tea-cake, muffin, or whatever is going. 
I came across some finely grown and very plump young cats the other day, and on inquiring about their diet I heard it consisted of raw meat and Neaves' food. The result was certainly very satisfactory.

It is not advisable to feed a cat just before she starts on a journey. Give a good meal three or four hours previous to packing her up. The receiver will be pretty sure to attend to her wants on her arrival. It is a mistake to put food into the hamper, and pussy generally shows her good sense by refusing to touch it.

Many fanciers are averse to giving horseflesh to their cats, and, no doubt, in hot weather it is not to be depended upon. If, however, really reliable cat's meat can be obtained during the winter months, I am sure it forms an excellent and nourishing food. As a rule, the pussies delight in it. I have known cats who become well acquainted with the days on which their butcher calls, and even if they are in a sound sleep they recognise the voice of the charmer, and will make a wild rush for the back door.

During hot weather it behoves all cat fanciers to pay extra attention to the condition of the meat, which should be carefully looked over to see if it has been tainted by flies. It is best to dip the meat in weak vinegar and water, but this might give it a taste if to be eaten raw, so use boiling water only and rub with a cloth. Flyblown meat is most injurious for cats.

Most cats are very fond of lights, and these make a nice change. I find it is best to half cook them, and cut up finely. Ido not recommend lights to be given more than twice a week.

Have you ever tried boiling sheeps' heads till all the meat falls away from the bone, and then mixing it with some of its own gravy? It makes a delicious dish for pussy, and not an expensive one. It is surprising what a quantity of meat there is on a head, and I believe it is very nourishing. I use rabbits' heads in the same way, and add some Freeman's scientific food with the meat to make it go farther. 


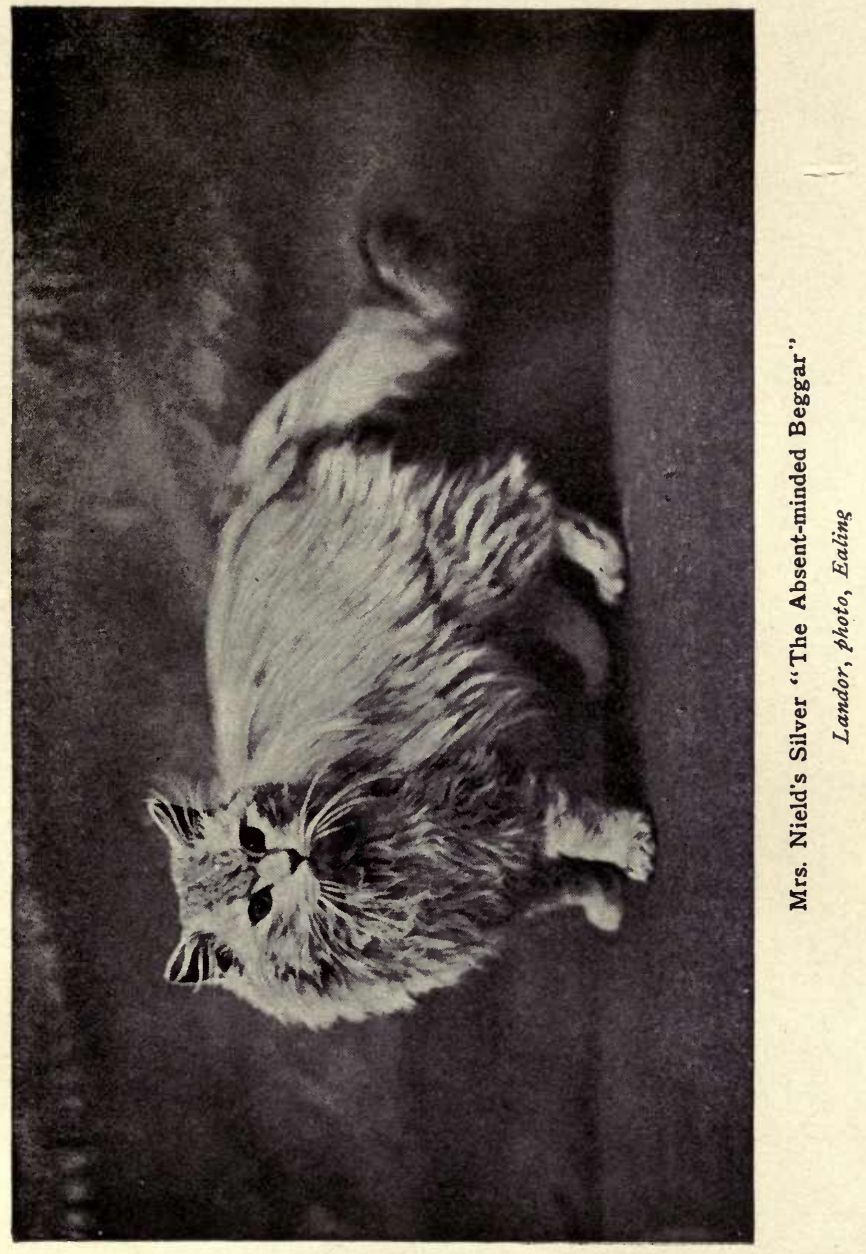



Eggs are very nourishing, we all know, but few fanciers ever think of giving them to their cats. It is true that London eggs cannot be depended upon, and the so-called "newly laid eggs" are expensive, but dwellers in the ccuntry would do well to try their pussies with a fresh egg very lightly boiled or mixed with hot milk.

I have been told by an experienced cat fancier that bone meal is an excellent thing for cats, especially delicate animals needing stamina. This article can be procured from a corn merchant, and a little can be sprinkled amongst the cat's food.

I am not an advocate for tinned meat for man or beast, but I confess I have often been very glad to fall back on a tin of rabbit when my stock of food has run short. I find the cats delight in it. Care must be taken to clear out all the bones, and only the best brands of tinned meat should be given.

It is a curious fact that all cats adore asparagus. This is an expensive vegetable, but it is well to know of something with which to tempt our pussy should she have quite lost her appetite. Some cats will enjoy beetroot, and cheese is a delight to others.

It is a mistake to suppose that because a cat catches birds and mice she needs no other food. On the contrary, feed pussie well and she will do her duty better. A cat enfeebled by neglect or starvation is not in the best condition to successfully hunt and catch its prey.

A cheap fish for our cats is hake, and I find they are very fond of it. There is more meat and less bone than in haddock, which is a usual fish to select, as it is not so expensive as other kinds.

I was told a curious fact by a fancier the other day, namely, that frogs cause severe throat inflammation in cats, if chased and played with by them. I can only suppose that some poisonous exhalation comes from these reptiles. Moral : Don't let your cats go frog-hunting. 


\section{Care of Coats}

When cats are shedding their coats, it is particularly important they should have a daily brush, so as to get away the loose fur as quickly as possible, and thus the new hair will have a better chance.

It is never an easy matter to wash a long-haired cat, and certainly in cold weather it is dangerous. If you want to clean your puss and prepare her for showing, then purchase a box of Pears' white precipitated Fuller's Earth. Rub this well into the fur, especially fingering the parts that are at all greasy. Then clear away the powder with a soft brush, and you will see a vast improvement in your pussie's appearance. Camphorated chalk can also be used, but it has a clogging effect on the coat, is more difficult to brush out, and is not good for the cat should she take to licking it.

Avoid washing your cats if possible, and specially be warned against putting any carbolic in the water, with a view to killing the fleas; you will probably kill your cat, and certainly change the colour of his coat, if he be a Cream or Orange.

When a cat's fur looks "spiky," that is, standing out in separate bits of hair instead of being fluffy, you may be pretty sure that puss is troubled with worms.

When our pussies are rapidly shedding their coats they need a little extra care and extra food. I feed oftener in the hot weather, giving less at a time. It is bad at any season to leave food standing about, but this is especially the case in hot weather.

Parasites, or to be more explicit, lice on cats and kittens, are very troublesome and destructive. They increase with great rapidity, and thrive better on an unhealthy specimen than a robust one. These horrid insects, as well as fleas, exist on the blood of their victims. It is, therefore, most important to check the evil at the commencement. 


\section{HINTS ON CARE AND MANAGEMENT 5I}

I don't like to see a cat for ever washing herself and leaving her coat in a drenchiny condition. I suspect some internal or external irritation, and the troubles may be caused by worms.

We all know what a splendid thing sulphur is for our pets. It is one of the best and safest blood purifiers. - It is not always easy to get our dainty feeders to take their milk or water in which sulphur has been introduced. A good plan is to sprinkle the powder on their coats, say about once a week, and then, when the cat cleans itself, a certain quantity will be swallowed.

Don't let the traces of fleas remain in your pussies' coats. The accumulation of this dirt is bad for the skin and fur. It is best to use a small tooth comb. With a little care and attention you will soon make a clearance, and pussy would thank you if she could speak.

Many cats are very fidgety when they are being groomed. There is no remedy for this but patience, and after your puss once becomes accustomed to her morning's toilet she soon gets to like, and will even look forward to the luxury.

Many fanciers, especially novices, are alarmed when they find dry scaly and scurfy spots on their cats, and imagine they have eczema or mange. This roughness really only proceeds from an over-heated system, probably from overfeeding. Give plenty of grass or green food and apply equai parts of sulphur and vaseline for three days, and then comb with a small tooth comb.

\section{Dosing}

How difficult it is to poultice a cat! Yet in cases of enteritis and pneumonia it is often the saving of poor puss. For enteritis or gastritis when the stomach becomes tender and distended, make a roller of flannel, wet with tepid water and bind tightly round the abdomen. Over this a piece of oil silk covering to exclude all the air, and over this a roll of dry flannel. This forms a continuous poultice. It must be renewed when it gets cold, and the kitten kept warm. 
A fish bone in a cat's throat is a troublesome obstruction. If it can be pushed down with the finger all well and good, but if not the only thing is to wait and let it dissolve. This generally takes place after about five days. You may have to feed the cat in the meantime.

A simple means of lubricating a cat's throat, if it seems sore or swollen, is to butter her paws, she will then lick off the butter just as many times as you put it on. A spoonful of warm salad oil often clears the throat, and after this the cat may have a try to swallow the food from which she had previously turned away.

If in giving your puss oil, you grease her coat, apply a little vio'et powder with your fingers, rubbing it well into the fur. I have also found the pavier poudré sold for the complexion an excellent means of removing greasy substances which are so disfiguring to a cat's coat.

After giving worm powders to your cats, I recommend a saucer of hot milk, about an hour afterwards, whether the dose has taken effect or not.

The eyes in cats vary very much according to their state of health. I have seen cats' eyes seem half their natural size when puss has been suffering from worms. Stud cats quickly lose the depth of colour and brilliancy of their eyes. But this in no way affects their progeny.

I came across a case the other day of a big strong neuter cat who was certainly a victim to a tape worm. We tried various vermifuges in fairly large quantities, but with no results, so I determined to experiment with some of Spratt's puppy worm powders, and the pests were speedily got rid of. These powders, however, are much too strong for kittens and must be used with caution even for cats.

It is very important to make sure that a dosing for worms has been effectual. For this purpose it is best to shut a cat up after medicine has been given and to place a thin layer of earth in the pan provided for her. 


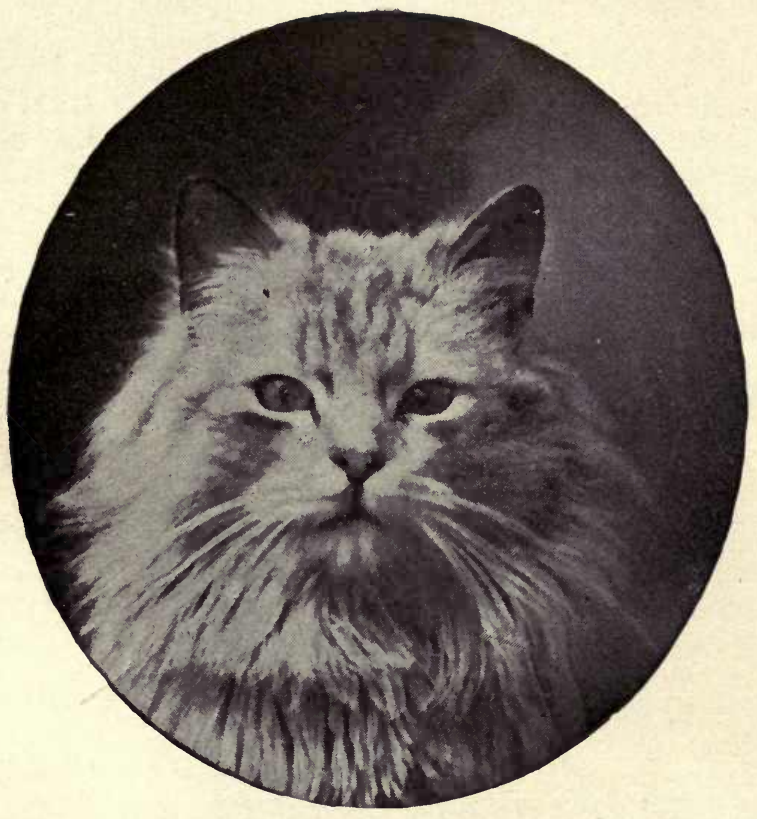

Mrs. Neild's Silver "Lord Hampton"

Landor, photo, Ealing 

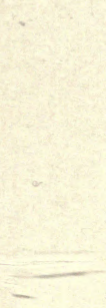
. 
There is a knack in giving medicine to cats. It is always best to have an assistant if your cat is at all difficult to manage. Struggling with a sick animal often does more harm than the medicine to be given can do good.

In dosing cats it is essential to consider the age as well as weight, and a young cat and a very old one require smaller doses than middle-aged pussies.

Oil has a most deplorable way of imparting its taste and smell to everything it comes in contact with. Try and avoid using it outwardly or inwardly for your pussies. It takes a long time to get rid of a greasiness of coat and fur.

Before starting a cat on a course of tonics I should recommend a mild aperient, and one occasionally during the course is often advisable.

\section{Neuters}

If you intend having a cat made neuter you should keep him on low plain diet for two or three days before the operation. Do not hand your pet over to an inexperienced person, but take it to a good veterinary and pay the extra fee for cocaine or chloroform to be used.

Opinions differ as to the most suitable age for a cat to be made neuter. I think that from five to eight months is the best time, as kittens gelded when very young do not attain the same fine proportions. After eight months there is more risk to the animal, and the operation ought not to be performed at all if the male has shown any desire to mate. At all times send your puss to a well-qualified veterinary.

I have been told on good authority that if a female cat is to be made neuter she ought to be allowed to have one litter before the operation is performed. 


\section{Miscellaneous}

Do not let those little bits of dry brown accumulations remain at the corners of your cat's eyes, as in time they wear off the fur, and, when removed, bare places disfigure your pet's face.

Unless absolutely necessary do not send your puss away from home when ill, but nurse her in her own familiar surroundings, where she will far more likely recover than in a strange place, amongst strangers.

I know there is a superstition that it is unlucky ever to weigh your cat or kitten, but I think it is a very useful way of finding out whether your puss keeps in good health. If after taking the weight of my cat, I found him rapidly getting lighter, I should give a course of cod liver oil. This is a speciaily good thing during the winter months. I find that most cats will lick it up with a relish, but it is best to mix a teaspoonful with fish.

If you notice an offensive smell coming from your cat's mouth have a look at his teeth. It is sometimes necessary to have the teeth scaled. There may also be a decayed tooth that needs extraction.

If you have had any infectious complaints in your catteries, such as distemper or influenza, after removing your pussies fumigate your cat-house. Close it up as thoroughly as possible, place an old shovel in the centre on the floor containing sulphur. Put a live coal in the powder, and leave it a whole day or night. It is a good plan to afterwards syringe into all cracks and crevices with a strong solution of carbolic acid.

I have unlimited faith in Eucalyptus, and in the preparations of the Eucryl Company this is the chief ingredient. I would draw special attention to their Salubrene, which has most valuable antiseptic and deodorising properties. It is not of a corrosive or poisonous nature, and the slight aroma is a most ayreeable one. For cleansing and disinfecting catteries it is splendid. 


\section{III}

\section{BREEDING AND EXHIBITING}

Having referred in the last chapter to the rearing of kittens and the treatment of Queens and Stud cats, I propose now more especially to confine myself to the various matings and crossing of breeds which are gererally considered admissible and advisable. A broad rule may be laid down to start with, namely, that Selfs should not be crossed with Tabby-marked cats or vice versa. Take white cats for instance. It is a great pity to cross them with any other variety as probably broken breeds would be the result. Some fanciers have tried them with Silvers in order to get very pale and unmarked kittens, but I have not heard of any satisfactory results. Black cats may be mated with great success to Blues. I know of many instances where anyhow, one kitten of such parents, has proved to be a beautiful Blue with the deep amber eyes so much desired. I have one in my possession which has taken high honours. Then again an Orange or Tortoiseshell may be crossed with a Black. In fact a really good Black, male or female, is a cat to be cultivated by fanciers both for breeding and exhibiting purposes. It has been the ambition of many a fancier to breed a Tortoiseshell Tom and I believe the most likely mode of succeeding is to pair a strong young black male with a Tortoiseshell Queen of more mature age. 1 have never seen or heard of a Long-haired Tortoiseshell Tom, although we have some short-haired specimens in the Fancy. I have had a good deal of experience in breeding Blues, and if it is desired 
to have all good Blue kittens, then keep these clear of any other breed. If bred with Blacks, you must be content with perhaps only one or at most two Blues in a litter. A Blue and a Tortoiseshell may be mated together if Creams are desired and, again, a Blue and a Cream can be crossed for the same purpose. You must run the risk, however, of getting an oddity half blue and half cream, commonly called Blue Tortoiseshell. These are useiul for breeding Creams, but they are not desirable for exhibition purposes. The experiment of crossing Blues and Silvers cannot be said to be satisfactory; the blue tinge destroys the purity of the silver tone and very often only light Smokes are the outcome of such matings. These nondescript cats can find no abiding-place in the Show pens for some judges call them Smokes and others declare they can only be judged in the "any other colour" class. Blues mated with Tabbies too often result in Blue Tabbies or the sound solid colour of the blue will be marred by markings. Two Brown Tabbies almost invariably produce a Black in the litter. Very good Brown Tabbies are bred from Tortoiseshells. There is no doubt that Brown Tabbies are amongst the hardiest of longhaired cats and they have more massive limbs and broader skulls. Therefore, if stamina is desired, get some Brown Tabby blood in your strains. A Silver Tabby weak in markings may be crossed with a Black to bring out their density. The great failing in this beautiful breed is too often their blurred appearance and want of distinctness in the tabby marks and this is frequently the result of mating with a Silver. By the way, what a thing of beauty a cat marked like a zebra would be! Silver Tabbies should not be mated with any other variety of Tabby. The Orange or Red Tabby is an attractive cat though finely marked specimens are scarce and, as is generally known, females of this breed are much rarer than males. Breeders of Tabbies should strive to eradicate white chins which are too much in evidence. Silvers or Chinchillas have had all sorts of experiments tried upon them but I think that in this breed, as in Smokes, it is best to keep the purity of colour so beautiful in the Silver and the white undercoat so desirable in the Smoke Persians. In shorthaired breeds it will only be necessary to draw attention to the Siamese, Manx and Blue 


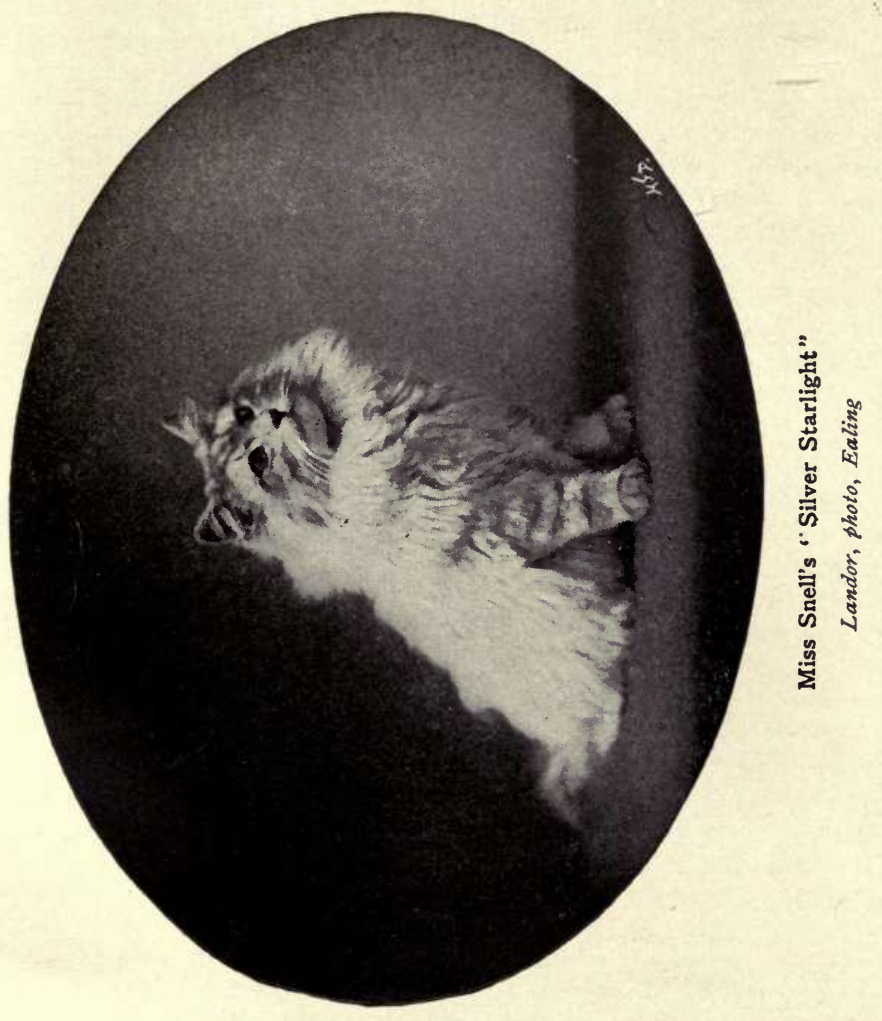



as my remarks regarding the mating of Selfs and Tabbies apply equally to the short- and to the long-haired breeds. Siamese are a special breed to themselves and should be kept as such and the same may be said of Manx and Blues. All attempts to cross these cats with other breeds should be discouraged.

It is the laudable ambition of all breeders to become exhibitors, and certainly there is infinitely more honour and glory in winning with a cat or kitten which one has bred than with an animal that money has purchased. I have given some hints in my paragraphs as to the best way of preparing cats for exhibition. There is no doubt that cat fanciers do not pay the same amount of attention to the specimens they are intending to send to a show as do members of the dog, rabbit or pigeon fancy. This is a pity, for condition goes so far to propitiate a judge, and a noted winner with almost perfect points may fail to " catch the Speaker's eye" if his coat is knotted and his tail draggled. We generally speak of a Persian cat being out of condition when it is not in good coat, and certainly I should advise such cats being kept at home. There are so many shows held nowadass, that if your puss is shedding her coat at the time of one show, you may reasonably hope she may be in form for the next.

A word about judging may be of interest. I find the easiest and quickest way to set about making the awards in a large class is to start by first marking the absent exhibits, then placing a cross against those specimens that could not come within the prize list. After this I search for my winners, and having perhaps brought down the number to about six or seven, I proceed to take the cats from their pens, and if arrangements permit to have two out at a time, so as to make comparisons. For this purpose, judging pens are most useful. In Selfs it is soundness of colour that the judge should first consider; in Tabbies, the markings must rank first ; in Silvers, according to the dictates of specialists of this breed, paleness of colour is of paramount importance. Some judges, however, will be guided by purity of colour and the general shape of body, limbs and head, and darker shadings and tabby markings will be secondary considerations. The Blue and Silver classes are perhaps the 
most difficult to judge, and also they are generally the largest. The many specialist clubs have their standard of points (as given in the concluding chapter), but a good judge will bring his experience and his common sense to bear upon the exhibits, and these definitions therefore are likely to be of more service to fanciers, who should always aim at perfection, though they may not attain to it. For the benefit of novices in the fancy, let me say that, before showing a cat at any of the large shows, the first step is to register it with the Club under whose rules the show is held. At the present time the National Cat Club and The Cat Club are at loggerheads over the question of registration, but without entering further into the matter, I would say that it is the earnest hope of all fanciers that in the future one register should be kept. The forms at present used by the respective clubs are here reproduced. To any one with average intelligence the filling in of these is not a difficult matter. If a schedule of the show is not sent to you, apply to the secretary whose name and address will be published in the cat papers. Then read carefully the exhibition rules, and pay special attention to the classification before filling up the entry form, which together with the fee should be forwarded in good time to the secretary. I have given several hints in my paragraphs as to the best modes of packing the pussies both in cold and hot weather, so I would only impress on fanciers to do all in their power to mitigate the discomfort and risk which must always attend a cat travelling alone to and from a show.

\section{REGISTRATION}

The Registration Rules of the National Cat Club are as follows :

I. Every Cat exhibited at a show under National Cat Club Rules must (except such as are exhibited exclusively in Local Classes, or exhibited in Classes exclusively for litters of kittens), previous to the time of entry for such show, have been entered in a registry kept by the National Cat Club at their offices. A charge of Is. each shall be made for registration. In such registry shall be inserted the name and breed of the cat, and its breeder's name, the date of birth, names of sire and dam, and of grand-sires and grand-dams, and if the dam was served by two or more cats their several names must be stated. If the age, pedigree or breeder's name be not known the cat must be registered as breeder, age or pedigree "unknown," any 
or all as the case may be. If the name of a cat be changed, or an old name re-assumed, such cat must be again registered, and identified before exhibition in its altered name.

2. A name which has been duly registered in accordance with Rule I cannot be again accepted for registration of a cat of the same breed, without the addition of a distinguishing number, prefix or affix, for a period of five years, calculated from the first day of the year next after the one in which the name was last registered; but the name of a cat after publication in "Our Cats" and the Stud Book, or which has become eligible for free entry therein cannot again be assumed.

N.B. - The name of a cat that has become eligible for free entry in the Stud Book in any year shall not be changed after the 3ist of December of that year.

Cats do not receive a Number on registration. Numbers are only assigned to Prize Winners, or cats entered in the Stud Book on its publication, on payment of a fee of Five Shillings, in addition to One Shilling for registration.

The application for Registration must be made on a form as follows :

Number of Breed as per List in Margin Colovr

I wish to register the following Sex? by the name of

Previously registered by the name of

Signature of Owner

Mr. and Mrs. or Miss

Address

LATE OWNER (if any)

SIRE

OWNER OF Sire $\left\{\begin{array}{l}\text { G. SIRE } \\ \text { G. DAM }\end{array}\right.$

DAM $\left\{\begin{array}{l}\text { G. SIRE } \\ \text { G. DAM }\end{array}\right.$

OWNER OF DAM

DATE OF BIRTh

NAME \& ADDRESS OF BREEDER

Note.-If this name cannot be registered, I select one of the following, and name them in the order named: (I) (2) (3) 
Only one Cat must be entered on one form, which must be forwarded with a remittance of one shilling to Mrs. A. Stennard Robinson, Hon. Sec., at 5, Great James Street, Bedford Row, London, W.C.

The various varieties as recognised by the Club are as follows :

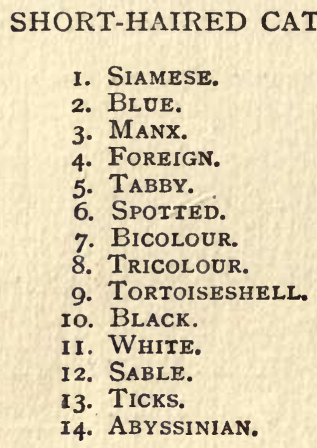

\section{LONG-HAIRED CATS.}

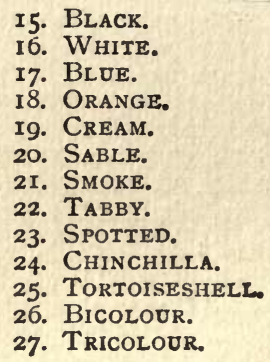

The Rules for Registration in the Cat Club are as folluws :

In the following Rules the word "CAT" shall be interpreted to include domesticated Cats of both sexes and neuters, and the word " Kirren " shall be interpreted to include domesticated Kittens of both sexes and neuters, five months old and under eight months old on the first day of the show.

RULE r.-Every Cat and Kitten exhibited at a Show held under The Cat Club Exhibition Rules must (except such as are exhibited exclusively in local classes), previous to the time of entry for such show, have been entered in the Register kept by The Cat Club for that purpose alone. Registration in any other Club shall not be accepted. A charge of sixpence shall be made for each Cat or Kitten registered. In such Register shall be inserted the name, breed, and colour of the Cat or Kitten, and its breeder's name, the date of birth, name of sire and dam, and of grand-sire and grand-dam. If the age, pedigree, or breeder's name be not known, the Cat or Kitten must be registered as "age, breeder, or pedigree unknown"-any or all, as the case may be.

If the name of a Cat or Kitten be changed, or an old name be reassumed, such a Cat or Kitten must be again registered and identified, before exhibition in its altered name, for which a fee of one shilling shall be charged. 


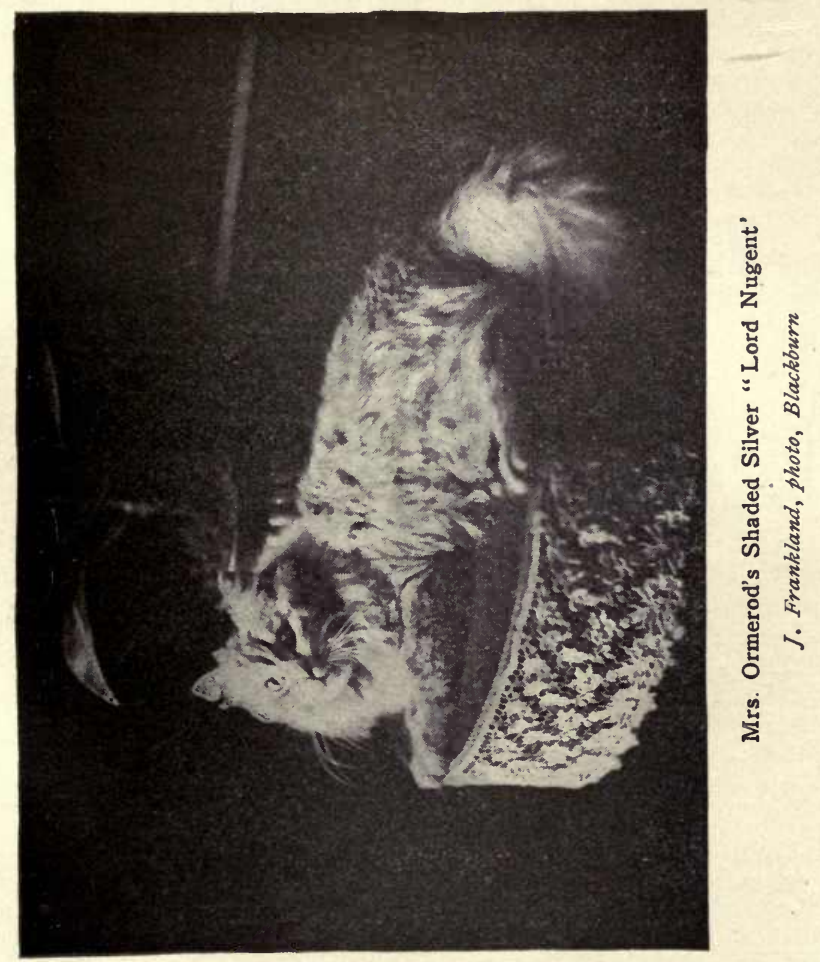




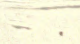


On change of ownership, the transfer of a Cat or Kitten must be registered; and no Cat or Kitten will be eligible for exhibition at any show held under The Cat Club Exhibition Rules until such registration shall have been made, for which a fee of one shilling shall be charged.

The Register shall be published every twelve months at least, and at such prices and in such form as the committee may decide upon from time to time.

Registration forms shall be supplied free of charge to breeders, owners, and exhibitors of Cats and Kittens, and also to secretaries and promoters of shows held under The Cat Club Exhibition Rules.

RULE 2.-A name which has been duly registered in accordance with Rule I cannot be again accepted for registration of a Cat or Kitten of the same breed, without the addition of a distinguishing prefix or affix.

RULE 3.-Any Cat or Kitten exhibited at a Show under The Cat Club Exhibition Rules, must be the bona-fide property of the Exhibitor in whose name it is entered, and must have been so fourteen clear days before the first day of the show.

Each Cat or Kitten must, on the entry form, be clearly identified in accordance with and as required in Rules $I$ and 2-save that the names of the grandparents need not be stated-and on such entry form must be a declaration, signed by the exhibitor, that the Cat or Kitten is entered subject to The Cat Club Exhibition Rules.

RULE 4. - If the name of a Cat or Kitten which has won a prize in a class in any Show held under The Cat Club Exhibition Rules, has been changed; on entering the said Cat or Kitten for a show, the exhibitor must, on the entry form, give the former name or names, as well as the new name, until the change or changes have been duly published in The Cat Club Stud Book.

The name of any Cat or Kitten, after publication in The Cat Club Stud Book, or which has become eligible for entry therein, cannot be changed.

RULE 5.- If a Cat or Kitten is owned by more than one person, the names of all the owners must be given on the entry forms, and on the registration, change of name, and change of owner forms; but only one fee shall be charged for each such entry, whatever the number of owners may be.

RULe 6.-If a Cat or Kitten be entered, except as before directed by Rules $I, 2,3,4$, and 5, such Cat or Kitten shall forfeit any prize that may have been awarded; and if the error be detected in time, sucb Cat or Kitten shall not be allowed to compete, and shall, in either case, forfeit all entrance fees and subscriptions-save that the General Committee of The Cat Club may, on appeal to them, for good cause shown, remit all or any part of the forfeits herein mentioned. 


\section{III (continued)}

\section{PRACTICAL HINTS ON BREEDING AND EXHIBITING}

\section{Breeding and Mating}

IN selecting a male cat for stud purposes, you should be guided a great deal by the size of head and limbs. A good sire for future generations should possess a massive, wellformed body with broad head. Take especial notice of the width between the ears, and beware of a long nose and face. Very large and pointed ears are most undesirable. It also spoils the appearance of the cat if the ears are very wide at the base.

Siamese kittens are always white when born, and gradually their ears, legs, tail, and face darken. The denser these points become the more valuable are the specimens. A kink in the tail is considered a beauty. Blue eyes are very essential. It is a pity that Siamese cats gradually lose the beautiful pale fawn colour, and their coats darken as they grow older. It is quite the exception to see a grown-up Siamese light in body colour. Never try mating a Siamese with any other breed. Experiments have been made in this respect, but no good results have followed.

To novices in the Silver fancy, let me say that they must not be disappointed if after sending their queen to a noted Silver stud, she should produce what appear like very dark smoke, or almost black kittens. These will become lighter 
every day, and it is often the darkest kittens that turn out the palest Silvers.

The days of pussy's gestation are about sixty-three, but I generally find it is best to calculate for three days extra, this being counted from the last day of mating. It is always safer after the queen has been on a visit to keep her shut up for a few days.

Do not worry if your queens refuse to feed during the time they are mating. When quieted down puss will make up for lost time.

If you have a stud cat and receive queens, it is alway: courteous and kind to write a line to the sender immediateiy on the arrival of the traveller. Thus the anxious mind of the owner is set at rest. Then you should give due notice of the time of train by which you are returning the visitor. Avoid despatching a cat on a Saturday.

I am not much in favour of mating Blues and Silvers together, as this cross frequently results in Silver Smokes, a surt of nondescript cat that finds no abiding class at our shows, and is also rather an unsatisfactory cat from which to breed.

In selecting a stud cat we should consider the points of our queens. It is not always the greatest prize-winner that is the most desirable mate for a particular female. We must pair them according to the good points in one and the defects in the other, and thus we may gain the happy medium. If your queen is wanting in breadth of skull and shortness of face, try to remedy and counterbalance these defects by finding a stud cat with these points strongly developed. Two prize-winning cats may not produce even average good kittens.

Of all the breeds of long-haired cats, brown Tabbies may be said to be the strongest. This handsome breed seems coming to the fore. Certainly to a novice in the tancy brown Tabbies are less trouble, by reason of their hardy 
natures. Two brown Tabbies mated together often produce a black in the litter, and generally a very good specimen.

Do not let your queens mate before they are nine months old, and it is better to wait another three months if possible. I do not think sufficient attention is paid to the desirability of stud cats and queens being in good coat at the time of mating.

It is considered the correct thing to forward your fee for mating at the same time you send your queen. The usual rule in catty circles is to allow a second visit should the first prove unsuccessful, but this cannot be insisted upon, and therefore it is better for the sender to ask if this courtesy will be permitted when writing to announce the despatch of the queen.

I have often been asked if I consider that the litters of a Persian queen who has mismated previously with a common cat are in any way affected afterwards. I believe this question has never been satisfactorily answered, but I know a case in point, and certainly these kittens of a good Persian sire and dam are remarkably poor specimens and are what might be called half-breds. I can only attribute this to the blue female having twice strayed from the paths of virtue previous to the attentions of the prize-winning Persian.

If you are purchasing a self-coloured cat, be careful to examine whether it has a white spot or tuft of white hairs on throat or stomach. This is a decided blemish, and repeats itself in future generations. Our best judges consider a white spot should count as a point against a cat entered in a seli-coloured class. This is much fairer to both exhibitor and judge than to relegate a good Blue or Black with the few offending white hairs to the "any other colour class."

One of the most difficult cats to breed is a pale Cream, uniform in colour, and having no markings on head and legs. A Tortoiseshell and a Blue often produce good Creams. 


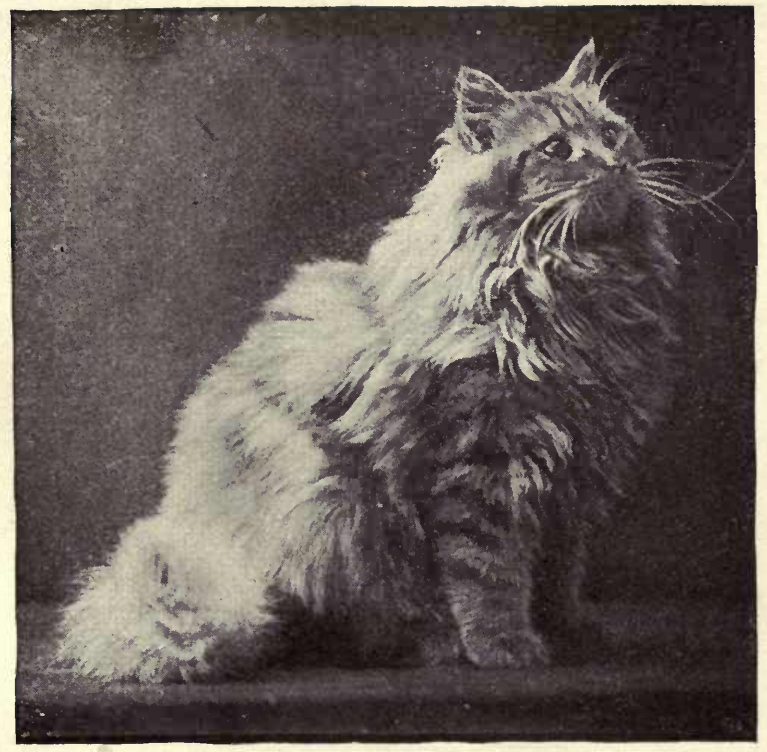

Mrs. W. Vidal's Orange Persian Male

"Torrington Sunnysides" 


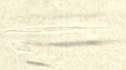


Do not mate tabby-marked cats with self-coloured ones. For instance, a blue Persian queen should be sent to a stud cat of her own colour, or to a Black, not to a brown or orange Tabby. Breeders have lately been crossing Blues with Chinchillas, or Silvers, and some good results have followed, but this should not be attempted if the Silver is at all heavily marked with stripes. In this case the litter might consist of blue Tabbies, and although these are pretty cats for pets, they are useless for breeding or show purposes.

I have always considered that the mating of a good ambereyed Black queen with a pale Blue male is most satisfactory in results. I have seen several examples. In one litter two almost perfect blues and two black, in the other, one blue gem and three blacks. The blues were particularly sound in colour and had the round orange eyes, which are so attractive in black cats.

It is not always that the best blue-eyed Whites or orangeeyed Blues are bred from parents who are both possessed of these desirable points, so don't distress yourself if you have an odd-eyed White queen, but send her to a good blue-eyed White stud, and some in your litter may yet have the correct-coluured eyes.

It is very seldom, if ever, that a Blue stud cat retains the deep tones of orange or yellow in his eyes. These get lighter with age and service. This fact does not, however, affect the progeny. Orange eyes are rarer in Blue cats of a pale tint than in those of darker colour, and it is more difficult to obtain absolute soundness of colour in light Blues than in those of a medium shade.

In order to obtain the nice rich tawny colour so desirable in brown Tabbies, one is tempted to try mating with an Orange. I have found, however, that the experiment has resulted in a description of tortoiseshell Tabby which is no good for breeding or showing purposes. If your Tabby queen is rather drab in tone, select a good sire of the golden brown order, and you will be rewarded. 
I would never recommend fanciers to try and breed from a queen that has confirmed snuffles. There is no doubt that the kittens are affected by this complaint in the mother, and are weak and ailing. Snuffles can doubtless be cured in young cats, but when this distressing disease has been of long standing, it is really hopeless.

A gnod tortoiseshell female Persian is a splendid investment, but care should be taken to obtain a really fine specimen. There are several cats called tortoiseshell, which are really tortoiseshell Tabbies, others that have streaks of colour running into each other. A good Tortoiseshell is a combination of red, yellow, and black patches, without any white. A Tortoiseshell queen can be mated with advartage to almost any coloured sire, and her litters may, and probably will, be very varied. I think that even the rising generation in the cat world know how rare a thing is a Tortoiseshell Tom!

It is filse economy to purchase cheap and indifferent queens, if you intend to go in for breeding and exhibiting. I am inclined to think that more depends on the quality of the dam than the sire. Certain it is that the kittens more frequently take after their mother as regards colour. A Black female mated to a Blue stud seldom has more than one like the father, and I have frequently known the whole litter to be of the mother's dusky hue.

It is always advisable before sending your queen to mate to find out the pedigree of the stud she is to visit, so that in-breeding may be avoided. I am not against one mating of father and daughter, or mother and son, for I have known excellent results from this arrangement, but the experiment must not be repeated. Avoid entirely the mating of brothers with sisters.

If your young queen has shown signs of wanting to mate more than twice, do not keep her back again, although she may be under a year old.

Any one possessing a well marked silver tabby Persian 
female ought to make a point of mating her with a silver Tabby male, avoiding Chinchillas and shaded Silvers, as such a cross weakens the markings, and kittens of the "wrong class" and "no class" descriptions are the result. There is certainly an opening for breeders of silver Tabbies.

It is a great mistake to breed Smokes with Blues, as in this case you lose the lovely white undercoat which is the chief glory of this handsome breed. Like to like should be the order of the day as regards Smokes.

Regarding the mating of Blues I would advise you to study soundness of colour in the first place, then shape of head. I like a massive frame in a male cat, with plenty of breadth and bone.

It is a great mistake to allow your male cat to mate until he is a year old. If he is used at stud earlier he will probably fail you later on.

In announcing the despatch of a queen on a visit to a stud cat be careful to write very distinctly. A hamper containing a lady visitor recently reached $\mathrm{me}$, and I discovered a letter enclosed, but I could only make a vague guess at the signature, and the rather lengthy address was still more unintelligible.

Some cat fanciers imagine that the number of kittens in a litter depends on the length of time the queen remains with the stud. This is an erroneous idea. Nor do I believe in colour feeding in regard to cats and their offspring.

Some queens are of such a timid nature that the very fact of sending them by rail to a strange place will completely upset them, and the visit will have no satisfactory results. In such cases it may be best to try and come to some arrangement with the owner of the stud, and perhaps for the consideration of a kitten in addition to the fee, the male cat may be lent for a few days.

I think I am right in stating that as regards registering 
visits and births in the cat papers, it is the owner of the stud cat who sends the notice of the visit and the proprietor of the queen that announces the arrival of the family. It is just as well to have some such rule amongst fanciers, otherwise, as is sometimes the case, a duplicate advertisement appears in the same column.

When your queen returns from visiting a stud cat, it is well to keep her shut up safely for a few days. Cats are often very restless after their return home, and the impression is often given that the visit has been fruitless. It is generally at the end of a month that one is able to judge whether puss is intending to present us with a family or not.

I do not approve of specials being offered in the form of free visits to stud cats. This savours too much of seifadvertisement, and does not certainly incur much sacrifice.

Try and avoid sending your queens away to mate on a Saturday, in case of delays, as poor puss may spend her Sabbath at a railway station.

It is well to keep a register of all the queens visiting your stud cats, filling in the date of arrival and departure. Such a record often comes in useful when wishing to purchase a kitten of a particular strain, or in answering inquiries from fanciers.

Senders of queens to stud cats should attach a label inside the hamper or box, stating the name and address of the owner, for should two or three visitors arrive in the same day, there is a fear of complication amongst the cats and their travelling trunks.

\section{Shows and Exhibiting}

If many cats are kept, and some are sent to shows, do not let these, on their return, mix with the others who have remained at home. It is a wise precaution to keep them apart for some days. 


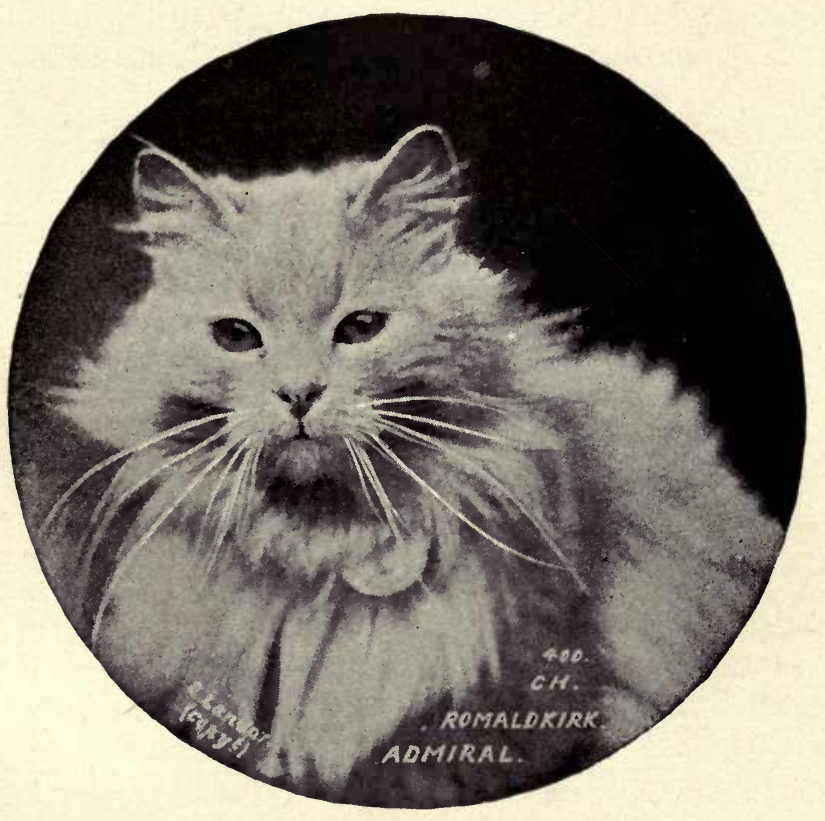

Miss Winifred Beale's Champion Cream

"Romaldkirk Admiral" 

If you are allowed to provide your pussies with cushions at a Show, let the neck ribbon correspond in colour, as this will have a better effect. I recommend flannelette in preference to more costly materials. It is warmer and not so slippery as silk or sateen. Some exhibitors ate able to afford velvet !

Exhibitors will find little slip rings convenient to put on metal tallies provided for the cats' necks at shows.

In sending your pussies to the show, if you pack them in hampers, whether lined or unlined, wrap the hamper in a large sheet of brown paper, leaving only a square space uncovered at the top round the handle. Fasten securely. If you padlock the box, don't forget to send the key to the secretary!

It is as well that exhibitors should understand that the labels and tallies sent by the show secretary are in themselves an acknowledgment of the money received for entries. Some impatient and unreasonable exhibitors write to the show secretary requesting their labels, \&c., before the advertised time of closing entries. How would it be possible to place the pen number on the labels when all the entries had not been received?

Margarine baskets are cheap and handy for cats to travel in; but when they are sent to shows exhibitors should attach some straps, as in the hurry of packing up the pussies it is not easy to have recourse to a packing-needie and string.

It is the custom for exhibitors to delay forwarding their entries till just before the lists are closed. This unfortunate habit entails much extra worry for the show secretary, and causes a desperate rush at the last.

I would like to impress upon exhibitors the importance of writing very distinctly when filling in their entries for shows. This hint especially applies to the names of the cats, some 
of which are often of an out of-the-way character, and cannot even be guessed at.

I would most earnestly impress upon exhibitors the necessity of writing distinctly their full address on the reverse side of the labels supplied for the return journey by the show authorities. Try by every means in your power to lessen the risks and discomforts for your pussies during their transit to and from the shows.

When by any chance labels are not received in time to be used by exhibitors, or they are lost, then the hamper should be addressed to the secretary of the show, and a note of explanation enclosed. The entry form can then be looked up, and the pen number discovered.

Of course, if possible, it is always best to accompany your pussies to a show, but if you are unable to do this, then it is very important you should ensure each hamper of live stock. Do not use straps which are detached from the box or hamper, as these are so apt to get misiaid or lost.

If you make up your mind to enter your puss and kits in a litter class send the whole family, as in judging a litter class quantity, with a due regard to quality, has to be considered. Thus, a litter of five very fairly good and level kittens ought to score over a family of three, though these may be possessed of better points. It is, therefore, advisable to always send the whole litter, not to pick and choose.

If you are the owner of White cats and take them to a show, I strongly advise you to see that the pens are thoroughly well rubbed down before you pen your pussies.

It is not well to give your cats a heavy meal before starting them for a show. Hope and trust that they may have something given to them when they are penned.

Need I say, never make any attempt at "faking" your cats when sending them to shows. It is a risk, as well as a most undesirable operation. 


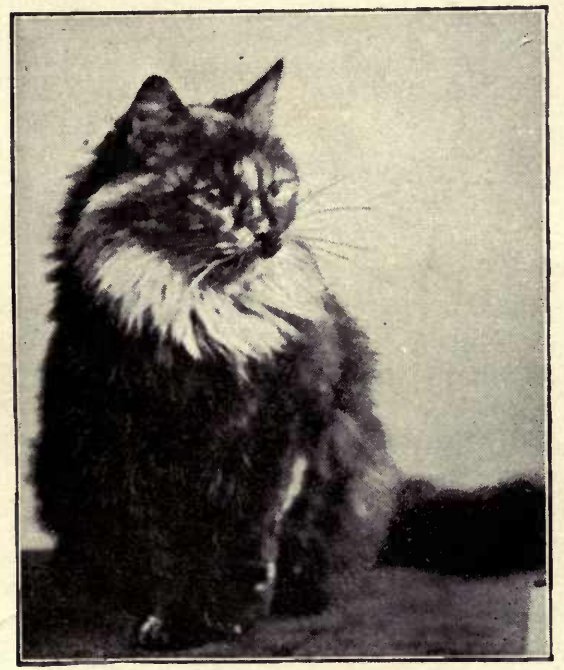

Miss Kate Sangster's Champion

"Royal Yum Yum"

Amery, photo, Portsmouth 
In sending specials for shows, be sure and state if they are for cats or kittens. For instance; "For the best Blue Male Cat" will mean that your prize will be awarded in the Cat Class, and only supposing a kitten were entered in that class, could it compete for your special. If you wish it to go to a kitten then don't omit to specify this. The limit age for kittens varies at shows, sometimes under eight months, and sometimes under six months.

A very good way of cleaning your cats previous to showing is to heat a good quantity of bran in the oven. Put it into a large bowl or foot-bath, and stand your puss in it. Rub the hot bran well amongst her fur for some minutes, and afterwards carefully brush it out. It is wonderful how soft and silky this process makes the coat. I do not advocate washing cats, even in summer weather, and certainly not in the winter.

When there is a class for pairs of kittens provided at a show, the two exhibits need not necessarily be of the same litter, but remember they are judged as a pair, so let their size and appearance be as alike as possible. It is no use to enter two kittens of different colours in a pair class.

When prize-money is sent to the winning exhibitors, they should acknowledge the sum to the show secretary, and don't forget to thank the donors of specials. The addresses are generally to be found in the catalogue index, or the secretary, if written to (with stamp for reply), will give the information required.

If your cats are not in good condition do not send them to shows. There is but one place for cats out of coat, and that is at home!

When cats are entered for shows in joint names it is advisable and desirable that the owners should let the secretary know to whom to send the labels and tallies. It is sometimes only possible to forward these a day or two before the show, and, if sent to the address of the owner 
who does not keep the cat, complications may arise from the delay.

It is always very important thoroughly to air and disinfect all hampers coming from a show. I place my pussy's travelling boxes or hampers outside for two or three days and nights, and let the sun, air and rain cleanse and purify them. Then I have them washed over with some disinfectant and water.

As regards pairs of kittens, which next to the litter class is, perhaps, the most difficult to judge, I would say, select two kittens as near alike as possible in colour, size and quality. It is as a pair that the awards should be given, and if one exhibit is much superior to its fellow, then the value of the pair is seriously diminished. If your kittens are different in colour and variety, say an Orange and a Tabby, then do not enter them in a pair class, but as single kittens, and they will stand a better chance.

I have noticed that many of our best show cats appear almost perfect in all points, save and except the ears, and these are wide at the base, tall and pointed. They should be just the opposite. Therefore if your queen has prominent ears, try to find a mate for her with these organs not in evidence. Ear tufts are great beautifiers.

Let me suggest to all winners of medals at shows that they should have them engraved with the name of their cat, the date of the show, and the place where the show was held. I think it is a pity that clubs do not undertake to have these inscriptions engraved, as they would greatly enhance the value of the prizes.

If your cat is timid and you want to exhibit him, I should advise you to obtain some pen or hutch and coax and encourage him to come up to the bars. In this way you will educate him to place himself in evidence instead of crouching at the back of the pen, and thus running the risk of being overlooked by the judge. Besides we all like our 
pets to show themselves off to the general public on these auspicious occasions.

I think it is only catty etiquette if one wins special prizes at one show that one should offer them for some other show. But not the same articles be it understood!

The tendency nowadays is to lower the standard of special prizes, and really some of the articles on show are often of very cheap manufacture. If a thing is worth doing, it is worth doing well.

If you consider an injustice has been done to you or your cat at a show you have a perfect right to lay your complaint before the Committee of the Club under whose rules the show is held. Then your case will be looked into.

There are two distinct ways of finding out from a judge why your cat did not take a prize, viz., a nice way and a nasty way. I am sure all judges are pleased to give information to exhibitors for their satisfaction asd profit if their inquiries are couched in courteous and reasonable terms. It is not pleasant to be attacked suddenly with this question, "Why have you not given my cat a prize?"

In calculating the age of a kitten when entering for exhibition the dates of the month and not the weeks should be taken. Thus from the 2 oth of July till 2 oth of October is three months.

It is very hard when you have entered your cat for a Show to find she is "wrong classed." If you are a novice in the fancy write and ask some reliable person, giving a full description of your puss, and ask advice as to the correct class to place her.

Certainly it is better to run a chance of starving your cat in the show pen rather than stuffing her. You can feed up your pet on her return home, and in a day or two she will be as plump as ever, but it is a different matter to remedy the 
ill effects of constipation, diarrhœa, and other troubles consequent on heavy feeding in close quarters.

Don't worry the secretary of a show with lots of questions, but read the rules and regulations set forth in the schedule with care and attention. They are always very comprehensive.

Special prizes call for special acknowledgment, and winners of the same should write and thank the donors. The secretary of the club giving the show should be addressed on receipt of a club badge or medal.

In sending your cats to shows it is a great help to the executive if you so arrange the label that it may be easily turned round and the address appear uppermost for the return journey. When you use a box, try and attach the label securely to a strap or fastening. Do not nail it down to the lid.

If you intend to fetch away your exhibits yourself on the morning after the show, be careful to write "To be called for," on reverse side of label.

Pink collar ribbons are the most becoming to Blue kittens until their eyes have changed, then orange or yellow will be found more suitable.

It is a mistake to tie very broad ribbons round your cats' necks when sending them to a show. I should choose a colour to match the eyes, about half an inch to three quarters in width. Tie it in a neat bow, and give a stitch in the centre, to prevent it coming untied. Don't leave two long ends. Orange is the most becoming colour for Blue cats.

It is a good plan to give your cat a gentle aperient on its return from a show. If a grown cat then half a Carter's little liver pill may be given with safety, and a smaller quantity for a kitten. It is, however, the elderly cats that have the greatest objection to the scant acconmodation provided by the scratchings of earth at the back of the pen 


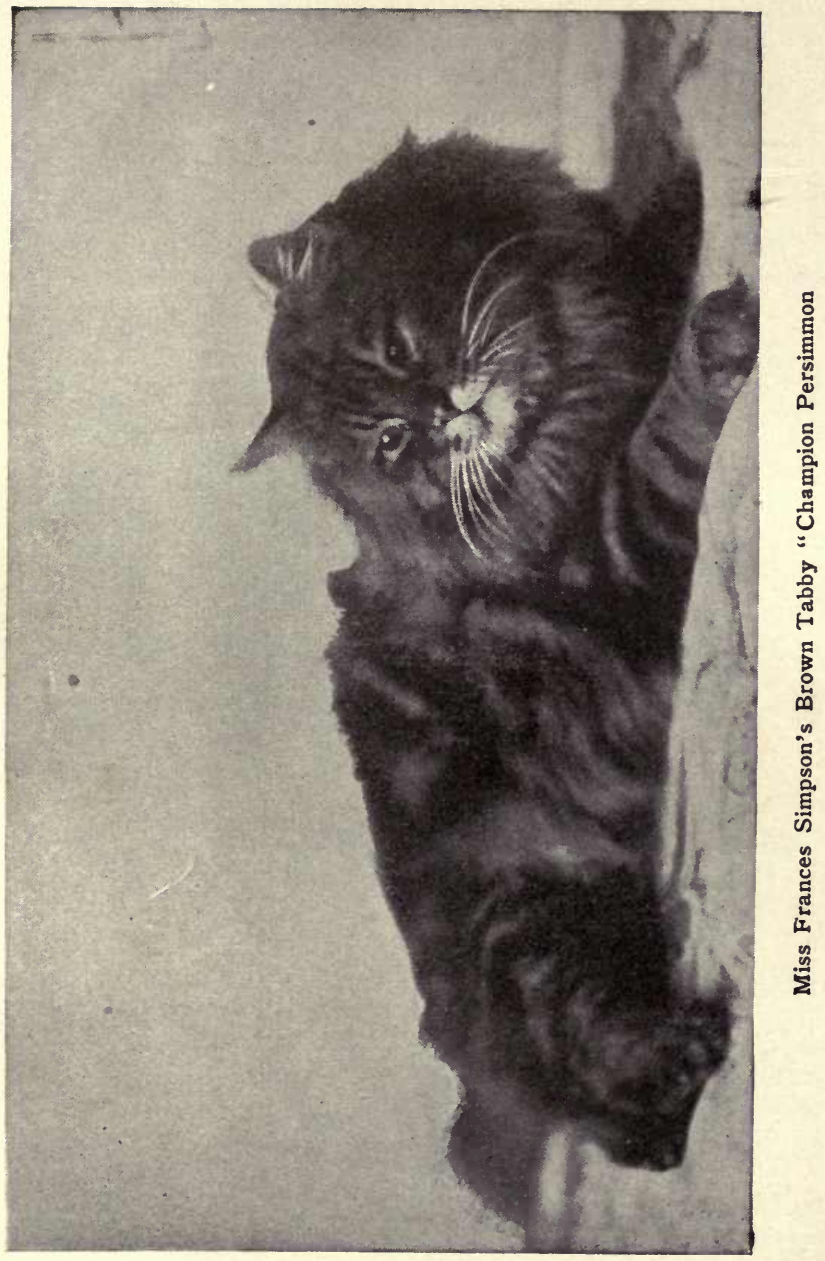



They will persistently await their return to the old familiar pan of earth or sawdust that they have been accustomed to. A clever cat fancier has told me that she gives her cats returning from a show a few drops of whisky in a spoonful of hot water. She says it "sort of cheers them up !"

Nothing is so vexatious as when your puss starts scratching out her lovely ruff just a week or so before the show for which you have entered her. Have a look to her ears, for the irritation may be there, and a little Condy and water and boracic powder will soon set matters right.

I do not think that cat fanciers pay sufficient attention to the condition of their cats when sending them to shows. The most successful exhibitors are those whose cats have been shown in the best condition. Extra attention ought to be paid to the feeding, exercising, and grooming of our pets. I do not advocate washing cats, but a bran bath or a good rubbing with white fuller's earth will greatly improve the fur.

A defective eye, or a damaged tail, would count against a cat in the show pen, and therefore I should advise exhibitors to keep these blemished pussies at home.

It is very necessary for show secretaries to state the entries close on a certain date, but still this date is often of an elastic nature, and it is always worth while for an intending exhibitor to write requesting that, if possible, their entry may be received, although it is forwarded after the advertised date.

The prize cards are placed in the hampers when sent back to exhibitors. If these are soiled or bruken on their arrival write to the secretary asking for fresh ones to be kindly forwarded.

The metal tallies sent for the cats at show time will hang much more gracefully round the neck if a slip ring, such as is used for fastening on buttons, is run through the hole of the tally and then the ribbon is put through the ring. Let 
me advise narrow ribbon, or if a broad bow is thought more stylish fold the ribbon half the width round the neck and then tie. In this way pussie's ruff will not be interfered with.

Many exhibitors are not aware that by paying an extra shilling they can obtain a double pen for their cats at shows. Of course if space in the hall or tent is limited this provision cannot be always arranged for.

It is very necessary to make positively sure of the sex of your kittens before sending to a show, also previous to disposing of them. A purchaser, who is a novice, desiring a male, and discovering only on the arrival of a family of "gutter" kits, that a mistake has been made, is naturally rather annoyed.

No doubt a one day's show is best for cats and kittens; but if you send your pets to a two days' show, I do not think it is advisable to remove them at night. You run a risk of exposing them to cold, and the carrying to and fro is really more trying for pussy than being in her pen; and if you know that she will be covered up at night, then probably your pet will sleep comfortably and forget her troubles.

In former days there used to be classes at our shows in which cats were judged according to their weight, and no matter what points the cat possessed or did not possess, the heaviest took the prize. The most weighty cat I ever handled turned the scale at 20 lbs. I do not think, however, that our pets should be fattened up like prize pigs for shows, and, therefore, these weight classes have been wisely done away with. 


\section{DISEASES AND REMEDIES}

There is a tradition that cats have nine lives, but many a breeder of Persians will agree with me that the diseases to which these highly bred cats may quickly succumb are more than nine in number! I do not intend to enter fully into these ailments in this chapter, as I have given a number of hints in the paragraphs, and have also appended a list of simple remedies for the usual diseases that pussy's flesh is heir to. I think the mistake in many of our cat manuals is the too technical nature of the prescriptions. Then again, many of the ingredients mentioned cannot be procured by an ordinary mortal without a doctor's order. I have tried, therefore, to suggest only the very simplest remedies, many of which are generally available in every household, and ought certainly to be within reach of every cat fancier. The preparations of Mr. Ward and Salvo that I have recommended I have had practical proof of as to their excellence in cases coming under my own notice. Mr. Ward may rightly be considered the wizard of the north, for he was the pioneer of "practical pussyology" apart from the regular qualified veterinary who may look with a kind and pitying eye on cats' ailments and infirmities, but yet who is just a little superior to the treatment of these too often despised animals. Salvo came as a boon and a blessing into our southern districts, and I am sure there are many cat fanciers who can testify to the kind and clever way in which he has attended to and prescribed for their sick pussies. To him I am indebted for some valuable hints and useful prescriptions. Mr. Freeman 
of Birmingham and Mr. James of Cheltenham are well known in the catty world, and supply remedies for every ailment. Sometimes I have found that the preparation of one veterinary will have no effect on a cat, whereas another of a different firm will have the desired result. We should always bear in mind that our cats are variously constituted, and we must use patience and perseverance. There are some serious and dangerous diseases amongst cats for which no simple remedy can be given with any satisfactory result. I would mention Gastritis, Enteritis, Bronchitis, Inflammation and Congestion of the Lungs, Distemper and Influenza. Now there is no doubt that in these complaints the only hope is for the case to be taken in time by a thoroughly reliable person. The difficulty that the ordinary fancier has to contend with is to discover what really is the matter with their cat, and if an attempt is made to doctor and dose a case without sufficient knowledge, serious results may follow. Too often fanciers set down every evil under the sun to worms. It seems to me, therefore, that what is really required is a clear and lucid description of the symptoms of these dangerous diseases, so that people can form some idea in the early stages of the nature of their cats' illness. If they are able to arrive at some conclusion, the best course to pursue is to wire to either Mr. Ward, Salvo, Freeman, James, or other competent person, and ask for medicine to be forwarded at once for such or such complaint. Let us, therefore, give the usual symptoms of a few of what may be called dangerous complaints. Gastritis, or inflammation of the stomach, has unhappily raged amongst our cats, and many a time fanciers have rapidly come to the conclusion that their pets had been wilfully poisoned. Truly, the symptoms are almost identical. The animal is sick; there is high fever, great thirst, a desire for drink, and yet sometimes a disinclination to take it ; for the poor creature will sit with its head over a bowl of water for hours. He will stretch himself on his stomach, preferring a cold flat surface to any soft comfortable bed we may prepare; and a total loss of appetite is accompanied very often with violent diarrhoea. It is worse than useless to attempt to feed, especially with anything solid. Enteritis, or inflammation of the bowels, is akin to gastritis, and the symptoms are much the same. 


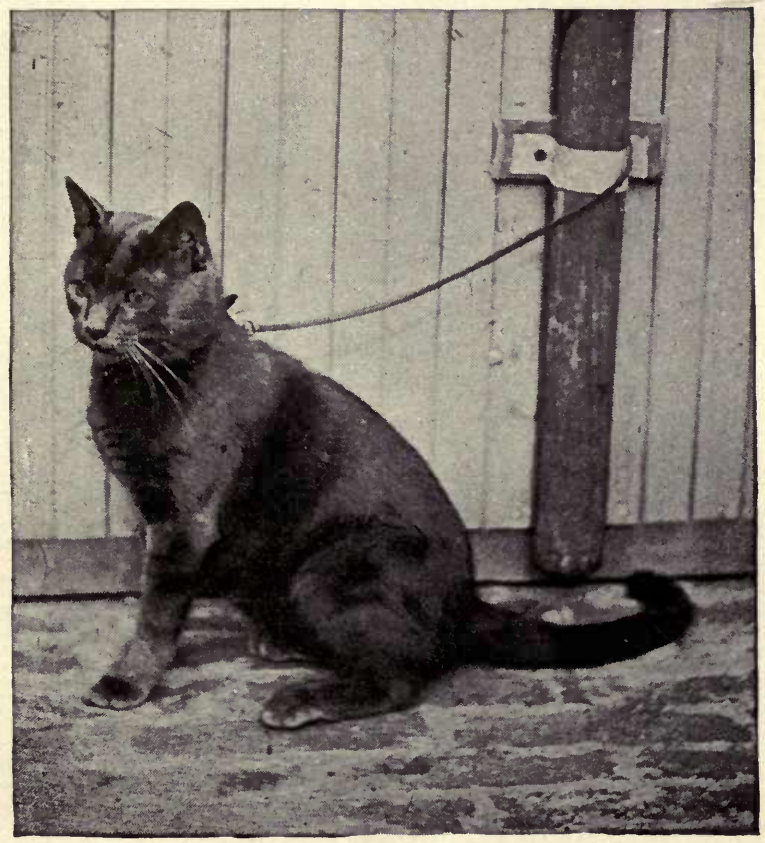

Lady Alexander's Short-haired Blue Champion "Ballochmyle Brother Bump" 
In both cases the stomach becomes distended and is painful to the touch. In bronchitis there is more or less fever, the nose and ears being hot, sometimes fits of shivering, the breathing is quick, and frequently the animal has a bad cough. There is often a frothy mucous discharge. When the inflammation of the bronchial tubes extends downwards to the lungs the danger becomes greater, the breathing still more laboured, and inflammation supervenes. In some cases of congestion and irflammation it is extremely difficult to discover what is the matter with your cat, for he is only very quiet and languid, and all the spirit seems taken out of him; his eyes are dull and mournful looking, and his coat rough and staring, Influenza has of late years made great ravages amongst our cats. This is a sort of catarrhal fever which produces great debility, vomiting, and sneezing, and a profuse discharge from the nose and eyes.

At first this is watery, but later the discharge becomes thick and yellow and the passages seem to be entirely stopped up, the animal breathing with great difficulty. The symptoms are much the same as in distemper and the two complaints are often mistaken the one for the other. In both the high fever is what is so difficult to battle against, and both diseases are contagious or infectious either by the medium of positive contact or through the air itself. In distemper there is a peculiar and distressing odour which is unmistakable. In my paragraphs I frequently allude to the symptoms which should lead one to suspect worms in our cats. I may say that an offensive breath is nearly always an accompaniment of worms.

It is most necessary, after a cat or kitten has been suffering from a trying illness, such as influenza or distemper, to build up the constitution again. I have used Animal Kreochyle (liquid meat) with very good results. It can be given without any fear to the most delicate animal, as it is the juice of the meat extracted without the process of boiling, so that it is speedily digested. This liquid meat should be given first thing in the morning, followed by a teaspoonful at midday and again in the evening. For very young kittens add a little warm water. I find my pussies delight in this preparation, and I am sure that cat fanciers 
in search of a pick-me-up for their pets cannot do better than give "Kreochyle" a trial.

In conclusion, I can with all confidence recommend not only those medicines which I mention but many other preparations carefully prepared by the advertisers in my book. The feline world is fortunate in having two such able and really cat-loving men as Mr. Ward and Salvo to turn to in their days of doubt, difficulty, and distress. Let me, however, impress upon all cat fanciers that delays are dangerous and that a stitch in time may save nine-cats or kits!

\section{A LIST OF SIMPLE REMEDIES}

Bronchitis.-A few drops of eucalyptus oil in a jug of boiling water. Let the cat inhale over it frequently.

Canker.-Salvo's Canker Cure.

Constipation.-Freeman's Aperient Capsules. Sweet oil for kittens.

Debility.-James No. I Magical Powders. Animal Kreochyle.

Diarrhcea.-Sprinkle a pinch of dry arrowroot or prepared chalk on the food once a day.

Dysentry.-Ward's Capsules.

Fits.-Place the cat in a bath of hot water up to the neck. Apply cold rags or sponge to the head. Administer two grains of bromide of potassium for cat ; one grain for kitten.

Fleas.-Mothaline rubbed into the coat frequently.

Jaundice.-Half grain of calomel daily for a cat.

Mange.-Advisable to put the animal painlessly to death. Paralysis or Weak Limbs.-Lime water half a teaspoonful in milk or broth given frequently.

Ringworm or Black Eczema.-IVard's Lotion.

Scurvy Spots.-Equal quantities of vaseline and sulphur rubbed on for three consecutive days. Then use a tooth-comb.

Sickness.-Carbonate of bismuth; three grains for a cat, one grain for a kitten.

Snuffes.-Salvo's Snuffle Cure.

Tape Worm.-Salvo's No. 3 powder.

Teething.-Ward's Teething Powders.

Worms in Kittens.-Salvo's No. I powder. Freeman's Capsules. 


\section{Gastritis}

No cat fancier should ever be without a small quantity of bismuth powder. It is an excellent and very safe remedy for many of the ills that feline flesh is heir to. We have had it highly recommended in cases of gastro-enteritis. Directly a puss refuses her food and persistently turns away from her most cherished dish of raw meat or other delicacy, then administer a good dose of bismuth, as much as would lie on a threepenny piece the first day, and reduce the dose each day afterwards. Don't force food down for the first twentyfour hours. Then start with Brand's essence or Animal Kreochyle, a little at a time, given often.

If your cat is attacked with that painful and very often fatal complaint, known as gastritis, or inflammation of the stomach, do not attempt to give your pet any solid ford. The symptoms of gastritis are very similar to those produced by some irritant poison. The animal will always crave for cold water, which should be constantly supplied.

\section{Intiuenza}

If your cat should fall a victim to a bad cold or an attack of influenza, you will no doubt find that its poor nose becomes quite stuffed up. Let me advise you to keep constantly applying lanoline, rubiring it well across and down the nose. It is wonderful how his treatment will give relief. Should you not have lanoline at hand, use butter, provided it has no salt in it. The result will be the same, and the more your puss rubs her nose with her paw and sneezes, the better it will be for her.

\section{Colds}

For any ordinary cold in a cat give small doses of aconite. Feed with beef tea and keep very warm. If there is fever and constipation, give half a Carter's liver pill. 


\section{Fleas}

"Prevention is better than cure," and in young kittens, cure is often next to impossinle, so that a watchful eye is very necessary. Be careful not to allow fleas to accumulate in the tiny mites, for these tiresome creatures give the yourgsters no rest, and as the greater part of the early life of a kitten should be spent in eating and sleeping, it is most important to have recourse to "Mothaline" to exterminate these pests from time to time.

I was asked the other day for a remedy for parasites in kittens, and recommended Mr. Ward's powder. I hear it is acting like magic, and the pair of insect beliows supplied with it are a splendid invention which should be in the possession of all cat fanciers.

\section{Anæmia}

If you notice that your cat's mouth, nose, and tongue are rather white, give some iron. The easiest and most effective way to administer this drug is by pills. Purchase a bottle of Blaud's iron pills, mild form, and for a cat I generally give half a pill once a day. If this treatment is regularly continued for a month you will see a great change in the colour of your pussie's mouth, which should be a nice deep pink if she is in perfect health. If your cat's tongue is yellow give an aperient.

\section{Worms}

The truth of the following extract from an American paper calnot be too frequently impressed on the minds of fanciers: "The worm has but little chance in the healthy stomach of a cat." So build up the constitution of your puss that she can resist the ravages of these pests.

Most cat fanciers know too well the symptoms which are suggestive of worms in their cats, but for the benefit of 


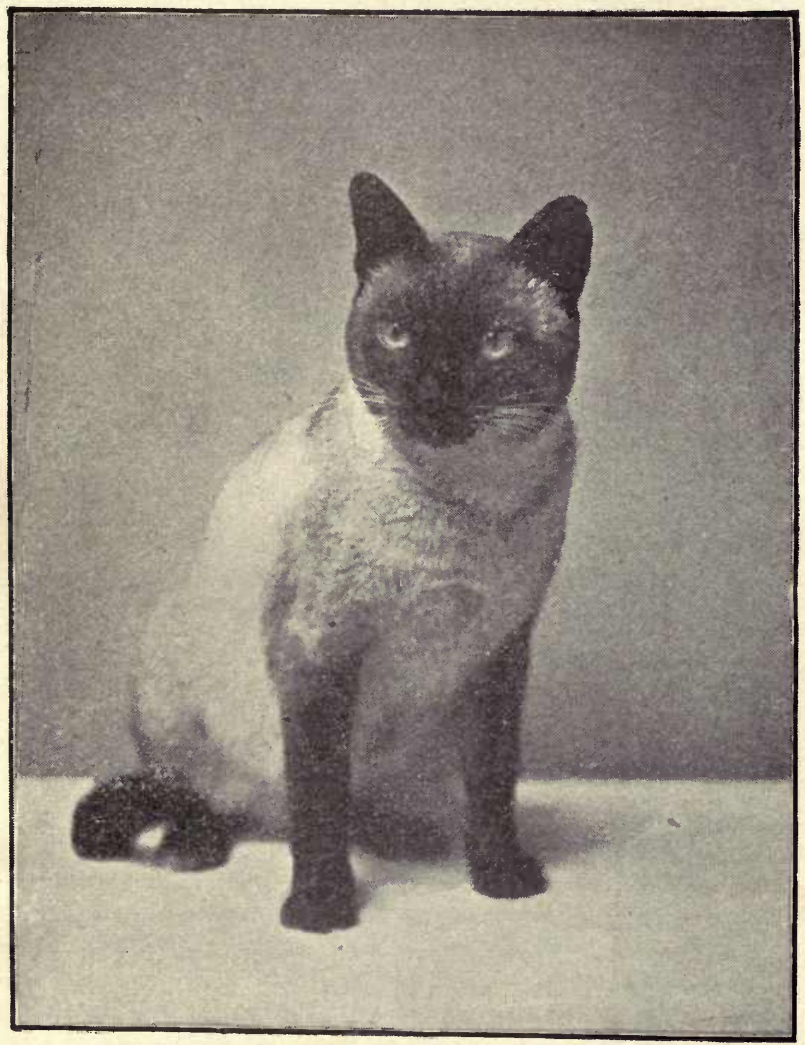

Mrs. Robinson's Siamese "Champion Wankee" 

beginners I would tell them to be suspicious when they find their pussies have ravenous appetites and yet seem to be none the better or fatter for their food. Again, the appearance of the coat is very tell-tale, the fur is "spiky" instead of fleecy and fluffy, and I have found no surer sign of worms than when the corners of the eyes come up in a sort of white skins. This betokens tapeworms, which are really even more serious than wire-worms.

A pinch of salt in pussy's fond is an excellent thing. I believe it is a preventive against worms, and it is good for the blood. Be careful, however, not to give too much, as this would cause skin trouble, and when a cat is in kitten extra care should be taken, as I have known a too lavish use of salt under such circumstances bring on a miscarriage.

If it is necessary to administer a dose for worms to your cat, do not give an aperient at the same time. Wait about an hour, and then the vermifuge will have done its work, and the aperient will cause evacuation of the worms. It is generally considered a bad sign if these pests are vomited, and denotes the presence of still more to be got rid of.

A very common cause of worms in cats is eating decomposed food. There are three kinds of worms-the small thread worm, which resembles a piece of crochet cotton, the long round worm, and the tapeworm. It is the last named that works most serious havoc.

There are several remedies for worms to be obtained of the leading veterinaries and cat specialists, but I am greatly against the "worming" of young kittens. It stunts their growth and interferes with their digestive powers. If delicate kittens are dosed, it sometimes finishes them off. I recommend all fanciers so to feed and nourish their young kits that they can have strength enough to resist these pests, which are more or less present in every animal. It is just a matter whether the worms or the creatures are the stronger.

It is always a bad sign if a cat or kitten in being sick brings up a worm. You may be very certain that there are 
lots to follow, so it would be best to start a course of powders at once. Delays are dangerous, especially as regards doctoring such sensitive creatures as Persian kittens.

After worming a cat or kitten it is very important to give the digestive organs a rest, and for this purpose a course of powders, such as are supplied by Salvo, will be found very beneficial.

A very sure sign of worms in a kitten is a prominent backbone with an inflated stomach. You may think your puss is nice and fat, but the size of its body is the result of indigestion and flatulency.

If you suspect your cat to be afflicted with tapeworm, I should recommend you to hand her over to some careful and clever veterinary. The only hope of expelling these pests is by administering either areca nut or oil of male fern, and these powerful medicines need most judicious handling. It is most important, and indeed essential, that the head of the tapeworm should be expelled. The rest of the creature comes away in sections.

It is a sure sign of indigestion probably due to the presence of worms if you find a sort of scale coming partly over the eyes of your cat. I have known novices in the fancy to imagine that in this case there is something wrong with the eye itself, and lotions have been supplied. It is, however, entirely caused by internal disarrangement, and your puss requires a course of treatment. Nothing gives a cat a more disagreeable appearance than this ugly film over a portion of the eye.

Some fanciers are under the delusion that castor oil is a universal cure for all ills, and they dose their cats accordingly. I have known this nasty stuff given for worms. Believe me, the worms thrive the more on it, and the result is upsetting poor pussie and causing her great discomfort.

Freeman's capsules for worms are the very smallest I have seen. They are so easily given, and are prepared for cats 
and kittens. I have found them excellent, and always follow them up with an aperient capsule of the same minute size, supplied by the same firm.

\section{Weak Eyes}

Bad eyes in kittens are frequently caused by worms or weakness. For which cases outward application of lotions is of small avail, and we must give strengthening medicines. Try a course of cod-liver oil, and admınister in capsules.

To apply a lotion the eyelids should be held open, and the liquid dropped on to the centre of the eyeball, so that the eye is quite filled. It is best to use an eye-dropper, or a fountain pen filler. Another method is to saturate cotton wool and squeeze it.

It is best to keep tiny kittens in a darkened place until their eyes are well open. Strong sun and bright artificial light tend to weaken the eyes, causing them to water.

A very good remedy for sore eyes in kittens is an application of alum and water. Put about a teaspoonful of alum into a claret wine-glass of tepid water and bathe frequently. Never allow the eyelids to become glued together, as it is then that inflammation sets in.

The complaint known as "pink eye" is seldom curable, and the disease generally destroys the sight in a kitten. It is best to destroy the poor little sufferer, as the torture must be very great.

It is not a good sign if kittens are born with their eyes open, or if they open within the first six days This generally means trouble in after-life.

No doubt many of the eye lotions advertised are of great benefit to suffering kits, but in some cases every remedy seems to fail, and then, I say, try a sun bath and a dose of fresh air. In other words, don't coddle up your patients, but put them out in the garden. An empty hox, with some 
wire netting, makes a capital hutch. Place this in a sheltered and sunny spot and you will find a marked improvement in your kittens' eyes.

A capital lotion to have in readiness for weak eyes in kittens can be made by putting one ounce of boracic acid powder in a pint of boiling water. Put this in a bottle when cold, and when needed mix again about one ounce to one ounce of tepid water.

The following is a simple and excellent prescription for an eye lotion: Boracic Acid, 30 grains; Cherry Laurel Water, 6 ounces. Bathe the eyes twice daily.

Very soft old linen rags or cotton-wool are best for applying lotion to kittens' eyes. Be careful not to use the same piece twice over. Always bathe the eyes first with tepid water before using any lotion, which should be applied very carefully and gently.

An easy and effectual way of dropping lotion into a kitten's eye, is to saturate a piece of cotton wool and then squeeze it. It is always difficult with a spoon, however small, to avoid letting it pour instead of drop into the eye.

Don't forget that a little sweet oil applied to the eyelids of your kits prevents them from getting "stuck up." Leave the rest to the mother, who by the gentle use of her tongue will do her best to keep them open.

\section{Diarrhœa}

If your cat or kitten is suffering from diarrhœa, be careful not to give anything hot. Let all food be just warm. There are so many causes for this troublesome complaint, viz., ind gestion, chills, worms. The difficulty is to diagnose the rtal seat of the trouble and treat accordingly. Nothing so quickly weakens a kitten as persistent diarrhœa.

A simple prescription for diarrhœa is the white of a raw 


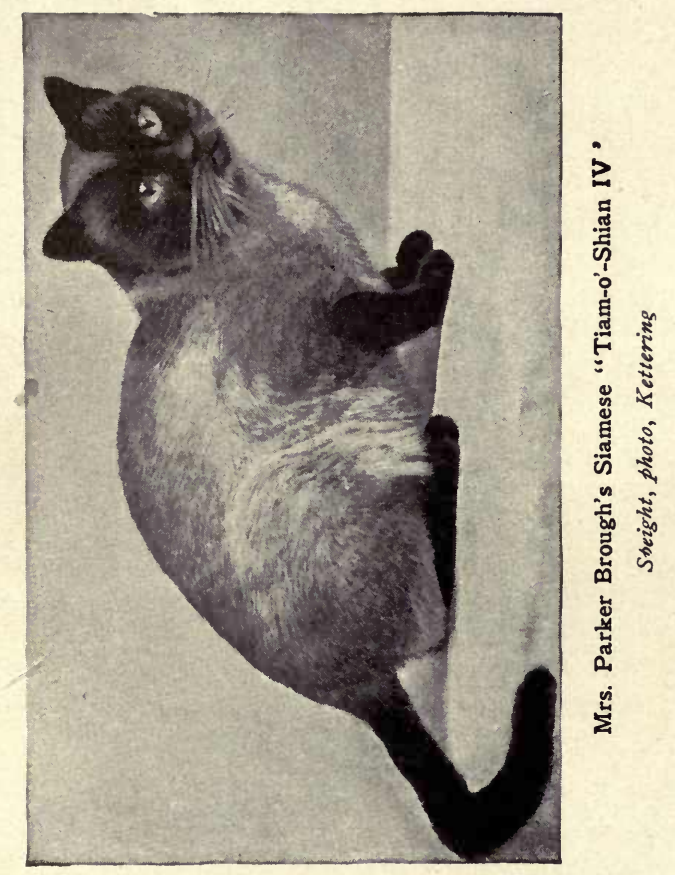



egg. A teaspoonful given two or three times a day will often have the desired effect when all other remedies have failed.

I have been told that for diarrhœea there is nothing to equal Bragg's Charcoal, given night and morning. About a quarter of a teaspoonful is sufficient, mixed in a little water.

Dry arrowroot will often check diarrhoa if given in the early stages. Never allow a cat or kitten to continue long with this weakening ailment.

\section{Skin Complaints}

Doubtless many of my readers have discovered from time to time little dry scurvy spots upon their cats. These come from heated blood and are easily cured. Ask your chemist to make up an ointment of equal proportions of sulphur and vaseline, apply this for two or three consecutive days, then use a small tooth comb and the roughness will come away.

A very troublesome and infectious complaint is blark eczema or ringworm. This appears in round dark patches on the skin, causing the fur to come off. There is a sort of coating of black scurf, and this gradually spreads. If taken in time the disease is easily cured. Mr. A. Ward has a strong solution which should be applied about three or four days running. Then use a small tooth comb, and the black scaly surface comes away. The hair quickly grows again, and the cat's health seems in no way to suffer.

Jaundice is not a common complaint amongst cats, but you may be sure if the eyes become glassy looking and the whites turn a yellow colour that there is serious mischief in the region of the liver, and your cat needs a strong aperient.

I have been told by an experienced fancier and breeder that it is a sure sign that a cat has internal eczema if she eats or gnaws at her kittens. A cat might look healthy and fat and well, and have fine kittens, but they will dwindle 
and die away, without any apparent cause if there is this internal trouble. Sometimes you may notice that a cat or kitten takes to perpetually washing itself. This is also a sign of internal eczema. Salvo has a cure for this rather mysterious complaint.

In case of any skin eruption it is always safe to administer sulphur. This is easily given in the cat's food, about as much powder as will go on a threepenny piece once a day.

The following is a very good remedy for eczema: Mix about two tablespoonsful of colza oil with one of paraffin and sufficient flour of sulphur to thicken the liquid. Each time you require to use the application, mix it well up. Divide the fur and rub on with fingers.

If a cat is suffering from any skin trouble, it is best to try and keep the affected parts covered with a bandage, to prevent the puss from licking them, as the roughness of the tongue prevents the healing up process.

Do not be alarmed if you find a sort of brown, damp scurf on your cat's tail. It is only natural grease consequent on the change of coat. Dust it with a little white fuller's earth.

\section{Snuffles}

There are many and various remedies suggested and recommended for that troublesome complaint commonly called "snuffles." I have known a complete cure effected by absolute change of air. I heard of one puss who was considered a chronic sufferer, but after a sojourn at the seaside she had not a sniffle leít.

There is nothing so cifficult to cure in. cats as "snuffles," by which I mean a sort of chronic nasal catarrh. This is sometimes the result of a bad cold, and it is often a remnant of distemper. There are many powders and medicines advertised by veterinaries, which may with patience prove effectual. I believe, however, there is nothing so beneficial 
as complete change of air for pussy. I have known this act like magic on what appeared a permanent case of "snuffles."

I heard of a bad case of snuffles in a cat being cured in the following manner: A little Sanitas oil dropped on the nose, just so that a drop or two enters the nustrils. Wet the front feet with the oil, so that the cat will rub it over her face when washing. Continue this for a few days, and if the discharge and sneezing still continue, inject a little Sanitas fluid, one part fluid to four of water, in the nostrils, and use the oil as well.

\section{Constipation}

It is very necessary in cases of constipation (generally caused by want of proper green food) to administer an aperient, and I must say I dislike giving castor oil to cats or kittens. Medicine done up in the form of pills or capsules is so much easier to give, and no risk is run of spoiling pussy's appearance.

For young kittens suffering from constipation, I much prefer sweet oil to castor oil. Some kits will lick it of their own accord. I am sure that many kittens succumb to this trying complaint before even the owners are aware of the trouble.

It is not a good sign for a cat to be constantly sleeping during the day-time, especially if we have every reason to believe that puss has enjoyed a good night's rest. In such cases, give half a Carter's Little Liver Pill, and you will find that your pet will be brighter and better.

Beware of giving too much Brand's Essence to young kittens. It is very constipating, and I have heard a very clever veterinary remark that many fanciers finish off their invalids by too frequently administering spoonsful of this essence. On the other hand, if used with discretion, it is most efficacious. The directions on the tin are for human beings, so give less for cats. 


\section{Fits}

Fits are rather common amongst highly-bred cats, especially at the time of teething. I have found the following course a most effectual one :-Plunge the cat in a bath of hot water right up to the neck. Place a rag soaked in cold water on the head, and bathe the face. By these means the cat will quickly recover. Bromide powders may be given to avoid a frequent recurrence of fits, and they hetp to soothe and quiet the nerves.

Some cats are subject to fits. These may be caused by worms or undue excitement. It may be well to give small doses of bromide of potassium from time to time to soothe the nerves.

\section{Chest, Throat, and Lungs}

I do not like to see a cat, who, so to speak, mews without making any audible sound. This betokens weakness of the chest or lungs. For these cats I should not advise "lights" as food, for the lungs of cattle are often affected, and thus your pussie's tendency to weakness in that quarter would be aggravated.

An easy and effectual remedy for sore throats in cats is chlorate of potash. Take a pinch of the powder, open the mouth wide, and drop down the throat.

\section{Ears}

All cats have the strongest objection to having anything cold put into their ears. Therefore, if you use any lotion, let it stand in hot water, so that the chill may be taken off. If Condy and water is used, let it be tepid. Use a sponge, not a syringe, as the ear is a very sensitive organ.

If you see your cat constantly scratching her ear you may be pretty sure there is some hidden irritation. Make a 


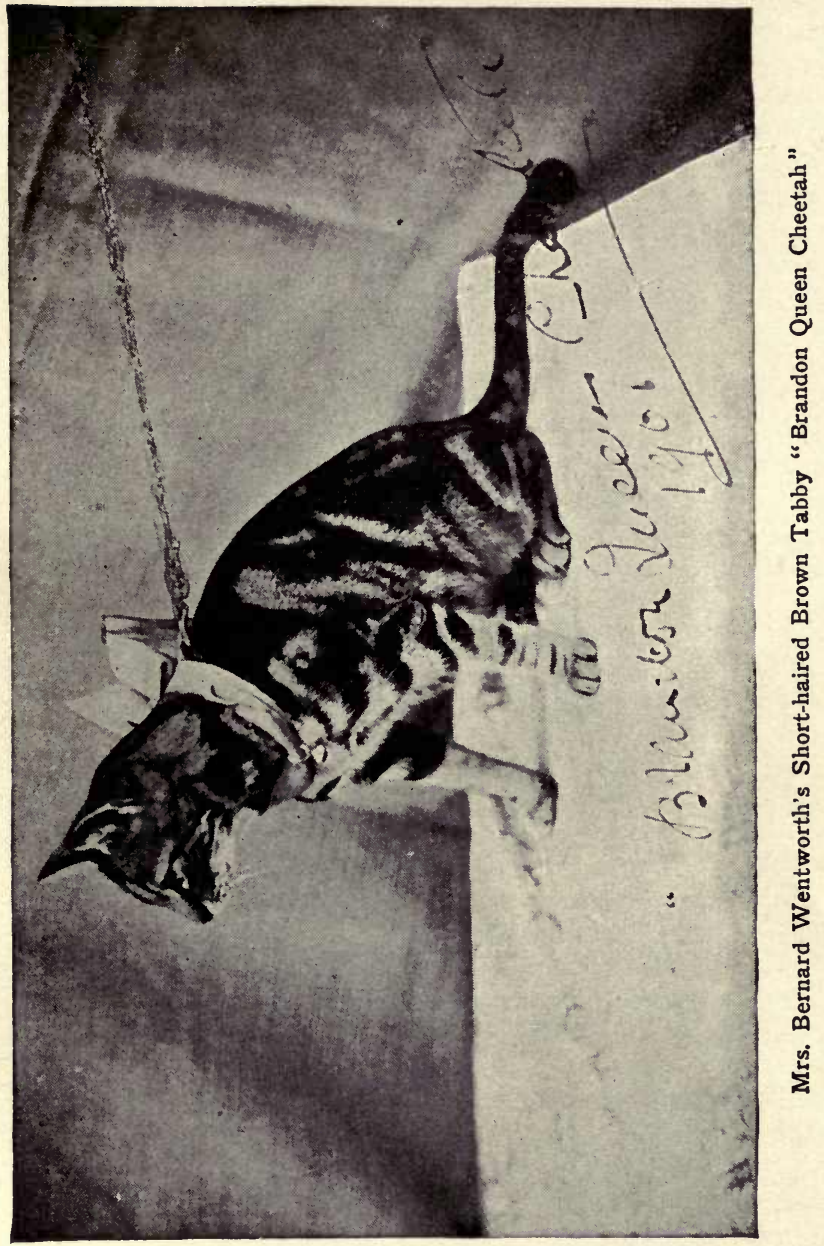




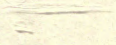


funnel of a piece of paper, place some boracic acid powder in it, and blow down the ear. Do this a few times, and then wash out with weak Condy and water.

A very troublesome complaint in cats is canker of the ear, and one which is often not discovered until the mischief has fairly begun. If you notice your pussie shaking her head continually, generally to one side, you should carefully examine her ears, and proceed to clean them out with weak Condy and warm water. Be careful to dry them thoroughly. Canker may be considered as a symptom of general ill-health.

\section{Debility}

A simple and a good tonic for a cat who is suffering from debility is the following:--Tincture of cinchona bark, one ounce; water one pint. Give a dessertspoonful of this mixture thrice daily.

There is an excellent tonic for cats prepared by $\mathrm{Mr}$. Croft, of Reading. It is a sort of malt food in a powder, which is prepared in the same way as Benger's Food. I am told it is especially good for nursing mothers and delicate cats that need something nourishing to get them into condition after an illness. It is too heavy and heating for young kittens.

For cats and kittens that have, so to speak, run down, try Benbow's mixture for dogs. I am told it acts like magic. A small teaspoonful may safely be given to a cat daily for about a week, and not quite half the quantity for a kitten. This mixture can be purchased at any chemist's.

If your cat is just a little out of sorts, try the effect of James' No. I Powder, called, rightly, the "magical." A well-known fancier, whose cats are always the pink of perfection, declares they have really worked wonders in her cattery.

In cases of debility, after attacks of distemper and 
influenza I have found Animal Kreochyle a splendid pickme-up for cats and kittens. It acts as a stimulant and reviver, and as it is easily assimilated, the digestive powers are in no way taxed. Two teaspoonfuls in a saucer of water for a cat and half the quantity for a kitten. I find my cats lap it up with a relish, with or without dilution. All cat fanciers should send for a sample.

\section{Distemper}

When distemper attacks our poor pussies, there is really nothing to be done but to try and keep up their strength, as this disease very rapidly produces intense debility. From the commencement give frequent small doses of strong beef tea, into which one grain of quinine has been introduced, twice a day, also a small quantity of port wine (from half to one teaspoonful) according to the size of the cat. No solid food should be allowed until convalescence has set in. The animal should be kept moderately warm. Brandy may be given as a last resuurce to arouse sinking vitality.

If your kits are attacked with distemper and the weather is warm and fine put them out on the lawn in the sunshine. Fresh air and sunshine work wonders for diseased animals. I have found the same experiment very efficacious when kittens are suffering from sore eyes. The air seems to have a healing effect. Of course a cold wind is a different matter and must be avoided.

\section{Miscellaneous}

It may not be generally known that the normal temperature of cats is higher than that of human beings. Our temperature in good health is 98.4; that of a cat is ror.4. It is a useful thing to be able to test the exact temperature of your puss if you fancy she is feverish or run down. The best position to place the thermometer is under one of the front paws, as the fur is less thick just there. If the thermometer registers three or four degrees above normal, then have recourse to a liquid diet, if below, feed up with a stimulating diet. 
I consider Salvo's Preventive Medicine a boon and a blessing to cat fanciers, and no one who values their pets should be without a bottle of this magic mixture. I know I recently warded off a serious attack by an immediate dosing, and before and after all shows $I$ intend to resort to this effective concoction-whatever it is, it is absolutely safe.

When medicine is ordered three times a day for your cat, eleven, three, and seven are good times and easy to remember. It is not fair to doctor or patient to give the doses irregularly and inaccurately measured. It is always advisable to give any kind of aperient or worm mixture on an empty stomach.

There is very often one weakly kitten in a litter. Sometimes there may hardly seem any life in the little creature when born. In such a case hold the mite in front of the fire for a time, or, better still, place it in a moderately heated oven. It is wonderful how quickly animation and vitality is produced by these means.

A very sure sign of a cat being out of sorts is when ears and nose are hot. Give an extra amount of green food or grass, and perhaps a gentle aperient of some sort would not be amiss. I like to feel a damp cold nose on a cat as well as on a dog.

A cat or kitten that is feverish is nearly always thirsty, and will hang over a saucer of water, preferring that to milk. A very small quantity of salicylate of quinine dissolved is an excellent remedy for fever. Quantity : about one grain to a tablespoonful of water.

When Persian cats are shedding their coats they are troubled with the quantity of hair which is swallowed during the process of the tollet. You may find your puss constantly choking or coughing in the effort to bring up the fur which has accumulated in the passages. Give her plenty of coarse grass or fern, and this will assist her in getting rid of the balls of fur. 
Remember it is not the quantity of food a kitten takes that benefits it. The secret of its health and well-being is in the quantity it digests. A kitten should only digest certain things in certain proportions, and whatever remains undigested produces irritation, and in this case a kitten cannot possibly develop, and is generally weakly and fretful.

If you suspect your cat has any internal inflammation never give milk, but Brand's essence in cold water and arrowroot and water, or rice water with two drops of brandy every hour alternately. 


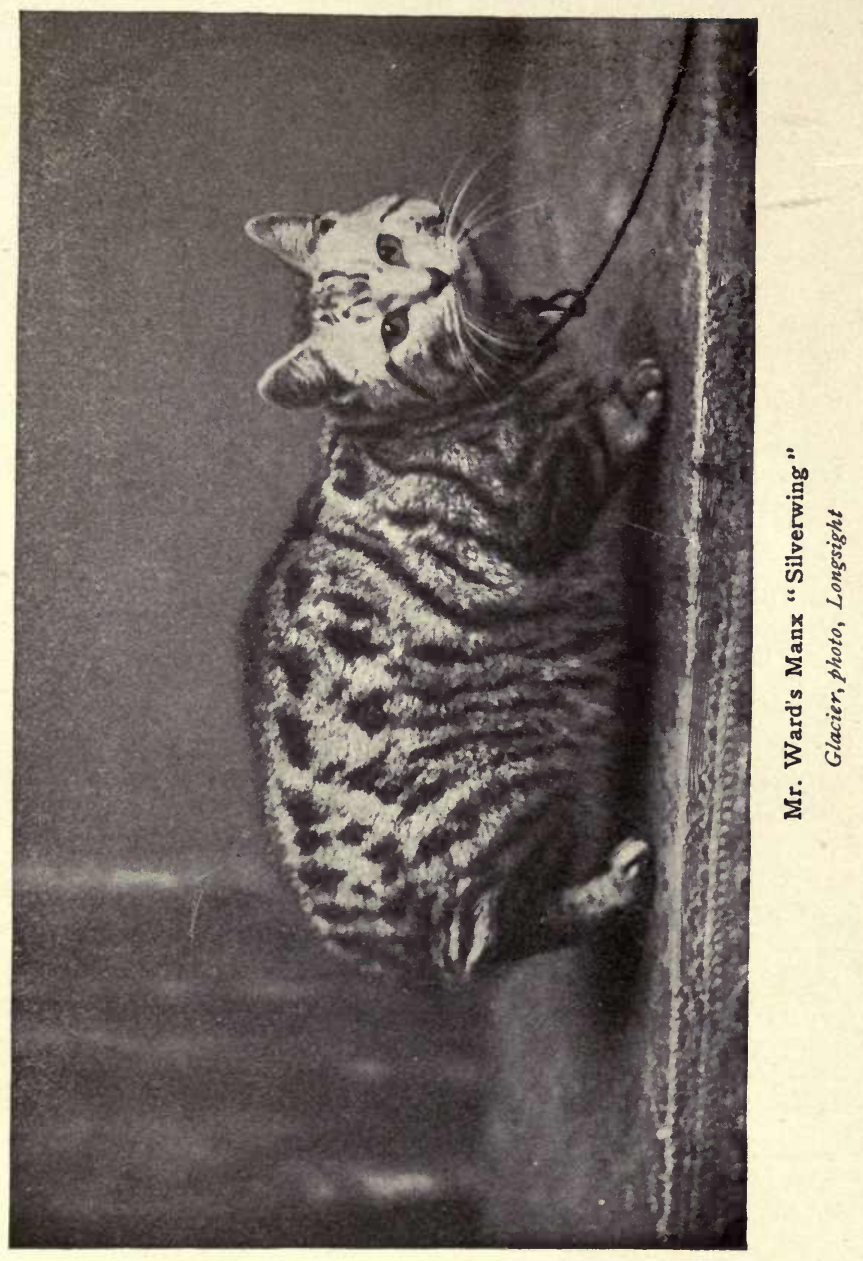




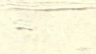




\section{V \\ CAT CLUBS AND CAT HOMES}

I AM almost afraid to think, much less to say, how many years ago it was that I attended the first Cat Show held at the Crystal Palace, which was organised by Mr. Harrison Weir. I well remember, however, when the National Cat Club was founded in 1887 ; and since that date the number of fanciers has steadily increased, and many new clubs and societies have been formed. Instead of one show a year, there are many, and Mr. Harrison Weir's prophecy is fulfilled. I quote from the preface of his book on cats written in 1889 : "But should a new order of things arise the cat will not only be a useful, serviceable helpmate, but an object of increasing interest, admiration, and cultured beauty, and thus being of value, will also be profitable."

The National Cat Club, now under the able management of Mrs. Stennard-Robinson, holds its two principal shows at the Crystal Palace and the Botanical Gardens, and every year the entries increase and the improvement in the various breeds of cats is most noticeable.

The Cat Club came into existence in 1898 , being instituted by Lady Marcus Beresford, who has done such gor d work in the cat world. The excellently managed shows held yearly at St. Stephen's Hall, Westminster, testify to the unwearied exertions and lavish generosity of the founder of the club. These shows have been held in aid of various deserving charities.

Other cat shows in all parts of England are held during 
the year, under the rules of either of these parent clubs, or independently.

In addition to the two principal clubs, which are well known to all cat fanciers, it may be interesting and useful to give a complete list of the Cat Clubs and Specialists Societies up to date, with names and addresses of their respective hon. secretaries.

\section{LIST OF CAT CLUBS AND SOCIETIES}

The National Cat Club, founded 1887. Hon. sec., Mrs. A. Stennard-Robinson, 5 Great James Street, Bedford Row, London, W.C. Annual subscription, I guinea.

The Cat Club, founded r 898. Hon. sec., Mrs. Bagster, I 5A Paternoster Row, London, E.C. Entrance fee, 20s.; annual subscription, Ios. $6 \mathrm{~d}$.

The Northern Counties Cat Club, founded rgoo. Hon. sec., Mrs. Herbert Ransome, Altrincham. Anuual subscription, Ios.

The Silver and Smoke Persian Cat Society, founded 1900. Hon. sec., Mrs. H. V. James, Backwell, near Bristol. Annual subscription, 5s.

The Blue Persian Cat Society, founded rgor. Hon. sec., Miss Frances Simpson, Durdans House, St. Margaret's-onThames. Annual subscription, 5 s.

The Siamese Club, founded I900. Hon. sec., Mrs. Baker, I 3 Wyndham Place, Bryanston Square, W. Annual subscription, $4 \mathrm{~s}$.

The Orange, Cream, Fawn and Tortoiseshell Society, founded I900. Hon. sec., Miss Mildred Beal, Ronaldkirk Rectory, Darlington. Annual subscription, ros.

The Chinchilla Cat Club, founded May r 901 . Hon. sec., Mrs. Balding, 92 Goldsmith Avenue, Acton. Annual subscription, $5 \mathrm{~s}$.

The Short-haired Cat Club, founded rgor. Hon. sec., Mrs. Middleton, 67 Cheyne Court, Chelsea. Annual subscription, 5s.; 2s. $6 \mathrm{~d}$. to working classes.

The Scottish Cat Club, founded 1894. Hon. sec., J. F. Dewar, 2 St. Patrick Square, Edinburgh. Annual sub. scription, $5 \mathrm{~s}$. 
The Midland Counties Cat Club, founded at Wolverhampton I90I. Hon. sec., Miss Cope, I36 Bristol Road, Birmingham. Annual subscription, 5 s.

The British Cat Club, founded rgor. Hon. sec., Sir Claude Alexander, Faygate Wood, Sussex. Subscription, 5 s.

The Manx Cat Clnb, founded rgor. Miss Hester Cochran, Witchampton, Wimborne. Subscription, Ios.

\section{CLUBS IN THE UNITED STATES}

The Beresford Cat Club (Chicago), founded I 899. President, Mrs. Clinton Locke; corresponding secretary, Mrs. A. Michelson, 220 East Sixtieth Street, Chicago. Annual subscription, I dollar.

The Chicago Cat Club, founded r899. President, Mrs. Leland Norton, Drexel Kennels, Drexel Boulevard, Chicago.

The Louisville Cat Club, founded r 900 . Corresponding secretary, Miss E. Converse. Annual subscription, 50 cents.

The Pacific Cat Club, founded 1900 . Corresponding secretary, Mrs. A. H. Brod, II 4 Broderick Street, San Francisco. Annual subscription, $\mathrm{x}$ dollar.

The Atlantic Cat Club, recently founded in New York in February 1902. President, Col. Mann; corresponding secretary, Dr. Ottolesgui, 8o West Fortieth Street, New York.

It will be seen from this list that the only long-haired breeds not provided for by any specialist club are Blacks, Whites, and Brown Tabbies. When the Blue Persian Cat Society was founded, the idea of making it a self-coloured society and including Blacks and Whites was raised, but the "Blue" fanciers wished to keep to their own colour. Probably before another year is out some enterprising and enthusiastic "self" breeder will gather these handsome breeds within the fold of specialist societies. Then the dear "Brownies" will be the only remaining variety, and I would fain start a little Society myself for these-my pet pussies, I frankly confess-but I fear I must leave it to some other friend of the Brown Tabby to muster the breeders of these handsome but neglected cats.

As will be seen from the list, America is well provided 
with Cat Clubs. The Chicago Club was the first in the field, followed by The Beresford Cat Club, which was founded in 1899 by. Mrs. Clinton Locke of Chicago, and was called after Lady Marcus Beresford. I think I am correct in stating that the members now number nearly 200. A very large Cat Show is held by this Club every year in January, where a wonderfully liberal classification is given. It is well known that our American cousins like everything of the best, and somehow they generally get it! Several very beautiful and noted cats have recently left these shores, and are now established in the States. "The Stud Book of the Beresford Cat Club," vol. ii., just received, is really well drawn up and arranged in a neat book of handy size.

There were no fewer than seventy-five classes at the last Cat Show held January 1902. Only two prizes in each class are given, the third award being a V. H. C. card and the fourth $\mathrm{H}$. C. The White classes in long-haired, open and novice include separate ones for blue-eyed and golden-eyed males and females. This Club provides for Orange and White in both the long-and short-haired sections and for Blue Tabbies, there being special classes for these cats, that on this side are relegated to the "Any other colour" class. Neuters are well provided for with four long-haired classes and three short-haired. There is a class for Blue or Maltese cats, male or female. Grey Tabbies are included with Brown Tabbies. These are the chief differences between the classification of the principal American Cat Club and our own:

I think it will be useful to give the standard of points drawn up by each Specialist Club. I therefore append the following list:

\section{BLUE PERSIANS}

Coat-Any shade of blue allowable; sound and even in colour; free from markings, shadings, or any white hairs. Fur long, thick and soft in texture. Frill full . . . Head-Broad and round, with width between the ears. Face and nose short. Ears small and tufted. Cheeks well developed . . . 25 Eyes-Orange; large, round and full : $: \quad 20$ Body-Cobby and low on the legs : : i5 Tail-Short and full, not tapering : : . xo 


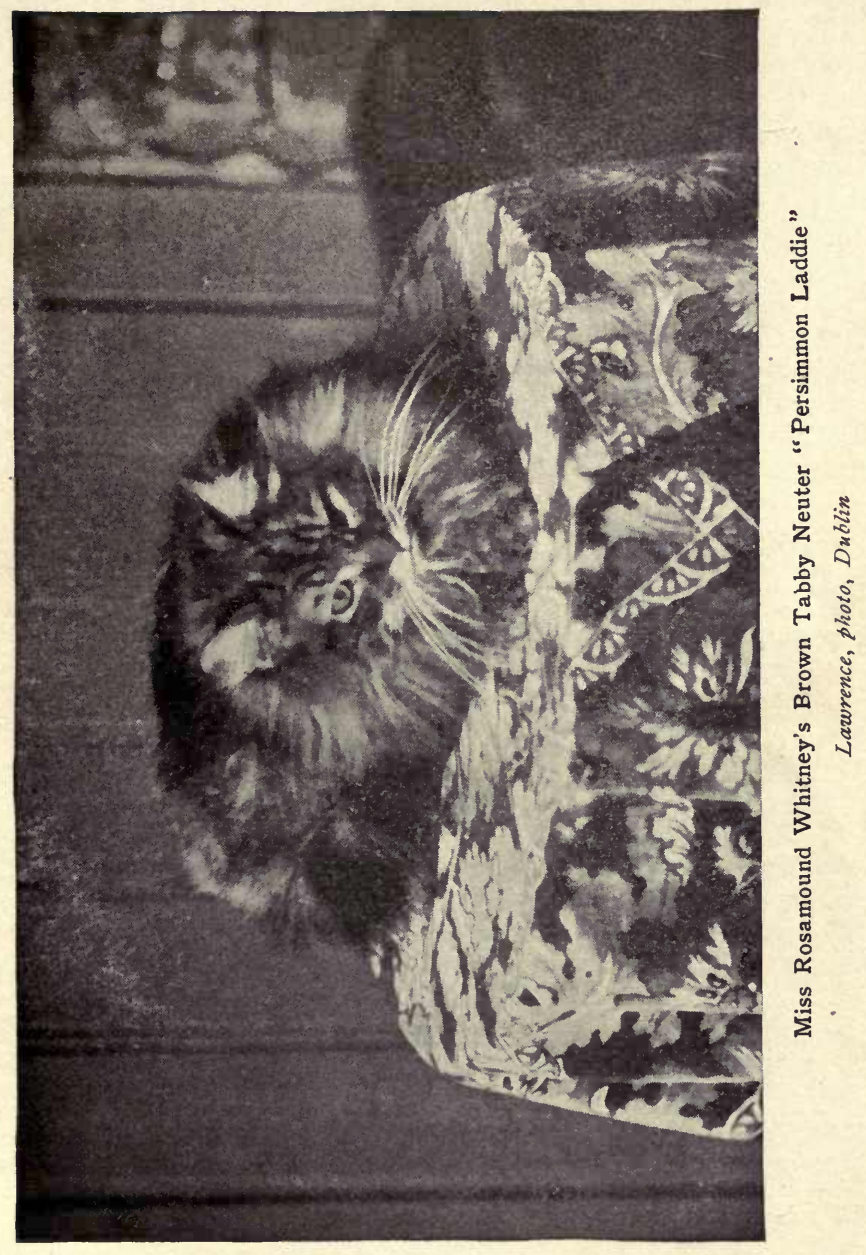




\section{SILVER OR CHINCHILLAS}

Silvers or Chinchillas should be as pale and unmarked a silver as it is possible to breed them. Any brown or cream tinge a great drawback. The eyes to be green or orange.

Value of points :

Head . • • • • • • 20

Shape : $: \quad: \quad \vdots \quad: \quad$ I5

Colour of coat $\quad$ : $\quad$ : $\quad$ : $\quad$ : 25

Coat and condition $\quad: \quad \vdots \quad \vdots \quad \vdots 20$

Colour, shape and expression of eyes . . . ro

Tail • . . . . . . . Io

\section{SHADED SILVERS}

Shaded Silvers should be a pale clear silver, shaded on face, legs and back, but having as few tabby markings as possible; eyes, green or orange. Any brown or cream tinge a great drawback.

Value of points:

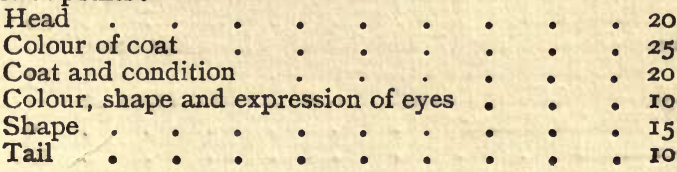

\section{SILVER TABBIES}

Silver Tabbies should be a pale clear silver, with distinct black markings. Any brown or cream tinge a great drawback; eyes to be orange or green.

Value of points :

Head and expression

Colour and markings

Colour of eyes

Coat and condition

Shape. .

Tail 


\section{SMOKES}

Smoke Cats should be black, shading to smoke grey) with a light an undercoat as possible; light frill and ear tufts; eyes to be orange.

Values of points :

Head and expression . . . . . . 20

Colour of eyes $\quad \bullet \quad: \quad \bullet \quad$ : 15

Colour of undercoat : $\quad: \quad$ : $\quad$ : ro

Absence of markings : $\quad$ : $\quad$ : : 15

Coat and condition : $\quad: \quad$ : $: \quad$ : 20

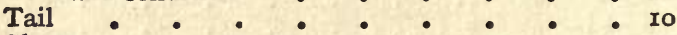

Shape : $: \quad \vdots: \vdots \vdots:$ 10

\section{CREAM OR FAWN}

Colour-To be as pure as possible without marking or shading, either paler or darker, dulness and white to be particularly avoided. All shades from the palest fawn to be allowable . 25

Coat-To be very long and fluffy . . . . 25

Size and Shape-To be large, not coarse, but massive, with plenty of bone and substance, short legs . . . . . . Head-To be round and broad, with short nose, ears small and well opened . . . Eyes-To be large and full, and bright orange or hazel in colour . . . . • . 5

Condition . . . . . . . . 10

\section{ORANGE, SELF OR TABBY}

Colour and Marking-Colour to be as bright as possible, and either self, or markings to be as distinct as can be got . . . 25

Coat-To be silky, very long and fluffy $\quad: \quad 25$

Size and Shape-To be large, not coarse, but massive, with plenty of bone and substance, short legs . . . . . 20

Head-To be round and broad, with short nose, ears small and well opened . . . . I5

Eyes-To be large and full, and bright orange or hazel in colour

Condition 


\section{TORTOISESHELL}

Colour and Marking-The three colours, Black, Orange, and Yellow, to be well broken, and as bright and well defined as possible; free from Tabby markings. No white . . . . 30 Coat-To be silky, very long and fluffy . . . 20 Size and Shape-To be large, not coarse, but massive, with plenty of bone and substance, short legs

Head-To be round and broad, with short nose, ears small and well opened . . . 15 Eyes-To be large and full, and bright orange or Condition hazel in colour

\section{CHINCHILLA}

Used also in America. The Chinchilla Cat Club having been invited to draw up the standard for judging Chinchilla Cats in the U.S.A.

Colour of Coat-Palest silver lavender tint preferred, nearly white at roots. No dark stripes, blotches, or brown tint. Darker tips to the long hairs give the coat an appearance of being lightly peppered with a darker shade, or with black. The whole appearance of the cat to be very pale . . . . . 30

Coat-Long and thick . . . . : . 20

Texture of Coat-Fine and soft : . . . Io

Tufts of hair inside and round the ears and between the toes. . . . ro

Head-Broad and round. Forehead wide. Ears small and set low, nose short . . . 25

Shape-Back level, not too short. Legs short. Paws round. Brush short, wide, and carried low . • . • . . .

Eyes-Large, luminous. Colour, green, or green and yellow mixture (called hazel in connection with cats), 5 points. Not yellow or orange . Io

\section{ROYAL CAT OF SIAM}

Body Colour as light and even as possible, cream being the most desirable, but fawn also admissible, with streaks, bars, blotches, or other body markings. 
Points-i.e., mask, ears, legs and feet, and tail, dark and clearly defined, of the shade known as "seal-brown."

Mask, complete-i.e., connected by tracings with the ears, neither separated by a pale ring as in kittens, nor blurred and indistinct, the desideratum being to preserve " the marten-face," an impression greatly aided by a good mask.

Eyes.-Bright and decided blue.

Coat.-Glossy and close-lying.

Shape.-Body rather long, legs proportionately slight.

Head.-Rather long and pointed.

General Appearance. - With points emphasised above, a somewhat curious and striking-looking cat-graceful, elegant, of medium size; if weighty not showing bulk, as this would detract from the admired svette appearance. In type, in every particular, the reverse of the ideal short-haired domestic cat, and with properly preserved contrasts of colour, a very handsome animal, often also distinguished by a kink in the tail.

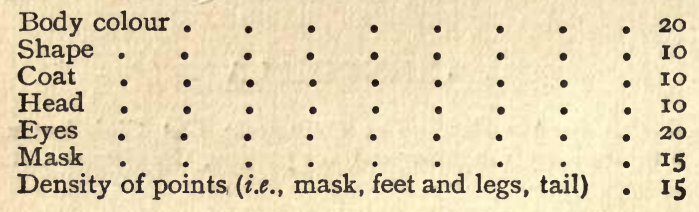

\section{SHORT-HAIRED CATS}

White Cats should be pure white, without markings; eyes, blue.

Black: Pure and rich black; no white; eyes, orange.

Blue: Pure blue without markings; no white; eyes, orange.

Tortoiseshell: Patched yellow, orange and black; no stripes, no white; eyes, orange.

Tortoiseshell with white: White patched with yellow, orange and black; no stripes; eyes, orange.

Silver Tabby: Pale silver grey, marked with rich black stripes or bars; no pure white; eyes, green or orange.

Brown Tabby: Golden brown, marked with rich black stripes or bars; no white; eyes, orange or green.

Orange Tabby: Light orange or red, with darker stripes or bars ; no white; eyes, hazel or golden brown.

Manx: Any colour, eyes, to follow colour as above; outer-coat rather long, and having a soft rabbit-like under-coat; no tail; hind quarters rather higher than fore quarters.

\section{ENTERING FOR EXHIBITION}

On the next page is a copy of the entry form used by The National Cat Club, which will serve as a sample of the general form used by various club secretaries : 


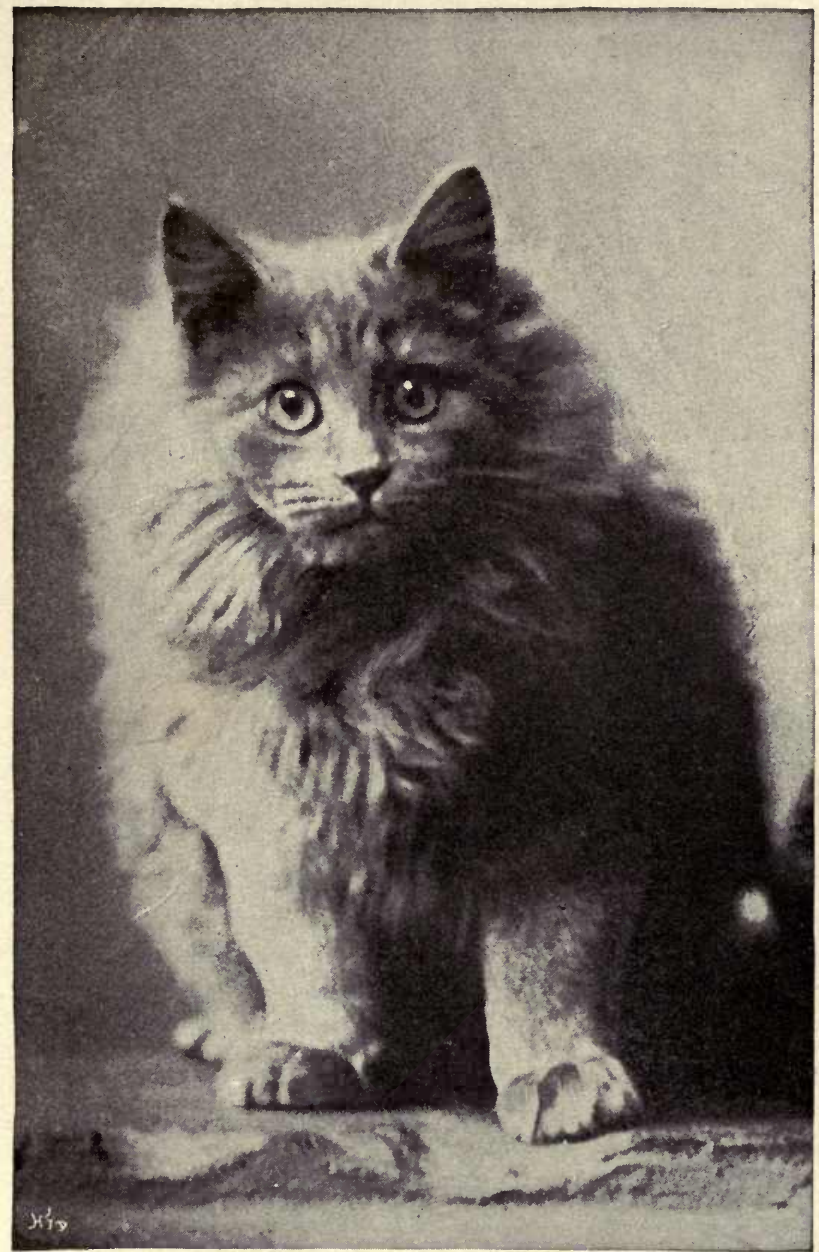

Miss Frances Simpson's Blue Kitten "Bonnie Boy'

Gunn \& Stuart, photo Richmond 



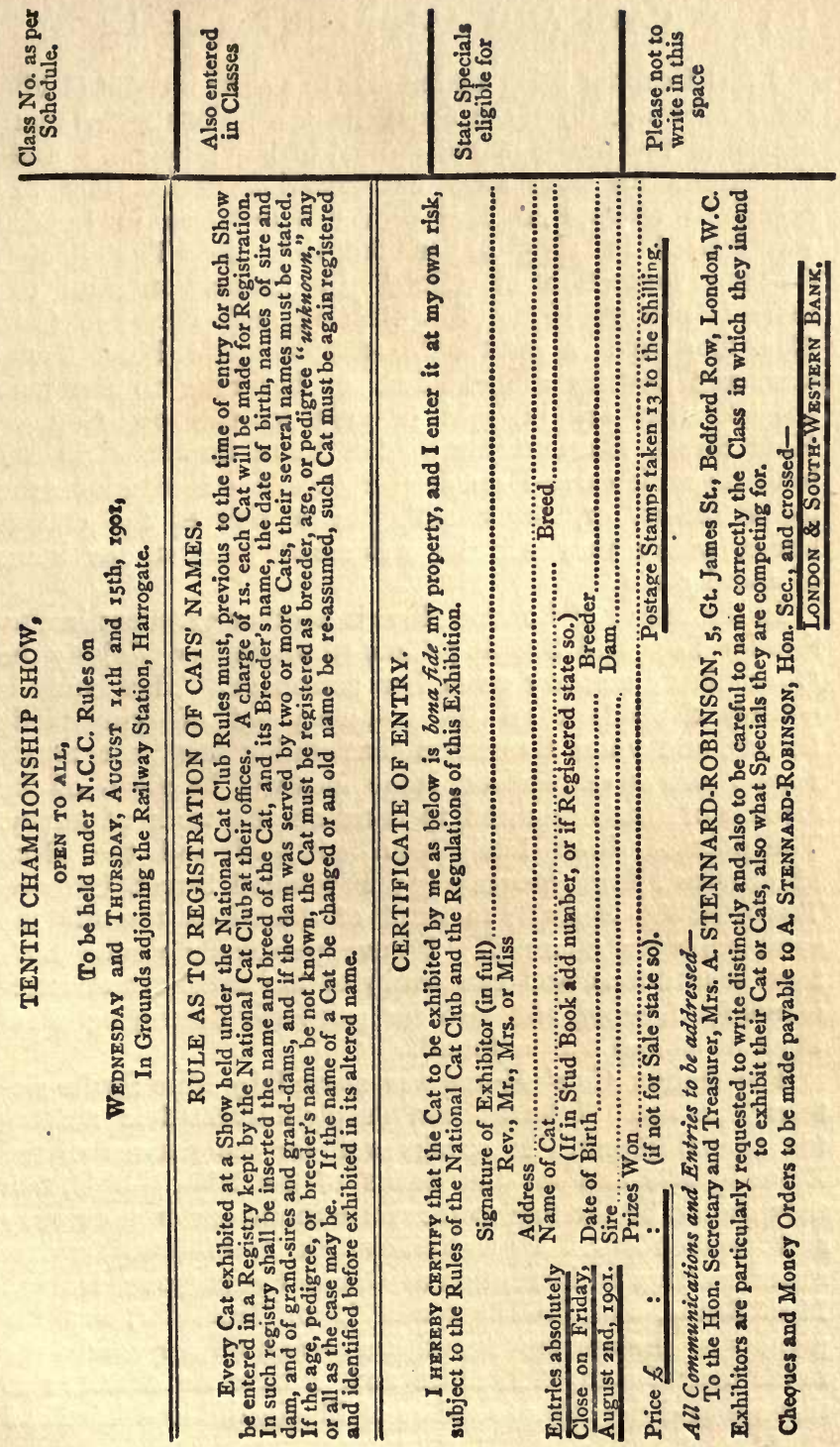


I feel I cannot bring my remarks to a close without making some reference to those excellent institutions which must appeal to the hearts of the animal-loving public. I mean the homes for poor stray and starving cats. The first organised attempt to deal with this question in London was started in 1895 under the title of "The Society for the Protection of Cats." In connection with this there is now A Home for Starving and Forsaken Cats. Mrs. Gordon is a most able and energetic Hon. Secretary, and devotes a great deal of her time to the poor animals that are brought or sent to Gordon Cottage, King Street, Hammersmith. Let those interested in the humane work carried on at this excellent institution send for a report, or, better still, pay a visit to the cottage home, where they will be welcomed between the hours of 2 and 5 P.M.

In the North of London there is another excellent institution for Lost and Starving Cats, to which her Majesty the Queen has graciously given her patronage. This home is entirely dependent on the voluntary aid of sympathetic friends, and when I mention that during last year nearly I2,000 cats were received, some idea will be given of the amount of funds required to carry on this work of mercy. The premises have lately been enlarged, and the Hon. Manageress, Mrs. Morgan (35, Ferdinand Street, Camden Town, N.W.), is sorely in need of donations towards the extra expenses incurred. I have personally visited both these institutions, and can testify to the excellent arrangements for feeding, and also for painlessly destroying them when no homes can be found.

The Dublin Cats' Home was started by Miss Swifte sixteen years ago. I have been deeply interested in reading the annual report. It speaks well for the natives of the Emerald Isle and for the hearts of the Irish people, that they should be the first to recognise the needs of poor stray and forsaken cats. With characteristic enthusiasm they set about erecting an institution at Grand Canal Quay, Dublin. Miss Swifte, the President and Hon. Treasurer, was the pioneer of the movement and has carried on her good work in the face of many difficulties and, I have no doubt, also that she and the other founders of like institutions have had 


\section{CAT CLUBS AND CAT HOMES}

to suffer much ridicule, for the majority of human beings have very little sympathy with "mere cats," and seem to think they, of all animals, are least deserving of kindness and consideration. Miss Swifte's private address is 2 Earlsfort Mansions, Earlsfort Terrace, Dublin.

The Battersea Home for Lost Dogs has also accommodation for cats as strays and boarders.

And now a few words about the boarding out of our pussies. I am constantly asked if I know of a good place where cats will be taken care of during the absence of the owner. I wonder that more cat lovers and cat fanciers wishing to add to their incomes do not start boarding-houses for cats. I think there is a great opening for such an enterprise. At present I only know personally of two ladies who receive pussies at so much per week. Miss Harper, of Briarlea, Haywards Heath, is well known in the Fancy, and although I have not been to see her "catteries," I am told they are capitally planned, and I have often recommended my friends to send their cats to be taken care of by Miss Harper, who gives her personal attention to all the boarders entrusted to her.

I have also had testimony to the excellent manner in which Mrs. Carew Cox caters for her pussy visitors. A fancier who had placed her cats at the Kremlin, New Milton, Hants, for some months, was so surprised and delighted at the appearance of her pets on their return that she wrote asking for a special description of the menu provided.

Mrs. Carew Cox and Miss Harper are both successful breeders of prize-winning cats, and they have also that genuine love for the animals which is so necessary and essential when taking charge of other people's pets.

I may here mention that the chief organs of the cat world in England are Fur and Feather and Our Cats, and in America, The Cat Fournal, The American Cat Neres, and Field and Fancy.

In regard to the Blue "Maltese" (a name which, perhaps, has as much justification as the English "Russian") in America, Mr. E. N. Barker says: "There are lots of Blues, light and dark, short-haired, and these are always called Maltese. The origin of the term I never could trace to its foundation, 
but they are much treasured. Occasionally you find Maltese (so called) of other colours, and Blue and White. The owners are generally under the impression that these cats are a special breed to themselves; this point, however, is open to doubt."

The same authority, referring to Tortoiseshells, says : "I doubt if this breed will ever find favour in America, and Blacks are too sombre for this country, where people enjoy a good deal of sunshine, the fancy being more apt to run to lively colours."

Another curious item about American cats is that there have been for many years, in the States of Maine and Massachusetts, and on the islands off that coast, quite a number of long haired cats, called by the natives "Coon cats," because of their jackets. History relates that they were brought from the East on ships, and being landed on the islands are tolerably pure, though some have crossed with wild cats and ordinary cats and have varied also from climatic influence. They are mostly rather large, strong cats, well coated, with wonderful tails, big in the ear, short of fur over the head and inclined to be long in the nose. Amongst the Maine cats are some of a curious seal-brown colour, or deep mahogany red, with not a vestige or sign of markings, giving them an undoubted suggestion (however impossible) of a 'coon (raccoon) strain in them. Hence, presumably, the name.

I confess that I should like to see specimens of these cats in England.

Miss Helen M. Winslow in her book concerning cats says that by many people this Blue or Maltese cat is not considered a distinct breed. It seems vaguely to be known as the Archangel, Russian, Spanish and Chartreuse, and yet probably it is only a cross between Blacks and Whites. Miss Winslow gives a picture of her "Pretty Lady" and describes her as a "beautiful, fascinating and seductive Maltese, with white trimmings to her coat." The illustration suggests a cross between a Russian and a short-haired English cat with an expansive white shirt front and white gloves. 


\section{VI}

\section{MISCELLANEOUS}

THERE is a great deal in the way in which a cat carries her tail. It ought not to be stuck up straight in the air nor yet curled under the hind legs, or dragged along the ground. I like to see a Persian cat's tail carried just on a level with the hody, and slightly curving upwards towards the end. Small ears are a great beauty in a cat. They should not be wide at the base, nor pointed at the tip. Nice ear tufts make a wonderful difference in the appearance of a Persian cat.

Ordinary hampers may be made more portable for cats it a double strap, such as is used for rugs, is run twice through the wicker work, and the handle brought to the top.

To fanciers wishing to start Persian cats, chiefly with a view to taking prizes at our shows, I would recommend them to obtain a really good Black queen, with amber eyes. At each of the principal shows the Black class is ever the weakest; this is specially the case as regards the female sex. A really handsome Black Persian is a thing of beauty.

Kittens that live out of doors and are constantly in the hot sunshine, readily get sunburnt and their pretty coats become tinged with brown. But do not be unhappy, as this will disappear with their kitten coat, and by fresh air and exercise and the strengthening rays of the sun, the little ones will be laying in a stock of health. 
A capital collar for a cat is a leather garter lined with flannel. The sharp edges being covered do not injure the frill and fur.

All White cats are not deaf, but in purchasing one of this breed it is always best to test their sense of hearing. If stone-deaf, the price should certainly not be so high, as although this fact does not prevent a cat from winning prizes, yet it is undesirable for our pets to be deaf to our entreaties.

White kittens are frequently born with a dab or splash of grey on their heads. This apparent serious blemish is only temporary, and as the kittens grow the dark hairs vanish.

Tabby markings are often visible upon Blues when they are tiny mites, and one is apt to fear lest these should become more and more apparent, but as the fur grows they quite disappear, leaving no trace of stripes or bars.

It would be a great benefit if the executive of all cat shows decided to supply only water for the pussies, unless milk was specially asked for. I think we should then hear of fewer disasters following exhibitions. Nothing collects germs so easily and quickly as milk, and in all weathers there is the risk of its turning sour. In and about London, and, indeed, even in the country, it is unfortunately the custom to introduce boracic acid as a preservative, which proves a poison to cats and delicate children.

Cobby cats are certainly to be preferred as regards appearance, but I incline to the belief that those females who are long-bodied are the best cats to breed from.

It is not a bad idea to have warm coats made for our travelling queens when making a long journey in cold weather. A lady was sent to my stud the other day clothed in a very smart jacket, through which her front paws were placed, and it was buttoned up on her back. This puss had also a pair of washleather boots on her back legs, so 
her appearance was a little startling! The boots were as a preventive to scratching her eyes or ears. I think only a very amicable cat would stand these trging appendages.

The eyes begin to change colour in kittens when they are about three months old. It is disappointing when the bright blue eyes of White kittens gradually assume a pale greenish hue, and finally about five or six months old, settle down into a decided yellow. In blue kittens we look out anxiously for the orange tinge. In these kittens the blue eyes quickly lose their brightness, and when first the colour appears to be changing it seems almost the same colour as their coats. It is a curious fact that in many cats it is impossible to state whether the eyes are green or yellow. This is especially the case in Blues and Silvers. The health of the animal has a great deal to do with the density of the colour in the eyes.

The question of hampers versus boxes for our cats when travelling is one that demands attention, more especially during winter. In cold weather I believe in boxes with ventilation on the top. Then comes the question of how to secure a sufficiency of air, as, in spite of our directions, "Live Cat, with Care," the railway officials will heap luggage on the top of our precious cargo. I advise fixing blocks of wood, about two inches in thickness, on the lids, and thus the danger of suffocation would be avoided.

It may sound foolish, but there is no covering so warm and air-tight as paper, and I have found this cheap commodity most useful and efficient. If you wish to send a puss on a journey in a hamper, then procure a large sheet of brown paper, place the hamper in the middle, and fold it up like a parcel, leaving a square space on top of the lid round the handle. This is really a better mode of protecting the cat than by any inner linings, which are often scratched down by struggling and protesting animals. If, however, you like to have a double protection, don't select red flannel, or any material of brilliant hue, as I have seen a lightcoloured puss issue from a basket partially dyed scarlet.

We all know what a very trying habit our pussies have of 
sharpening their claws on choice pieces of furniture. They generally show a great partiality for leather-covered chairs. It is quite necessary that cats should exercise their talons, so it is best to provide a large log of wood in the cattery or in the house, where they may claw away to their heart's delight.

Try and avoid sending your queens on visits in monstrously large packages, for many reasons it is not desirable. I think a cat is more apt to get knocked and rolled about travelling in a very big hamper than a small one. Then again, an unwieldy box or hamper gives more trouble and sometimes extra expense in getting to and fro from the station.

In insuring your pussies insist on having the yellow insurance ticket placed on the hamper in your presence. Sometimes you pay your money and then in the hurry of getting the package to the train the ticket is forgotten.

The theory that human beings can and do contract diseases from cats does not hold water. I have often asked caretakers of cats' homes and hospitals whether any of the complaints of the pussies have been given to the people who attend to them, and the answer has always been in the negative.

I have recently been purchasing cat travelling baskets for friends, and I can highly recommend those made by Spratt's. They are very strong, and have the straps for fasteners, which are vastly preferable to the wicker loops and stick. The latter seems always missing at the critical moment when we are sending off our pussies on a journey. Then, again, the loops break away, and we are at a loss to get tinem mended. The skeleton lids are a valuable addition.

It is not well, for many reasons, to allow stud cats to have their freedom - that is, if they are of any value. After a male has reached the years of discretion and discernment he will soon begin to stray away, and probably on his return after a day or two he will show signs of having had a sharp 
contest with some of his tribe. Then he runs the risk of being trapped or shot. The feline society with which he comes in contact during his rambles may have been anything but desirable. Infection may be brought back, and if there are other pussies at home this is a serious matter.

The difference between a good-shaped eye of a pale colour and a small, beady eye of a more correct shade is perhaps hardly appreciated by some judges, who without hesitation give the preference to the latter. Nothing lends such expression to a cat as a large, round, full eye-and, of course, let it be the correct colour if possible.

There is really no reason to regard distemper as a necessary evil in cats. In the case of one pet kept at home and well cared for, the chances are certainly against the occurrence of the disease. Then, I am of opinion that so-called distemper embraces a variety of complaints, from any or all of which a cat may suffer. A simple cold in the head, or an attack of influenza, sometimes is mistaken for distemper, and a gastric attack may be also thus designated.

As regards cross-journeys, do let me impress on all fanciers the importance of sending off their pussies as early as possible in the morning. If you wait till mid-day, and your cat has to cross London and be booked again to some suburb, it is certain she will be left all night in a parcels' office.

Any one who has tried getting kittens to sit for their portraits knows how difficult it is to make the fidgety little creatures be quiet. Try holding up a looking-glass so that the kit can see its own reflection. This experiment often answers splendidly.

A cat lover with a warm heart is often tempted to take in a wandering puss. By all means feed the hungry, but beware of letting a stray mix with your own kittens. Many a fancier has been bitten, and in consequence is shy of letting her sympathy run away with her prudence. 
It is most improving for the fur of young kittens to have a good romp. They delight in rolling about those little celluloid balls which rattle. Don't let them play with corks, as I have known them bite pieces off, and they swell in their inside and are most dangerous. I have also heard of string being swallowed, and becoming twisted round the intestines.

The enamel unbreakable ware is decidedly the nicest and most serviceable for our pussies. I recently observed upon the very convenient shape of some of these dishes in use in a very complete cattery. I was told they were frying-pans from which the handle had been removed!

It is curious that as a rule the lighter the coat of the cat the more fragile is the constitution. For instance, amongst Persians, Whites and Silvers are less hardy than Blacks and Tabbies.

If you wish to pick up a dangerous or strange cat be careful to seize it quickly and firmly by the back of its neck and hold it out at arm's length. It will then only be able to use strong language.

I have heard that the best way to part two fighting cats is to pour water upon them. I know from a painful experience that it is dangerous to attempt to separate them.

It is really better to give your puss a name suggestive of his or her sex. I can assure you this is of assistance to the judges and to those who have the arrangement of specials given at a show.

If any one is kind enough to send you a cat on approval and she does not suit you, do not return her the next day, especially if she has travelled far, but keep the poor puss for two nights and a day, and start her off early the following morning, giving the sender due notice of her return.

Beware of tying ribbons round your pussies' necks. They 
look very smart, but I have known of several sad and fatal accidents caused by these pretty adornments. There is the danger of cats being caught and hung in the bushes. It is also unwise to tether cats in the garden if within reach of any trees.

I don't agree with the use of the bucket for poor little rejected kittens, and consider the most humane way of destroying them is to put them in an air-tight box with a piece of rag or flannel that has been freely sprinkled with chloroform. They will gradually inhale the fumes and pass away in their sleep. For grown cats the same method should be adopted, and no cat fancier should be without a small quantity of chloroform. Accidents will happen in the best regulated catteries, and sometimes it is best to put our pets out of their misery. It requires some strength of mind, but if you feel you cannot summon up the courage, then take your puss to the nearest chemist, and insist on chloroforming, not poisoning.

A very safe and delicious disinfectant is "Eucryl," as used at the Cat Club Shows. The perfume is pleasant, and not the least overpowering. I have found it very efficacious to sprinkle in cat-houses, and a little mixed with water can be used with advantage in cleansing the floors and woodwork.

Now that there are specialist societies for several breeds of cats, prizes for these are well supplied at the various shows. I would, therefore, suggest that fanciers should try to encourage Blacks, Whites, and Brown Tabbies, who have no society to look after them, and offer specials on their behalf.

Cats are very sensible to strong odours or perfumes. They have a great objection to the smell of orange-peel. I am sure they resent the very strong disinfectants used at some shows. They particularly dislike their beds to be scented with any of these fluids or powders.

Have you noticed the different colours of cats' noses 
according to the breeds? In Blue cats they are just about the colour of the coat, the same with Black Persians. Orange cats have pink noses, and the Silvers mostly a sort of brick-dust colour; this also is the case with Brown Tabbies.

Here are particulars of two very inexpensive articles useful to fanciers. If you do not have your tins made for holding the earth, then purchase large earthenware flower-pot saucers. These are much preferable to wooden boxes. Baskets come expensive if you need many for cats travelling, so I advise you to lay in a stock of margarine baskets, which your butterman and grocer will let you have for a few pence.

Let me recommend my readers to pay a visit to the Camden Town Institution for Lost and Starving Cats. It is splendidly managed, and all information as to the most humane way of destroying injured or aged cats is readily given. One has to see, in order to believe, how absolutely painless is the sleep of death in the lethal box for poor pussy.

When your pets are in full coat, then is the time to have their photographs taken. It is often very convenient and useful to have a good picture of your stud cat or queen to send to would-be purchasers of them, or of their kittens. A reproduction in Our Cats has often proved a splendid advertisement for fanciers.

Never be persuaded into purchasing a cat or kitten that is suffering from snuffles, or nasal catarrh. This troublesome complaint, which is often the remnants of distemper, is seldom really curable. It is most distressing, not to say disgusting, to have a cat that is sneezing all over the place.

If you are desirous of discovering the pedigree of a cat, you should send a shilling to the secretary of the club and ask for it to be looked up and forwarded to you.

It is a very good thing to accustom your cats to answer to their names, and if you give them some high-sounding title 
for the register and the show catalogue, keep a nice short pet name for home use.

It is often supposed that worms take whatever medicine is given to the cat; but this is not so, the worm absorbs the nourishment, and if a substance is given that assimilates readily with the food then these pests are destroyed, and when dead, expelled.

When trying to pick out the best kittens in a litter of Selfcoloured ones, first see whether there is any white spot on throat or stomach, then direct your attention to the size of head, width between the ears, and broadness of face. A short tail is to be desired in both Persian and English cats.

When you are ordering medicines from any of the cat doctors, be sure and give the age of your cat or kit, and it is also advisable to mention some of the symptoms of the illness with which they are troubled.

A kitten may be considered a cat when it has shed its first teeth. This process takes place between six and nine months, and often during this period puss is our of sorts, and refuses her food, for the gums are tender and sore.

It is always a sure sign of good health if, when a cat or kitten has finished a meal, it slowly stretches itself, then sets to work to have a vigorous wash up, and finally curls itself round into a ball and falls asleep.

Many cat fanciers may not be aware that really good and healthy foster-mothers can be procured from the excellent homes for stray cats in and about London. The few shillings given go to help on the humane work of these splendid institutions.

It would seem that Self-coloured Manx cats are more rare, and consequently more valuable than Marked or Tabby ones. Therefore, when Black or White Manx cats are for sale it is well to secure them. 
The tail of a Persian cat should not be tapering at the end; this is a defect that we often meet with. The fur on the tail should be as long at the tip as higher up.

Ear tufts in Persian cats add wonderfully to their personal appearance. They take away from the size of the ear and fill in an ugly vacuum. In choosing a puss, look out for these fine feathers.

Keep the pick of a litter for yourself if you intend showing or wish to get a good sum for a grown-up cat, but don't be tempted to retain two or three just to see how they will turn out.

We do sometimes hear of the bite of a cat being fatal, but this is very rare. I have been badly bitten several times in separating cats, but beyond a certain amount of pain no bad results have followed. On each occasion I have plunged $\mathrm{my}$ hand into a basin of hot Condy and water, and kept it there for some minutes, and thus the poison (if any) has been drawn out of the wound.

Owners of stud cats are always gratified to receive letters from the senders of queens announcing the arrival of the family, mentioning the number of kittens, and any other interesting details. If one is born dead, or dies shortly after birth, it is considered correct to enter the birth of the whole number of kittens in the cat papers.

If you belong to a Specialist Society, try and assist your secretary by sending prompt replies to any questions which may be submitted to you as members, and if in your turn you wish to make some inquiry, it is only polite to enclose a stamp for an answer.

Never lose an opportunity of giving a helping hand to a novice in cat breeding, and don't offer the services of your stud cat just for the sake of the fee when you feel and know that a cat of a different type and breed would give better results to the owner of the queen. 
It is a difficult matter to let our stud cats have their freedom even for a short time or to give them an opportunity for exercise. I have often tethered my tom cat, and for a collar have used a leather garter lined with flannel. One must be careful to give only a sufficient length of cord to allow for safe exercise. No shrubs or trees should be within reach, as this is very risky for pussy's neck.

It is undesirable to keep kittens too long, if profit is to be considered. From eight to twelve weeks kittens are at their best. At about five months most young cats begin to shed their coats and are "leggy" in appearance.

It is so much easier to fill in your cat's pedigree on a properly drawn out pedigree form, and certainly it is pleasanter to receive them. I have had some written-out pedigrees sent to me from which it was impossible even to make sure of one of the parents.

It is a sort of sad satisfaction to know the cause of our pussies' deaths, and therefore I advise fanciers to send the remains to a veterinary for a post-mortem. The knowledge thus acquired may assist in determining the nature of any future illness in the cattery.

It is very annoying when your cat persistently tears out her ruff, more especially if you have entered her for show. I have known fanciers to tie up pussie's hind feet in pieces of wash leather, but this is a most irritating procedure so far as puss is concerned, and in some cases she will not rest till she has got rid of her shoes.

As regards insuring cats travelling by rail, I believe the usual rate is $3 d$. for each $£ \mathrm{I}$ of value. I find that, as long as the hamper is labelled with the insurance ticket, this is a sufficient safeguard against delays and exposure; so that, unless the cat is unusually precious, the payment of threepence is all that is required.

Having recently had occasion to send some valuable cats abroad, I can testify to the courtesy and efficiency of Messrs. 
Spratts Limited. A lot of trouble is saved by applying to them for all particulars regarding the shipping of cats to foreign ports.

It is always well to keep a record of the dates and names of visiting queens. I found this useful when receiving a letter from the owner of a mother puss who had a litter of nondescript kittens. The writer was much displeased, and seemed to imply that her queen had been mated with the wrong cat. I referred to my register and found that the kittens were born under the eight weeks from the date of the supposed mating. I therefore felt confident the lady visitor had made other arrangements prior to her arrival at my cattery.

It is always advisable to have an old pair of thick gloves to slip on when one has to handle strange cats. Sometimes the queens, when arriving on a visit, are very terrified on being lifted out of their basket or placed in the cattery, and it is just as well to protect oneself from a bite or a scratch. Care should also be taken when removing a queen from the stud cat, as often he resents the sudden departure of his lady love.

In administering medicine to cats an assistant is very necessary to hold the animal, which should be wrapped round with a towel and the four legs firmly secured. With the thumb and finger of the left hand open the mouth, and with the right put down the medicine. Remember that a cat cannot conveniently swallow more than a teaspoonful of liquid at a time, so if a larger dose is required it must be given by degrees.

It is quite possible to pull grown cats through an attack of influenza, but if kittens catch it, then I recommend owners to have them painlessly put out of their misery, for it is in vain to try and save them. The fever runs so high that the little creatures cannot contend against it.

It may not be generally known that whiskers are the cat's organs of touch. They are attached to glands under the 
skin, and each of the long hairs is connected with the nerve of the lip. The slightest contact of these whiskers is felt most distinctly by the cat, although the hairs themselves are insensible. Let our young friends remember this, and never torture poor puss by pulling her whiskers.

Nothing is so beneficial to a cat's health as change of air, and fanciers would do well to try and take one or two of their pets with them to the country or seaside. This is especially necessary if you reside in or near any large town.

Try and dispose of your kittens at or about eight weeks old, and be willing to take a rather lower price instead of keeping them till they reach the lanky stage, when their sale is never so easy or satisfactory.

Important to cat fanciers :

"If you your lips would keep from slips, Five things observe with care:

Of whom you speak, to whom you speak, And how and when and where!"

Before writing "Finis" to these chapters, let me say how pleased I have been with the many grateful letters I have received telling me that my notes in Our Cats had been of such service. I really had no idea these hints had been so useful and instructive. All these kindly expressions encouraged me to write this handbook and I sincerely hope that it will be the means of forming still turther friendships and of forging more closely the links that alrealy bind me to all true lovers of the dear pussy-cats. 


\section{INDEX}

\section{A}

Abyssinian cat, the, 23 America, cats in, 23, 97, 98, 105, 106

American Cat News, 105

Animal Kreochyle, 36, 79, 80, 81, 92

Anæmia, remedy for, 28, 82 "Any other Colour" Class, 22,64

Appetite, loss of, 46

Archangel cats, 106

Artificial heat, 29, 40, 4I

Asparagus, cats fond of, 49

Atlantic Cat Club, 97

\section{B}

BARKER, E. N., I05

Battersea Home for Lost Dogs, 105

Beef, Raw, as meat, 26, 29, $31,44,46,48$

Beresford Cat Club (Chicago), 97,98

Bismuth, 80, 8 I

Bite of a cat, II 6

Black cats mated with Blues,

$55,65,66$
Black Persian cats, 17, ro7,

I I 2, I I4

Blue Persian Cat Society,

I8, 96, 97

Blue Persian cats, $18,65,67$

standard of points for, 98

Blue short-haired cat, 22

Blue Tabbies, 56, 65

Blue tortoiseshell, 56

Blues, mating of, $56,63,65$, 67

Bone meal for cats, 49

Bovril, 36

Bowels, inflammation of the, 78

Bragg's Charcoal for diarrhœa, 87

Brand's Essence, 43, 89, 94 Bread and milk for kittens, 45

Breakfast, food for, 25

Breeding, 55-6I practical hints on, $62-$ 76

Breeds and varieties, $17-23$

British Cat Club, 97

Bronchitis, 79

remedy for, 80

Brown Tabbies, $20,56,63$, 65,97

Bunny cat, the, 25 


\section{INDEX}

\section{C}

CAMDEN Town Institution for Lost and Starving Cats, r 04, I I 4

Canker, 9I

Canker, remedy for, 80

Care and management, 2430 practical hints on, $3^{\text {I- }}$ 54

Castor oil, 84,89

Cat, to poultice a, 5 I

Cat Club, the, 95, 96

Registration Rules of, 60

Cat Clubs and Cat Homes, 95-106

Cat Fournal, The, 105

Cats, Bone meal for, 49

cobby, 108

deafness of white, 108

dosing of, 5 I

ears of, 90

ear tufts in Persian, 72, I 6

feeding of, $25,43,48$

fleas and lice in, 50

fond of asparagus, 49

fondest of ribbon grass,

47

gelded, 30, 53

hake for, 49

horseflesh for, 26,48

how to administer medi-

cine to, 47, I 8

lentils for, 47

long-haired, I $7,60,70^{\circ}$ macaroni for, 44

male, $39,62,67$

Maltese, 23, 98, 105,106
Cats (continued):-

Manx, 22

naturally timid, 25

on approval, II 2

shedding their coats, $5 \circ$,

93

sheep's head for, 48 stud, 29, 39, 63, I ro,

I 6, I 7, I 18

tripe for, 45

varieties of short- and

long-haired, 60

vegetable diet for, 26,47

water as a drink for, 46 , 108

Catteries, out-of-door, 28, 35,

40

fumigating, 54

Chartreuse cats, ro6

Chicagn Cat Club, 97, 98

Chinchilla Cat Club, 96

Chinchillas, I9

points of, 20, 99

standard of points for, in United States, I0I

Coats, care of, $29,50,7 \mathrm{I}, 75$

Cobby cats, ro8

Colds, remedy for, $8 \mathbf{r}$

Collar for cat, ro8, I 12, I 17

Condition for exhibition, 57 ,

75

Constipation, remedies for, 74, 80, 8r, 89

"Coon Cat," American, 23, I06

Cox, Mrs. Carew, and her catteries, 105

Cream Persian cats, 2 I, 64

standard of points for, I00

Crossing of breeds, $55,65,67$ 


\section{D}

DeAFNESS of white cats, $\mathrm{r} 8$, IO8

Debility, remedy for, 80,92 , tonics for, $9 \mathrm{I}$

Diarrhœa, 86

in kittens, 28,32

remedy for, 80

Diseases and remedies, 7794

Disinfectants, 54, I I 3

Distemper, 79

remedies for, 92, II I

Dosing of cats, $5 \mathrm{I}, 53, \mathrm{I} \mathbf{1} 8$

Dublin Cats' Home, ro4

Dysentery, remedy for, 80

\section{E}

EARS of cats, $17,34,62,90$, I07

Ear tufts in Persian cats, 72, I 16

Eczema, remedy for, 88

Black, remedy for 80,87

standard of points for, 99

Eggs as food, 49

Enteritis, 78

Entries for shows, 69, 70, 73 Eucalyptus, 54, 80

Eucryl Company, preparations of the, 54, I 13

Exhibiting, 57-61, 68-76, 102

Eyes, 17, 18, 21, 23, 52, 54, $55,65,75,85$, I09, I I I bad, in kittens, 68, 32 weak, 85 lotion for, 86
F

FEeding of cats, 25, 36, 43

Fighting cats, how to separate, $1 \mathrm{I} 2$

Fits, remedies for, 80,90

Fleas and lice in cats and kittens, $28,34,38,50$, $5^{\mathrm{I}}$

remedy for, 80,82

Food, hints on, 43

Foster-mother, selection of a, 26

Foster-mothers, $27,33,36$, 37,115

Freeman's foods and medicines, $25,46,77,80,84$

Fur and Feather, 105

\section{G}

Gastritis, 78, 8I

Gelded cats, 30, 53

Gestation, period of, 26, 63

Gordon, Mrs., and her home for starving cats, 104

Grass, 27, 47, 5I, 93

ribbon, cats fondest of, 47

\section{H}

HAKE for cats, 49

Hampers, 36, 41, 69, 70, 72,

75, 107, 109, I10

versus boxes, 4I, 109

Handling of cats, 25, 35, 37, II2, II 8 
Harper, Miss, and her catteries, 105

Horseflesh for cats, 26, 48

Hot water bottles, 27, 4I

Hovis bread, 44

\section{I}

INFLUENZA, 79, 81, I I 8

Insurance of cats, 70, I I0, II 7

\section{J}

JAMES, Mr., 78, 80, 91

Jaundice, remedy for, 80

Judging at exhibitions, 57 ,

$70,71,76$

\section{K}

Keating's Powder, 38

Kittens, bad eyes in, 28, 32,

85

best way to destroy, I 13 bread and milk for, 45

care and management of, $3^{\mathrm{I}-34}$

diarrhœa in, 28, 86, 87

feeding of, 27

fleas and lice in, 28, 38 50

remedy for worms in, 80

sea-air recommended for, 34 , I I 9

shedding their first teeth, $28,33,83,84$ sleep essential to, 36
Kittens (continued) :-

tripe for, 45

when they become cats, I 5

worms in, 28

Kreochyle, 36, 79, 80,81, 92

\section{L}

LABELS, exhibitors', 19, 70, 74

Lentils for cats, 47

Lights as food, $26,48,90$

Liver very laxative, 46

Long-haired cats, 17

varieties of, 60

Louisville Cat Club, 97

Lubricating a cat's throat, 52

\section{$\mathbf{M}$}

MACARONI for cats and kittens, 44

Maine, curious cats in State of, 106

Male cats, 29, 39

"Maltese" cat, the, 23, I06

Mange, remedy for, 80

Manx Cat Club, 97

$$
\text { cats, 22, 57, I1 } 5
$$

Mating, 26, 55, 62-68, II 8

Meat, $44,46,48$

Medals, advice to winners of, 72

Medicine, how to administer to cats, 47,118

Mellin's Food, 25, 27

Melox Food, the, 25 
Midland Counties Cat Club, 97

Milk, $27,32,34,36,46,47$, 52,108

Morgan, Mrs., and her home for lost and starving cats, I04, II 4

Mothaline, 4I, 80

Mother and young, care and management of, 34-39

\section{N}

NAMES for cats, II 2, II 4

National Cat Club, 95

entry form, 103

Registration Rules of, $5^{8}$

Neuters, 30, 53

Northern Counties Cat Club, 96

Noses of cats, II 3

\section{O}

OAtmeal as food, 25, 43

Orange cats, 20

crossed with a Black, 55

self or tabby, standard of points for, 100

Orange, Cream, Fawn and Tortoiseshell Society, 96

Our Cats, 105, II4

P

Pacific Cat Club, 97

Paper for bedding, 29, 42, Iog
Paralysis, remedy for, 80

Pedigrees, I I 4, I I 7

Persian cat, tail of a, 107, I I 5, I 6

Persian cats, $17,3^{8}, 107$

breeds and varieties, I 72 I

ear tufts in. 72, 106

Phonix Food, the, 25, 27

Photugraphing kittens, II I, I 14

Playthings for kittens, II2, I 14

Post-mortems, I 7

Poulticing a cat, $5 \mathrm{I}$

$\mathbf{R}$

RaIL, sending cats by, 69 , I 09, I I I, I I 2, I I 7

Remedies for diseases, 80 Ribbons for shows, 69,74 , I 12

Ringworm, remedy for, 80 , 87

Royal Cat of Siam, the, 22, 57 standard of points for, IOI

Russian cat, the, 22, 82

points for, 102

S

SALUBRENE, 54

Salvo, his food and medicines, $25,77,80,84,88,93$ Sanitary pans, 29, 32, 40, $4 \mathrm{I}, 43, \mathrm{II} 4$ 
Sardines, 45

Scottish Cat Club, 96

Scratching out coats, II 7

Scurvy spots, 5 I, 80

remedy for, 87

Sea-air recommended for kittens, 34, II 9

Self-coloured cats, I 7, 64, 65, II 5

Shaded Silvers, 19, 67

points of, 20, 99

Sheep's heads as food, 48

Short-haired Cat Club, 96

\section{cats, 17,2 I}

standard of points for, $\mathrm{IO} 2$ varieties of, 60

Shows and exhibiting, 5I6r, 68-76, 102

Show pens, training for, 72 Shows, returning from, 68 , $72,74,75,93$

Siamese cats, 22, 57, 62

Siamese Club, 96

Sickness, remedy for, 47 , 80

Silver and Smoke Persian Cat Society, 96

Tabbies, 20

$$
\text { standard of points }
$$

Silvers, 19 for, 99

points of, 20, 99

Skin complaints, 87

Sleep essential to kittens, 36

Smokes, points of, 19, 100

Snuffles, 66, 88, I 4 remedy for, 80

Society for the Protection of Cats, 104
Spanish cats, 106

Special prizes, 68, 7I, 73, 74, I I 3

Spotted Tabbies, 2 I

Spratts' cat travelling baskets, I IO

Cod Liver Oil Puppy Biscuits, 43

Stomach, inflammation of the, 78

Stud cat, selection of, 63

cats, 28, 39, I I O, I I 7

fees, 39,64

Sulphur, use of, 26, 5 I , 54

Sunburn, 107

Supper, food for, 26

\section{$\mathbf{T}$}

Tabbies, Brown, 20, 56, 63, 65,97

Silver, standard of points for, 99

spotted, 2 I

Tallies, metal, 75

Tape worm, 52, 84

remedy for, 80

Teething, remedy for, 80

Temperature of cats, 90

Throats, remedies for sore, 52,90

Tortoiseshell cat, the, $2 \mathbf{I}$, 66

Blue, 56

crossed with a Black, 55

standard of points for, IOI

Tom very rare, 66

Tripe for cats, 45 
U

United States, cats in the, 23, 97, 98, 105, 106 Clubs in the, 97

\section{V}

VEGETABLE diet for cats, 26,47 Visits, registering of, 67,68 , I 18

\section{W}

WARD, Mr., $38,77,78,80$, 87
Water as a drink for cats, 45 , 46, 108

Weak limbs, remedy for, 26 , 80

Weir, Mr. Harrison, pioneer of cat shows, 95

Whiskers, I 18

White Persian cats, 18, 65, 70, I I 2 cats not deaf, 108 spots, 18,64

Winslow, Miss, I06

Worms, 52, 83 in kittens, 28 remedy for, $28,50,80$, 82,84 , I I 5 



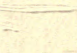





\section{ETURN CIRCULATION DEPARTMENT 202 Main Library}

\section{AN PERIOD 1 HOME USE}

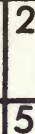

ALL BOOKS MAY BE RECALLED AFTER 7 DAYS

1-month loans may be renewed by calling 642-3405 month loans may be recharged by bringing books to Circulation De Renewals and recharges may be made 4 days prior to due date

DUE AS STAMPED BELOW

\section{EB 251978 \\ RED. CIR. JAN $25^{\prime} \cdot 78$ \\ UL 71978}

RER CIS, JIL
PER CIR IEC 3

PECG CIR DEC 4979

SRM NO. DD 6, 40m 10'77 UNIVERSITY OF CALIFORNIA, BERKELE BERKELEY, CA 94720 

